\title{
RERTR Fuel Development and Qualification Plan
}

D. M. Wachs

January 2007

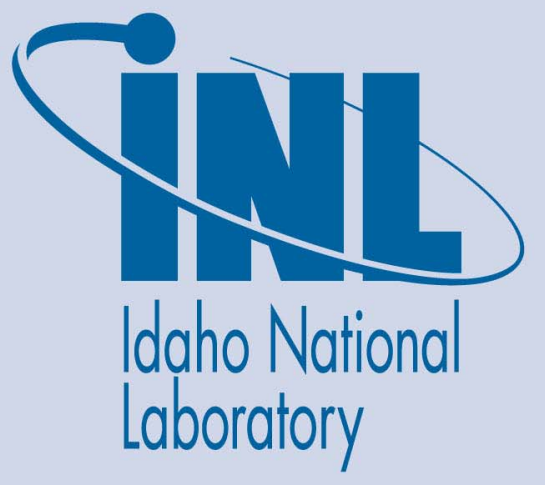

The INL is a U.S. Department of Energy National Laboratory operated by Battelle Energy Alliance 
INL/EXT-05-01017

Rev. 3

\title{
RERTR Fuel Development and Qualification Plan
}

\author{
D. M. Wachs
}

January 2007

\section{Idaho National Laboratory \\ Idaho Falls, Idaho 83415}

Prepared for the

U.S. Department of Energy

Office of Nuclear Nonproliferation and Security Affairs

Under DOE Idaho Operations Office

Contract DE-AC07-05ID14517 


\title{
RERTR Fuel Development and Qualification Plan
}

\author{
INL/EXT-05-01017 \\ Rev 3 \\ January 2007
}

Approved by

Daniel M. Wachs

Date

Dennis D. Keiser

Date

Mitchell K. Meyer

Date 


\section{SUMMARY}

In late 2003 it became evident that U-Mo aluminum fuels under development exhibited significant fuel performance problems under the irradiation conditions required for conversion of most high-powered research reactors. Solutions to the fuel performance issue have been proposed and show promise in early testing. Based on these results, a Reduced Enrichment Research and Test Reactor (RERTR) program strategy has been mapped to allow generic fuel qualification to occur prior to the end of FY10 and reactor conversion to occur prior to the end of FY14. This strategy utilizes a diversity of technologies, test conditions, and test types.

Scoping studies using miniature fuel plates will be completed in the time frame of 2006-2008. Irradiation of larger specimens will occur in the Advanced Test Reactor (ATR) in the United States, the Belgian Reactor-2 (BR2) reactor in Belgium, and in the OSIRIS reactor in France in 2006-2009. These scoping irradiation tests provide a large amount of data on the performance of advanced fuel types under irradiation and allow the down selection of technology for larger scale testing during the final stages of fuel qualification. In conjunction with irradiation testing, fabrication processes must be developed and made available to commercial fabricators. The commercial fabrication infrastructure must also be upgraded to ensure a reliable low enriched uranium (LEU) fuel supply.

Final qualification of fuels will occur in two phases. Phase I will obtain generic approval for use of dispersion fuels with density less than $8.5 \mathrm{~g}-\mathrm{U} / \mathrm{cm}^{3}$. In order to obtain this approval, a larger scale demonstration of fuel performance and fabrication technology will be necessary. Several Materials Test Reactor (MTR) plate-type fuel assemblies will be irradiated in both the High Flux Reactor (HFR) and the ATR (other options include the BR2 and Russian Research Reactor, Dmitrovgrad, Russia [MIR] reactors) in 2008-2009. Following postirradiation examination, a report detailing very-high density fuel behavior will be submitted to the U.S. Nuclear Regulatory Commission (NRC). Assuming acceptable fuel behavior, it is anticipated that NRC will issue a Safety Evaluation Report granting generic approval of the developed fuels based on the qualification report. It is anticipated that Phase I of fuel qualification will be completed prior to the end of FY10.

Phase II of the fuel qualification requires development of fuels with density greater than $8.5 \mathrm{~g}-\mathrm{U} / \mathrm{cm}^{3}$. This fuel is required to convert the remaining few reactors that have been identified for conversion. The second phase of the fuel qualification effort includes both dispersion fuels with fuel particle volume loading on the order of 65 percent, and monolithic fuels. Phase II presents a larger set of technical unknowns and schedule uncertainties than phase I.

The final step in the fuel qualification process involves insertion of lead test elements into the converting reactors. Each reactor that plans to convert using the developed high-density fuels will develop a reactor specific conversion plan based upon the reactor safety basis and operating requirements. For some reactors (FRM-II, High-Flux Isotope Reactor [HFIR], and RHF) conversion will be a one-step process.

In addition to the U.S. fuel development effort, a Russian fuel development strategy has been developed. Contracts with Russian Federation institutes in support of fuel development for Russian are in place.

The overall RERTR fuel development program thus currently results in qualification of fuels suitable for conversion of 19 listed research reactors that consume almost $600 \mathrm{~kg}$ of highly enriched uranium (HEU) per year. 



\section{CONTENTS}

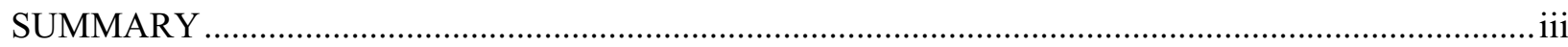

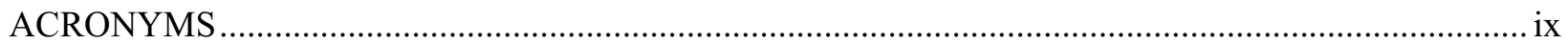

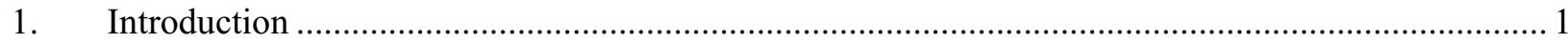

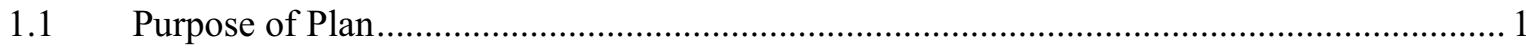

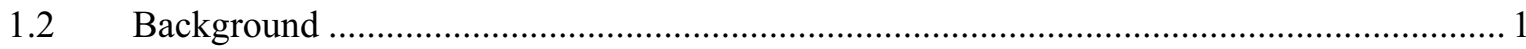

1.2.1 1.2.1 The RERTR Fuel Development Program from 1978 - 1988 ..................... 1

1.2.2 Selection and Early Irradiation Testing of Very-High-Density Alloy Dispersion

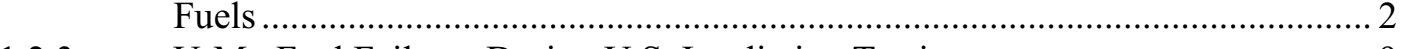

1.2.3 U-Mo Fuel Failures During U.S. Irradiation Testing ...................................... 9

1.2.4 U-Mo Fuel Irradiation Testing in the Other Countries..................................... 10

1.2.5 Path forward for very-high-density fuel development .................................... 16

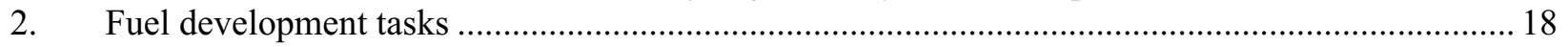

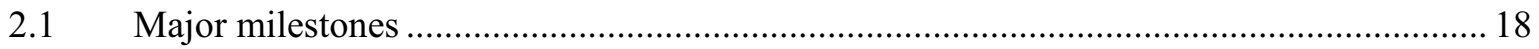

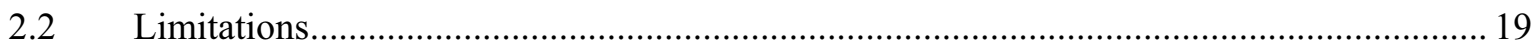

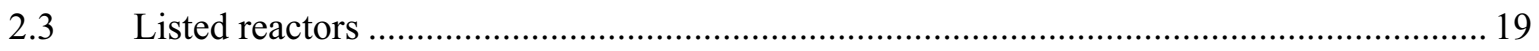

2.3.1 Reactors that can be converted with very-high-density dispersion fuel ............20

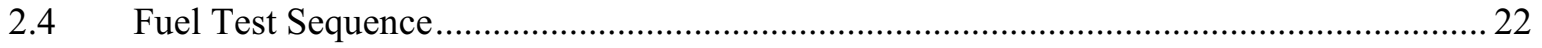

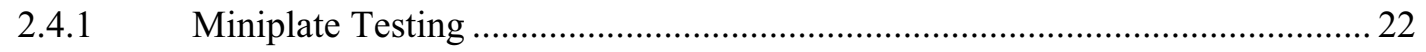

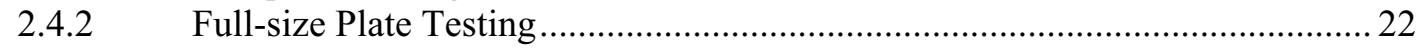

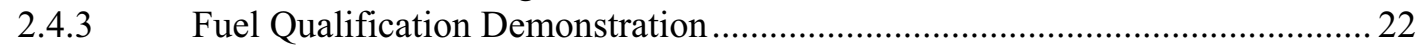

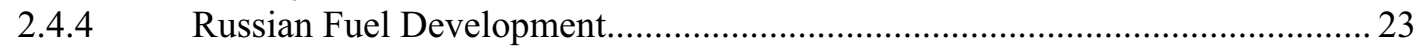

2.4.5 International Fuel Development Collaboration ................................................ 24

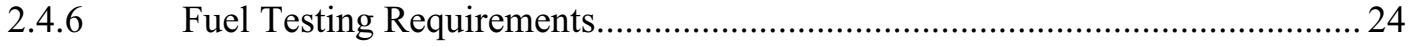

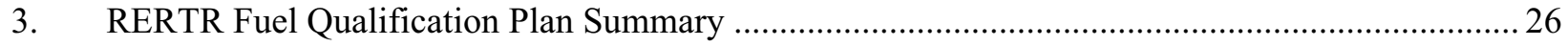

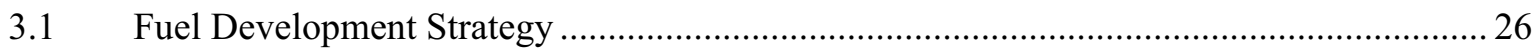

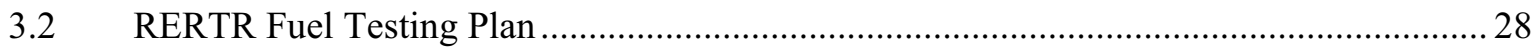

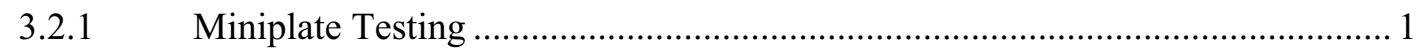

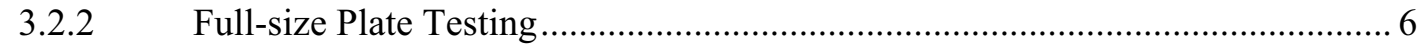

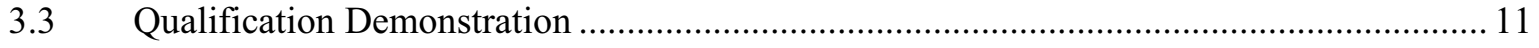

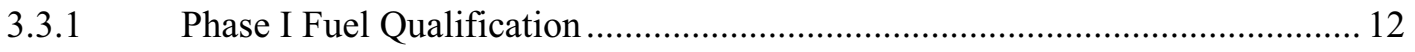

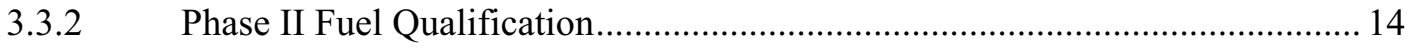

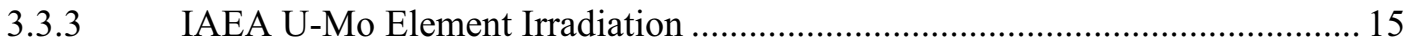

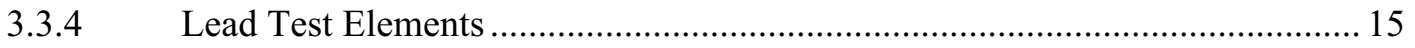

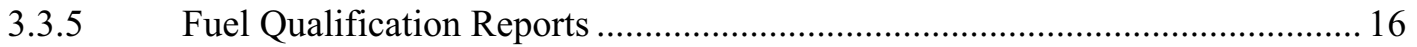

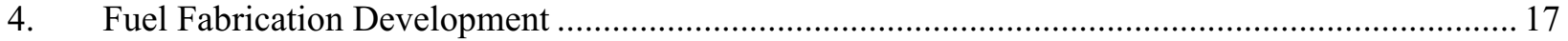




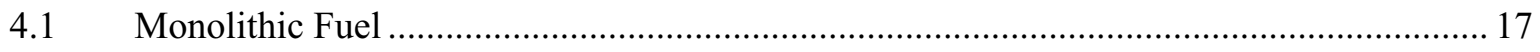

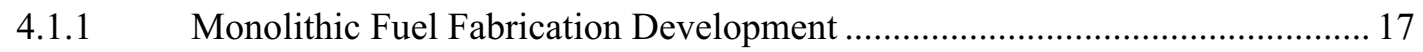

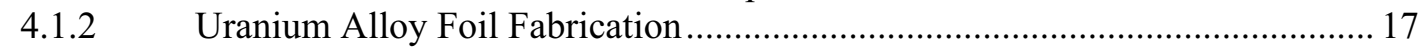

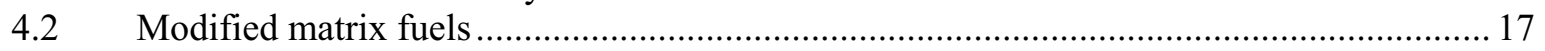

4.2.1 Modified matrix dispersion fuel with density $<8.5 \mathrm{gU} / \mathrm{cm}^{3} \ldots \ldots \ldots \ldots \ldots \ldots \ldots \ldots . . . . . . . . . . . .17$

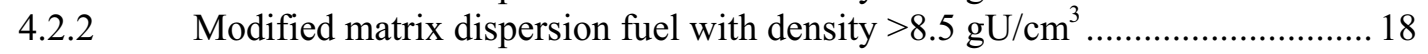

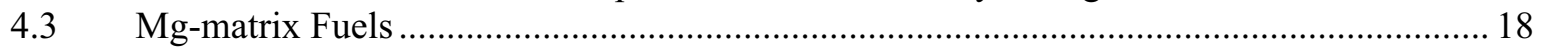

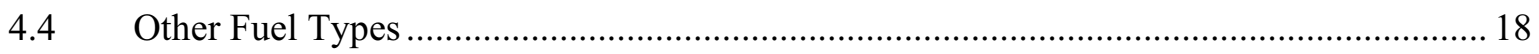

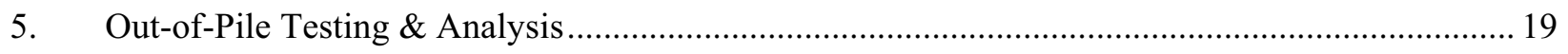

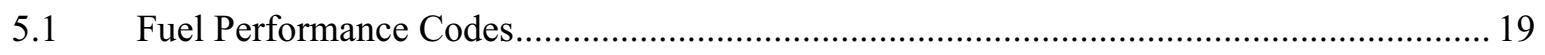

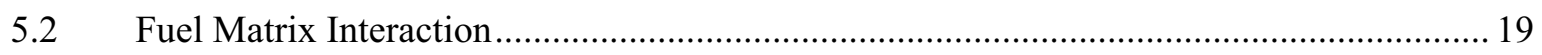

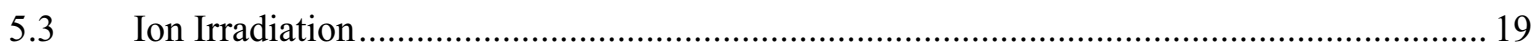

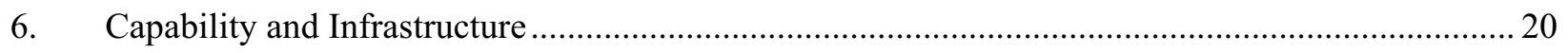

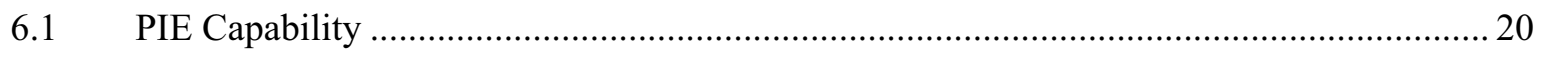

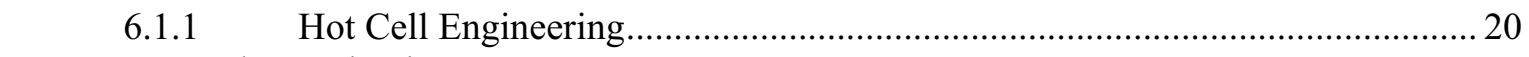

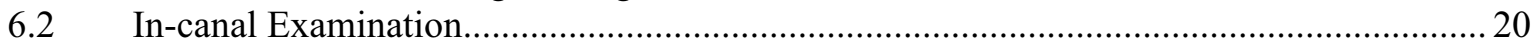

6.3 Transportation of Irradiated Fuel........................................................................... 20

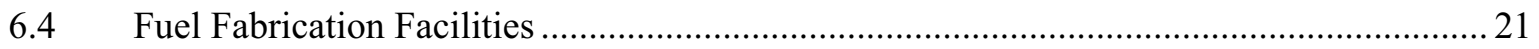

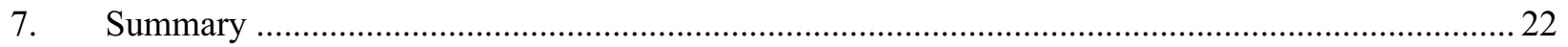

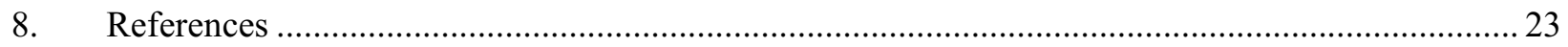

\section{FIGURES}

Figure 1.1. U-10Mo atomized (left) and ground (right) fuels after irradiation to $\sim 70$ at. $\%{ }^{235} \mathrm{U}$ burnup at $65^{\circ} \mathrm{C}$

Figure 1.2. Microstructure of U-10Mo atomized fuel from RERTR-3 and comparison with RERTR-1 .... 5

Figure 1.3. Left- Optical micrograph of RERTR-4 U-6Mo fuel plate 623AB after 78 at.\% burnup

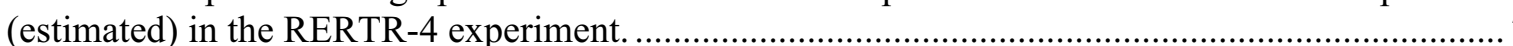

Figure 1.4. Left- Optical micrograph of a U-7Mo/Al-0.2 Si dispersion plate after approximately $50 \%$

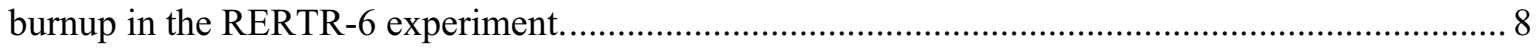


Figure 1.5. Optical micrograph of a U-10Mo monolithic fuel plate fabricated using friction stir welding after irradiation.

Figure 1.6. RERTR-5 fuel plate Q8003I irradiated for 106 days after cladding failure. ......................... 10

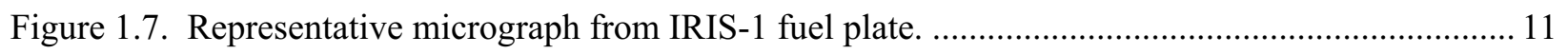

Figure 1.8. Metallographic cross section of sibling to failed plate from the UMUS experiment. ............. 12

Figure 1.9. Cross section of pillowed fuel plate from the FUTURE experiment. .................................. 13

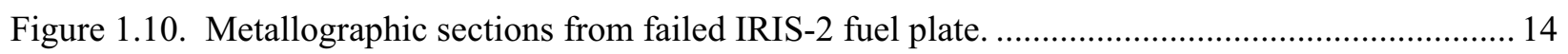

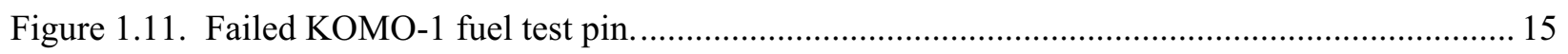

Figure 1.12. Cross section of failed U-Mo fuel tube from testing in the IVV-2M reactor...................... 16

Figure 3.1. Schematic of experiment test sequence leading up to fuel qualification...............................2 27

Figure 3.2. RERTR Fuel qualification timeline $(12 / 06)$. ...................................................................... 1

Figure 3.3. Sketch of generic miniplate to be used in the RERTR-6, $-7,-8$, and -9 experiments............... 1

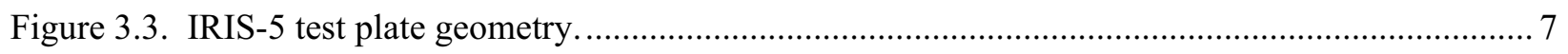

Figure 3.4. Top - AFIP center flux trap position concept. Bottom - Approximate AFIP plate dimensions.9

\section{TABLES}

Table 1.1. Fuel alloys chosen for irradiation screening tests (alloying element in wt $\%$ ) ......................... 3

Table 2.1. Western designed and supplied research reactors that require new very-high-density fuels to convert to LEU and estimated HEU consumption. .................................................................... 19

Table 2.2. Russian designed and supplied research reactors that require new very-high-density fuels to convert to LEU and estimated HEU consumption. ................................................................. 20

Table 2.3. Reactors that may be able to convert to LEU with U-Mo dispersion fuel with a density of $8.5 \mathrm{~g}$

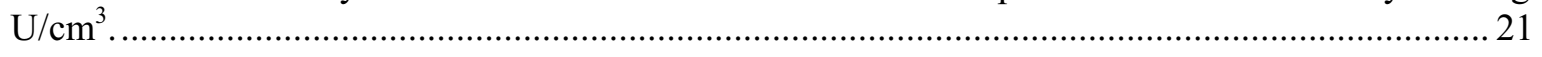

Table 3.1. ATR RERTR experiment irradiation schedule …............................................................ 28

Table 3.2. RERTR-6 experiment matrix................................................................................... 2

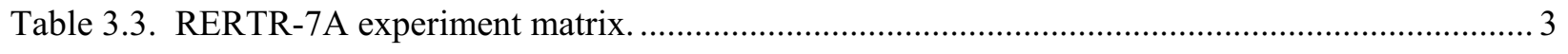

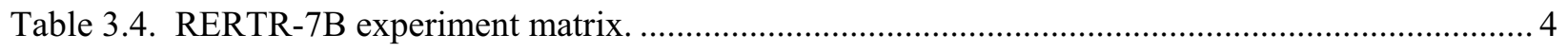

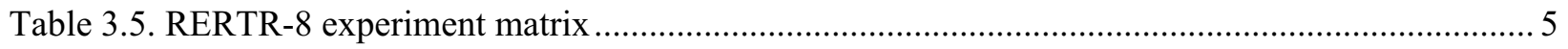





\section{ACRONYMS}

AECL ANSTO

ATR

BOL

BR2

CEA

CERCA

DOE

EFPD

FNR

FRM-II

FUTURE

GTRI

HANARO

HEU

HFEF

HFIR

HFR

INL

IRIS

IRIS-TUM

JHR

JMTR

KAERI

KOMO

LEU

MAPLE

MIR

MTR

NNSA

NRC

NRU

NUKEM

NUREG
Atomic Energy Canada, Limited, Canada

Australian Nuclear Science and Technology Organization

Advanced Test Reactor, Idaho

beginning of life

Belgian Reactor-2, CEN/sck Center, Mol, Belgium

Commissariat de l'Energie Atomique, France

Compagnie pour l' Etude et Realization de Combustibles Atomique, France

United States Department of Energy

effective full-power days

Ford Nuclear Reactor

Forschungsreaktor Munchen II (German: Research Reactor Munich II)

U-Mo fuel irradiation experiment in the BR2 reactor (Belgium)

Global Threat Reduction Initiative

High-Flux Advanced Neutron Application Reactor, South Korea

highly enriched uranium

Hot Fuel Examination Facility

High-Flux Isotope Reactor

High Flux Reactor

Idaho National Laboratory

Irradiation experiment in the OSIRIS reactor at CEA Saclay Center

Irradiation experiment conducted by the Technical University Munich and CEA

Jules Horowitz Reactor

Japanese Material Test Reactor

Korea Atomic Energy Research Institute, South Korea

Irradiation experiment in the HANARO reactor (South Korea)

low-enriched uranium

Multipurpose Applied Physics Lattice Experiment (Canadian Research Reactor)

Research Reactor, Dmitrovgrad, Russia

Materials Test Reactor, U.S

National Nuclear Security Administration

U.S. Nuclear Regulatory Commission

National Research Universal reactor, Canada

German research reactor fuel fabricator

U. S. Nuclear Regulation 
OPAL

ORR

OSIRIS

PIE

PLATE

PNPI

$\mathrm{R} \& \mathrm{D}$

RERTR

RHF

RIAR

TRIGA

UMUS

VNIINM
Open Pool Australian Light-water reactor.

Oak Ridge Research Reactor

French MTR-type reactor at CEA-Saclay Center

post irradiation examination

Plate Lifetime Accurate Thermal Evaluation (fuel performance code)

Petersburg Nuclear Physics Institute, Petersburg, Russia

research and development

Reduced Enrichment Research and Test Reactor

Reactor High Flux, Grenoble, France

Research Institute of Atomic Reactors, Russian

training, research, and isotope reactors (built by GA)

French irradiation experiment conducted in the HFR-Petten reactor

All-Russian Research and Development Bochvar Institute of Inorganic Materials 


\section{RERTR Fuel Development and Qualification Plan}

\section{Introduction}

\subsection{Purpose of Plan}

This plan is designed to be used as a guiding document, laying out methodology, major milestones and deliverables, decision points, and required inputs to meet Global Threat Reduction Initiative (GTRI) fuel development program goals.

Detailed work plans and budgets to achieve these goals will be developed on a yearly basis, consistent with GTRI Fuel Development Program funding and National Nuclear Security Administration (NNSA) guidance. This plan will be revised annually to reflect changes in the status of research and development, budget, and schedule.

\subsection{Background}

\subsection{The RERTR Fuel Development Program from 1978 - 1988}

A major element of the "Atoms for Peace" program, announced by Dwight Eisenhower in 1953, was the provision of research reactors and of fuels needed for their operation $\left[{ }^{i}\right]$. The research and test reactors supplied by the "Atoms for Peace" program initially used low-enriched uranium [(LEU), $\left.<20 \%{ }^{235} \mathrm{U}\right]$ fuel. The demand for higher specific powers and neutron fluxes increased with the accelerating development of nuclear technology, and drove the need for fuels with higher fissile loading. The higher power research and test reactors began to use highly enriched uranium (HEU) fuel, and by the late 1970's the U.S. was exporting about 700 kilograms of HEU annually for foreign research and test reactors. In response to increasing congressional and public concern about the potential diversion of HEU for use in nuclear weapons, the United States Department of Energy (DOE) in August 1978 initiated the Reduced Enrichment for Research and Test Reactors (RERTR) program. The primary objective of the RERTR program is to develop the technology needed to minimize and eventually eliminate use of HEU for most civilian applications worldwide.

The key to making reactor conversions feasible lies in developing fuels with higher uranium density, since in LEU every atom of ${ }^{235} U$ must be accompanied by approximately four atoms of ${ }^{238} U$. In 1978 , the main fuels used in western designed reactors were plate-type $\mathrm{UAl}_{\mathrm{x}}-\mathrm{Al}\left(1.7 \mathrm{~g} / \mathrm{cm}^{3}\right)$ and $\mathrm{U}_{3} \mathrm{O}_{8}-\mathrm{Al}(1.3$ $\mathrm{g} / \mathrm{cm}^{3}$ ) dispersions enriched to $93 \%$ and rod-type training, research, and isotope reactors (built by GA) (TRIGA) fuel based on $\mathrm{UZrH}_{\mathrm{x}}$ and enriched to $70 \%$ with a uranium density of $0.5 \mathrm{~g} / \mathrm{cm}^{3}$.

Initial RERTR fuel development efforts began by increasing the volume loading of fissile particles in these fuels. Miniplates were fabricated by the RERTR program and irradiated in the Oak Ridge Research Reactor (ORR). The plate-type fuel fabricators Compagnie pour l'Etude et Realization de Combustibles Atomique (CERCA) in France, NUKEM in Germany, and Atomics International in the U.S. were informed of test results and began to fabricate and test full-size plates and elements of the more promising materials. The only fabricator of TRIGA fuel (General Atomics) developed LEU TRIGA pins with a uranium density of $3.7 \mathrm{~g} / \mathrm{cm}^{3}$, and these were tested by the RERTR program in the ORR. The outcome of 
the initial effort was successful demonstration of aluminum-based LEU dispersion fuels with uranium concentrations of $2.3 \mathrm{~g}-\mathrm{U} / \mathrm{cm}^{3}$ for $\mathrm{UAl}_{\mathrm{x}}-\mathrm{Al}, 3.2 \mathrm{~g}-\mathrm{U} / \mathrm{cm}^{3}$ for $\mathrm{U}_{3} \mathrm{O}_{8^{-}}$and $3.7 \mathrm{~g} / \mathrm{cm}^{3}$ for $\mathrm{UZrH}_{\mathrm{x}}$. The Ford Nuclear Reactor (FNR) at the University of Michigan was the first reactor converted by the RERTR program in December 1981 using an $\mathrm{UAl}_{\mathrm{x}}-\mathrm{Al}$ fuel with a density of $1.7 \mathrm{~g} / \mathrm{cm}^{3}$.

Also under development were fuels based on $\mathrm{U}_{3} \mathrm{Si}_{1} \mathrm{U}_{3} \mathrm{Si}_{2}$, and $\mathrm{U}_{6} \mathrm{Me}$ intermetallics ( $\mathrm{Me}$ - transition metal). $\mathrm{U}_{3} \mathrm{Si}$ miniplates began to fail at high burnup in 1982, and were dropped from the U.S., French, and German programs. In Canada, the Atomic Energy Canada Limited (AECL) continued development of $\mathrm{U}_{3} \mathrm{Si}-\mathrm{Al}$ fuel in pin form and used it to successfully convert their NRU reactor. (The better behavior of $\mathrm{U}_{3} \mathrm{Si}$-Al in the pin-type NRU fuel is inferred to be due to the constraint that the pin-type fuel imposes on fuel swelling). $\mathrm{U}_{3} \mathrm{Si}_{2}-\mathrm{Al}$ dispersion fuel, which has a uranium density of $4.8 \mathrm{~g} / \mathrm{cm}^{3}$, had been tested in parallel with $\mathrm{U}_{3} \mathrm{Si}_{2}-\mathrm{Al}$ dispersion fuel and was found to be very stable under irradiation. Irradiation testing of full-size LEU $\mathrm{U}_{3} \mathrm{Si}_{2}$-Al dispersion fuel elements was successful, and in 1986-1987 a full-core demonstration of this fuel was successfully performed in the ORR. In 1988, LEU U $\mathrm{Si}_{2}-\mathrm{Al}$ dispersion fuel received generic approval by the U.S. Nuclear Regulatory Commission (NRC) in the form of a Safety Evaluation Report (NUREG-1313). Since 1988, $\mathrm{U}_{3} \mathrm{Si}_{2}$ has been used in the conversion or new startup of more than 30 research reactors. After this program was completed, the RERTR fuel development effort experienced a lull in funding during which no further substantial gains in fuel technology were achieved, although significant advances were made in understanding the irradiation behavior of $\mathrm{U}_{3} \mathrm{Si}_{2}-\mathrm{Al}$ fuel and dispersion fuels in general.

\subsubsection{Selection and Early Irradiation Testing of Very-High-Density Alloy Dispersion Fuels}

Conversion of the highest-power density reactors operating in the mid-1990's requires LEU fuel densities in the range of 8 to $10 \mathrm{~g} / \mathrm{cm}^{3}$. Funding for the RERTR fuel program was restarted in 1996 to develop fuels targeted for these applications. Due to limited program funding, it was deemed preferable to develop this fuel to allow for fabrication using the current commercial infrastructure and methods. This sets a practical upper limit on fuel loading of approximately 55 volume percent, so that fuel phases with uranium densities of at least $14.5 \mathrm{~g} / \mathrm{cm}^{3}$ must be used. Two types of fuel were available that met this density criterion; these are metallic uranium of low alloy content and the $\mathrm{U}_{6} \mathrm{Me}$ class of high density intermetallics. In this latter class, $\mathrm{U}_{6} \mathrm{Fe}$ and $\mathrm{U}_{6} \mathrm{Mn}$ have been shown to have poor irradiation behavior $\left[{ }^{\mathrm{ii}}\right.$ iii $]$, and it is likely that other $\mathrm{U}_{6} \mathrm{Me}$ compounds will behave in a similar manner. The emphasis for USRERTR advanced fuel development was therefore placed on metallic uranium alloy fuels. Screening of the potential alloy candidates based on gamma stability and what was known about irradiation behavior eliminated all but U-Nb-Zr and U-Mo alloys from consideration early in the process. Since little irradiation data existed on the performance of metallic fuels in the high burnup, low temperature range, required for research reactors, screening irradiation tests were used to identify alloys with good irradiation performance under these conditions. A chronology of these tests and other irradiations leading to the present is provided below.

\subsubsection{The RERTR-1 and RERTR-2 tests}

The RERTR-1 and -2 test vehicles contained 11 fuel alloys and two intermetallic compounds irradiated to nominal burnup of 40 and 70 atom percent ${ }^{235} \mathrm{U}$ depletion in the Advanced Test Reactor (ATR). $\left.{ }^{\mathrm{iv}}{ }^{\mathrm{v}}{ }^{\mathrm{N}}\right]$ The fuel alloys selected for the RERTR-1 and -2 irradiation capsules can be divided into four fuel types based on $\gamma$-stability and microstructure, as shown in Table 1.1 . 
Table 1.1. Fuel alloys chosen for irradiation screening tests (alloying element in wt $\%$ )

\begin{tabular}{cccc}
\hline Most $\gamma$ stable & $\begin{array}{l}\text { Intermediate } \\
\gamma \text { stability }\end{array}$ & $\begin{array}{l}\text { Least } \gamma \text { stable } \\
(\alpha+\gamma)\end{array}$ & $\begin{array}{l}\text { Precipitate } \\
\text { Dispersion within } \\
\text { Fuel Particles }\end{array}$ \\
\hline U-10Mo & U-6Mo & U-5Nb-3Zr & U-10Mo-0.05Sn \\
U-8Mo & U-6Mo-1Pt & U-4Mo & U-0.1Si \\
U-9Nb-3Zr & U-6Mo-0.6Ru & U-2Mo-1Nb-1Zr & \\
& U-6Nb-4Zr & & \\
\hline
\end{tabular}

The two test vehicles each consisted of a flow-through "basket" holding eight vertically stacked flowthrough capsules. Each capsule held four miniplates in a miniature fuel element configuration. The irradiation vehicles occupied small I-hole positions (I-22 and I-23) in the control drum region of the ATR. Based on calculations, the neutron flux, microplate power, surface heat flux, and fuel centerline temperature were approximately $1.3 \times 10^{18} \mathrm{n} \mathrm{m}^{-2} \mathrm{~s}^{-1}, 500 \mathrm{~kW}, 5.5 \times 10^{5} \mathrm{~W} \mathrm{~m}^{-2}$, and $65^{\circ} \mathrm{C}$, respectively, at the axial position of highest neutron flux at the start of the irradiation. The RERTR-1 test was irradiated for 94 effective full-power days (EFPD) during the period August 23, 1997, through November 30, 1997, and RERTR-2 was irradiated for 232 EFPD during the period August 23, 1997 through July 6, 1998, achieving (calculated) ${ }^{235} \mathrm{U}$ burnups between 39 and $45 \%$ and between 65 and $71 \%$, respectively.

Post irradiation examination (PIE), in general, indicated excellent irradiation behavior for U-Mo alloys with greater than $6 \mathrm{wt} . \%$ molybdenum content and for the ternary U-Mo-Pt and U-Mo-Ru alloys [ $\left.{ }^{\mathrm{vi}}\right]$. The $\mathrm{U}-\mathrm{Nb}-\mathrm{Zr}$ alloys were found to be less suitable due to the propensity for these alloys to exhibit the metallographic precursors to breakaway swelling. Micrographs comparing the behavior of some of the fuels are shown in Figure 1.1.

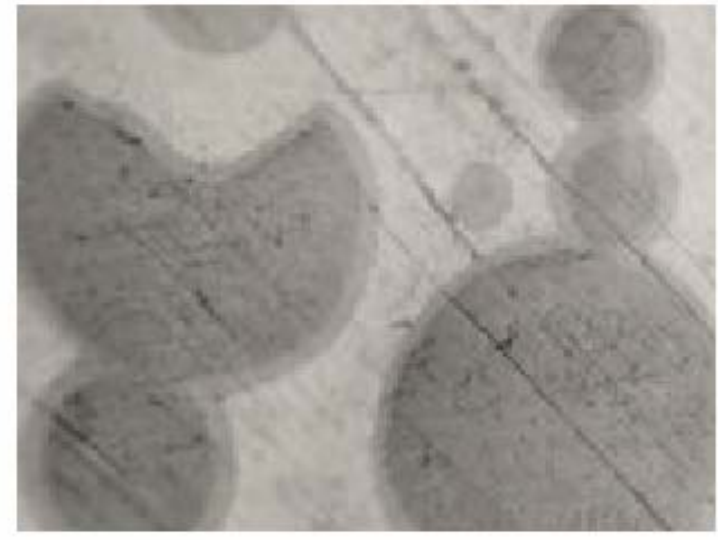

ET291931, 537Y3

$(500 \mathrm{X}$

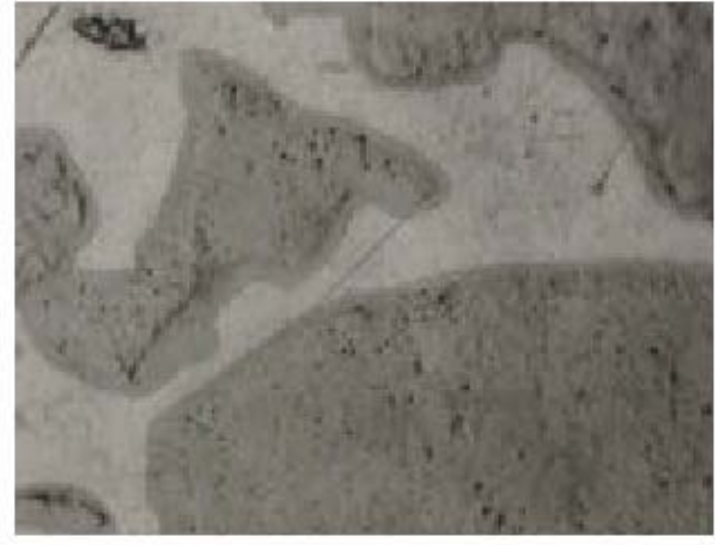

ET291973, 557V3

$(500 \mathrm{X})$

Figure 1.1. U-10Mo atomized (left) and ground (right) fuels after irradiation to $\sim 70$ at. $\%{ }^{235} \mathrm{U}$ burnup at $65^{\circ} \mathrm{C}$. 
Conclusions drawn from this experiment at low irradiation temperature $\left(\sim 65^{\circ} \mathrm{C}\right)$ to relatively high burnup (71\%) were as follows:

- U-Mo alloys with at least 6 wt.\% Mo exhibited low swelling and stable irradiation behavior. These alloys are very promising for further development of high-density dispersion fuels.

- Alloys with 4 wt.\% Mo and U-Nb-Zr alloys exhibited irradiation behavior that indicated imminent break-away swelling. These alloys did not warrant continued testing.

- The extent of fuel-Al interdiffusion under these irradiation conditions was similar to that seen in $\mathrm{U}_{3} \mathrm{Si}_{2}-\mathrm{Al}$ dispersion fuel.

\subsubsection{The RERTR-3 irradiation test}

The RERTR-1 and -2 irradiation test capsules were followed by the RERTR-3 irradiation test at higher temperature to moderate burnup. The RERTR-3 experiment consisted of six flow-through capsules stacked vertically inside an aluminum outer basket. Two columns of four fuel test specimens were arranged within each capsule, for a total of eight specimens per capsule. The experimental test matrix was composed of uranium-molybdenum alloys, and included Mg-matrix fuel test specimens.

The RERTR-3 experiment began irradiation on October 7, 1999 and was exposed for a total of 48 EFPD over two reactor cycles. Peak plate burnup ranged from 24.9 at. $\%{ }^{235} \mathrm{U}$ for the plate farthest above the core centerline up to $41.0 \%$ burnup for plates near the core centerline. The desire to irradiate at high flux limited the choice of flow-through irradiation positions in the ATR. The B-7 position, a $22.2 \mathrm{~mm}$ diameter flow-through hole just outboard of driver fuel element 33 was used for this test. The small diameter of this position necessitated the use of small irradiation test specimens; each test coupon was $10.0 \mathrm{~mm} \times 41.1 \mathrm{~mm} \times 1.52 \mathrm{~mm}$, and contained approximately 0.6 grams of fuel.

Because of the small size of these specimens, analysis of fuel behavior during PIE was heavily dependant on the use of quantitative metallography. The volume fractions of fuel, unreacted aluminum matrix, and fuel/matrix interaction product were carefully measured. On PIE, it became immediately evident that the rate of fuel/matrix interaction was faster than anticipated based on extrapolation of the results from the RERTR-1 and RERTR-2 tests. Representative micrographs from the RERTR-3 fuel specimens are shown in Figure 1.2. Comparison of the fission gas behavior shown in this figure indicates stable irradiation behavior of the U-Mo fuel particles themselves. The consequences of formation of this large amount of fuel/matrix reaction on fuel performance appears to be benign; within the range of burnup and temperature examined to this point, the interaction layer formed on U-Mo plates during irradiation exhibited stable irradiation behavior, comparable to that of $\mathrm{UAl}_{\mathrm{x}}$ particulate dispersions. These fuels are mixtures of $\mathrm{UAl}_{2}, \mathrm{UAl}_{3}$, and $\mathrm{UAl}_{4}$ and exhibit stable irradiation behavior to high burnup. Fuels containing initially stoichiometric $\mathrm{UAl}_{3}$ and $\mathrm{UAl}_{2}$ fuel show similar behavior. [vii,viii]

It also became evident that the rapid growth of the interaction layer was resulting in a positive temperature feedback inside of the fuel meat and an uncertain thermal history. As the fuel reacted with the aluminum matrix, the fuel meat thermal conductivity decreased, resulting in a temperature rise in the fuel and, in turn, a faster reaction rate. The PLATE code was developed, in part, to deconvolute the temperature history of the fuel as a function of irradiation history. 


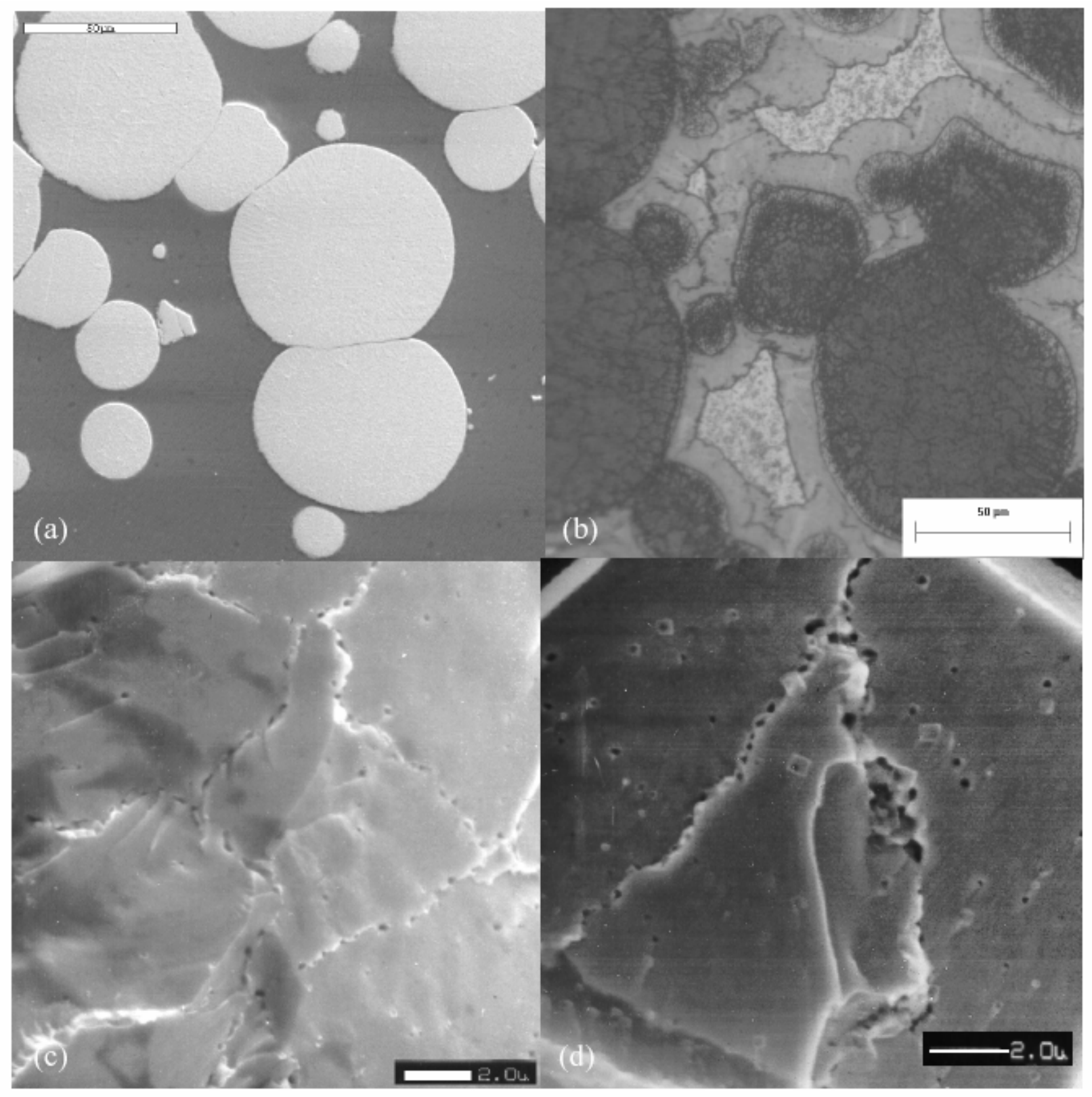

Figure 1.2. Microstructure of U-10Mo atomized fuel from RERTR-3 and comparison with RERTR-1. (a) SEM micrograph of as-fabricated plate. (b) Etched optical microstructure of plate V03 after 37.6\% U235 burnup. Same magnification as (a). (c) SEM micrograph of V03 fracture surface. (d) SEM of RERTR-1 plate V002 after 38.4\% burnup.

Conclusions from PIE of the RERTR-3 test were as follows:

- The extent of fuel swelling was acceptable and stable. 
- Swelling was predominantly due to U-Mo/Al interdiffusion up to burnup where the matrix aluminum was essentially consumed by this interdiffusion process.

- The aluminide interaction product appears stable and contained no fission gas bubbles. It has a low thermal conductivity, however, which results in an increased fuel temperature.

- The swelling behavior of the unreacted fuel was athermal in the range of temperature and burnup tested.

- Lowering of Mo content results in somewhat higher rates of interdiffusion and fission gas swelling, as observed in metallographs.

- Mg-matrix fuel specimens showed no interaction between the fuel particles and the Mg-matrix and behaved well under RERTR-3 irradiation test conditions.

\subsubsection{The RERTR-4 and RERTR-5 irradiation tests}

As in previous irradiation experiments, the miniplates irradiated in RERTR-4 and 5 contained either atomized fuel particles, supplied by Korea Atomic Energy Research Institute (KAERI), or machined fuel particles, in this case supplied by AECL. The composition of the fuel alloys ranged from, nominally, 6 wt.\% Mo to $10 \mathrm{wt} . \%$ Mo. The fuel plates in these tests measured $100 \mathrm{~mm}$ x $25 \mathrm{~mm}$ x $1.40 \mathrm{~mm}$; the meat was in a rectangular zone nominally $0.64 \mathrm{~mm}$ thick and contained 6 and $8 \mathrm{~g} \mathrm{U} \mathrm{cm}^{-3}$ in the fuel meat. The RERTR-5 experiment and the RERTR-4 experiment were inserted into positions B-12 and B-11, respectively, of the Advanced Test Reactor (ATR) core for cycle 123B. Irradiation began on August 19, 2001, and RERTR-4 and RERTR-5 were irradiated for 204 EFPD and 116 EFPD respectively.

In addition to 30 dispersion fuel miniplates, test RERTR-4 also included two miniplates with solid U-Mo alloy cores (monolithic fuels). These plates each contained thin discs of U-10 Mo of $\sim 12$-mm diameter and $0.3-\mathrm{mm}$ thickness. These plates showed stable irradiation behavior.

The RERTR-5 experiment was removed from the reactor at a peak burnup of $\sim 50 \% \mathrm{U}-235$, whereas the RERTR-4 test terminated at $\sim 80 \%$ burnup. Unfortunately, the location of the test assemblies in the reactor was switched at some point during the irradiation, so that the irradiation history of the fuel miniplates is not definitively known, complicating quantitative analysis of the postirradiation data. Postirradiation microstructures of the fuel specimens are similar to those of the irradiated RERTR-3 specimens, with the exception of the development of some porosity between the (U-Mo) $\mathrm{Al}_{\mathrm{x}}$ reaction layer and the aluminum fuel matrix. Some general conclusions that could be drawn following PIE of the RERTR-4 and -5 tests were as follows:

- Results from the RERTR-1 through RERTR-5 irradiation experiments continued to show good irradiation behavior of U-Mo/Al dispersion fuel with uranium loadings of up to $8 \mathrm{~g}-\mathrm{U} / \mathrm{cm}^{3}$.

- Swelling of the U-Mo alloys was athermal and stable up to $\sim 300^{\circ} \mathrm{C}$.

- The interaction between U-Mo and $\mathrm{Al}$ affects overall meat swelling to various degrees depending on irradiation conditions, primarily temperature. The main effect of $\mathrm{U}-\mathrm{Mo} / \mathrm{Al}$ interaction is a decrease in meat thermal conductivity.

- Some porosity was noted in the high burnup plates, but this did not appear to be typical of the porosity observed as a precursor to breakaway swelling of fuel that had been previously identified.

- The components of the irradiation behavior were believed to be largely understood at this point and allow detailed modeling of the fuel plate swelling and time resolved temperature profile.

- The initial tests of monolithic U-Mo fuel meat were promising, opening the possibility for development of fuel with uranium densities well in excess of $8 \mathrm{~g}-\mathrm{U} / \mathrm{cm}^{3}$. 

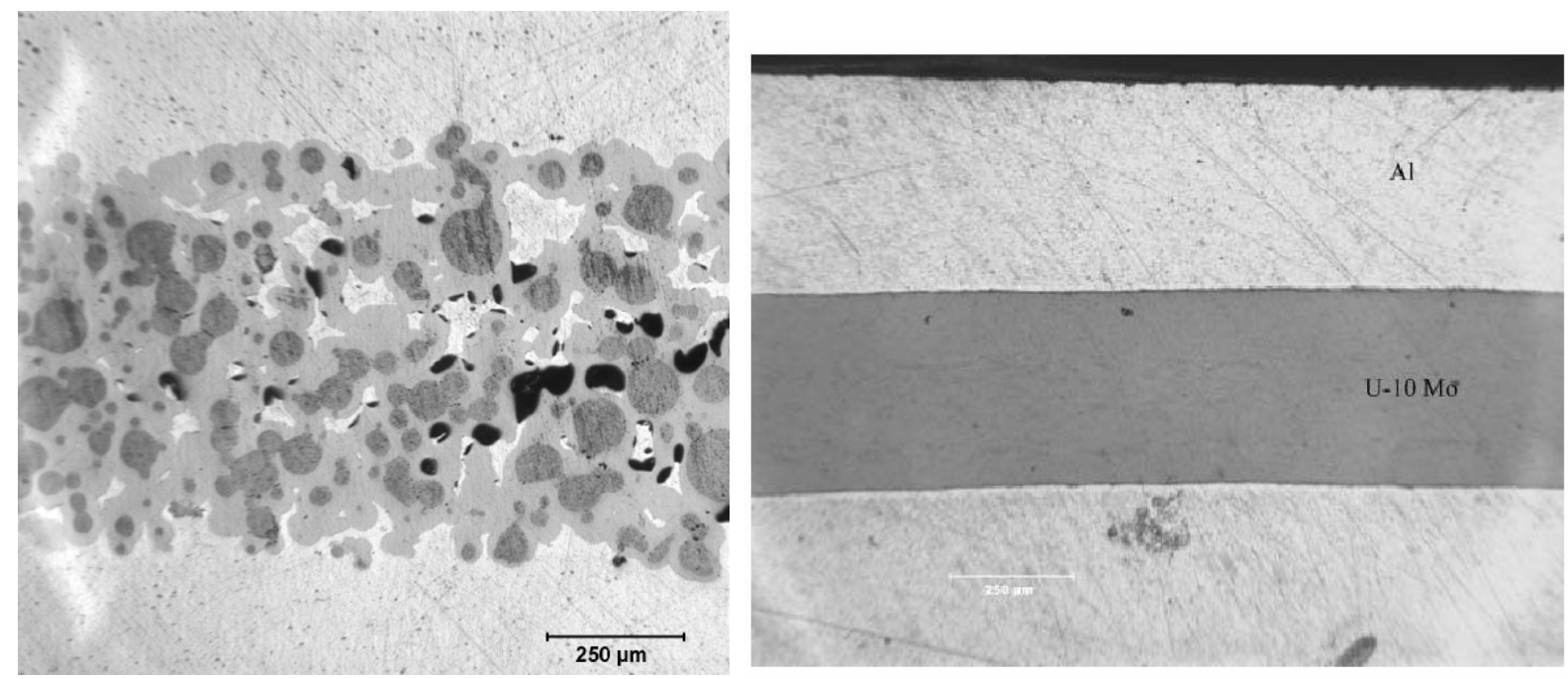

Figure 1.3. Left- Optical micrograph of RERTR-4 U-6Mo fuel plate 623AB after 78 at.\% burnup (estimated) in the RERTR-4 experiment. Note the presence of porosity at the interface between the (uMo)Alx interaction product and the aluminum matrix. Right - Micrograph of U-10Mo monolithic fuel specimen $623 \mathrm{~F}$.

\subsubsection{The RERTR-6 Irradiation Test}

Subsequent to completion of the RERTR-4 and -5 tests, full-size plate tests performed in Russia and France (discussed in section 1.2.3) identified that the porosity observed to form within the (U,Mo) Al interaction product would lead to breakaway swelling at high burnup for plates of prototypic geometry. The RERTR-6 experiment was designed to evaluate modified fuel designs proposed to address this issue. The experiment utilized the same mini-plate geometry as RERTR-4 and -5 (100 $\mathrm{mm} \times 25 \mathrm{~mm} \times 1.40 \mathrm{~mm})$ and was irradiated in the ATR B-12 position for $135 \mathrm{EFPD}$ (cycles 134AB, 135B, and 135C) to as much as 50 at.\% burnup under moderate power conditions.

The addition of silicon to the matrix material to reduce the growth of the interaction layer and to stabilize it during irradiation was implemented in the RERTR-6 experiment. Silicon bearing matrix materials including binary Al-Si alloys (with 0.2 and $2.0 \mathrm{wt} \% \mathrm{Si}$ ) and high silicon commercial aluminum alloys (Al-6061 and Al-4043) were tested. The dispersion plates were fabricated at Argonne National Laboratory using atomized fuel particles fabricated by KAERI. The primary conclusion regarding modified dispersion fuel performance from the RERTR-6 experiment can be summarized as:

- Use of an aluminum silicon alloy as the fuel meat matrix material can significantly reduce the amount of fuel/matrix interaction (as shown in Figure 1.4). For the conditions tested, $0.2 \%$ silicon showed little or no effect but the substantial reduction in interaction thickness was achieved with both $2.0 \% \mathrm{Si}$ and $\sim 5 \% \mathrm{Si}(\mathrm{Al}-4043)$. 


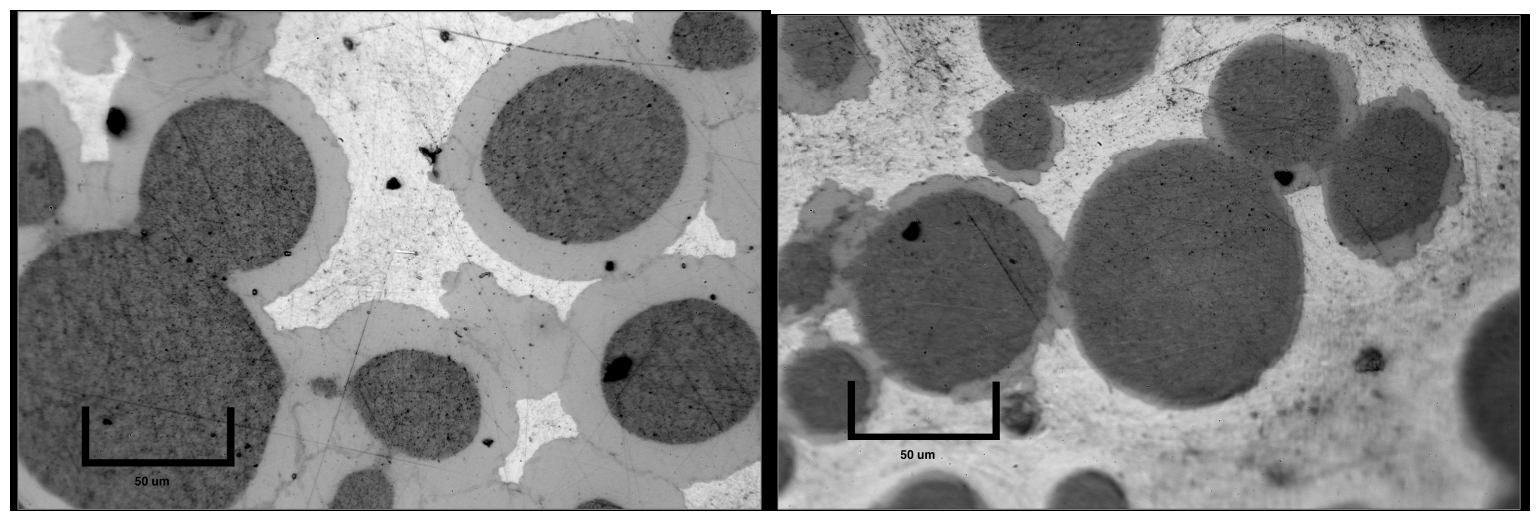

Figure 1.4. Left- Optical micrograph of a U-7Mo/Al-0.2 Si dispersion plate after approximately 50\% burnup in the RERTR-6 experiment. The interaction layer thickness is approximately $12 \mu \mathrm{m}$ thick. RightOptical micrograph of a U-7Mo/Al-2.0 Si dispersion plate after approximately $50 \%$ burnup in the RERTR-6 experiment. The interaction layer thickness is approximately $2 \mu \mathrm{m}$ thick.

In addition to greatly increasing the peak achievable fuel density, it was anticipated that the monolithic fuel form first tested in RERTR-5 would mitigate irradiation performance issues by substantially reducing the amount of fuel/aluminum interface and, thus, the formation of undesirable interaction products. The RERTR-6 monolithic fuel plates were fabricated by hot rolling U-Mo foils and using a friction stir welding process to bond the aluminum cladding directly to the fuel foil, which represents the first monolithic fuel plates fabricated with a 'prototypic' process. The PIEs showed that:

- The base U-Mo fuel form continued to perform well during irradiation

- Low molybdenum content alloys (i.e. U-7Mo) tended to interact more rapidly with aluminum than did higher molybdenum content alloys (i.e. U-10Mo) during fabrication at elevated temperature.

- Fuel plates exhibited a tendency to delaminate at the fuel/clad interface after irradiation during metallographic examination (Figure 1.5), implying a weakening of the interfacial bond. The incipient formation of fission gas bubbles in the interaction layer was observed even though the reaction layers remained very thin or unchanged from the as-fabricated condition.

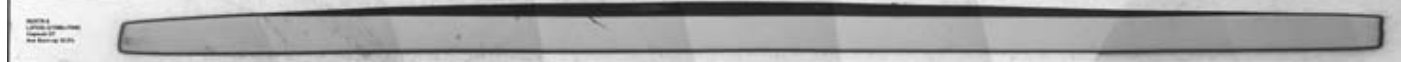

Figure 1.5. Optical micrograph of a U-10Mo monolithic fuel plate fabricated using friction stir welding after irradiation. The image shows that the fuel/clad interface at the top of the plate has delaminated. 


\subsubsection{The RERTR-7 Irradiation Tests}

The RERTR-7 experiment was designed to evaluate the modified fuel compositions at under high power conditions. The irradiation was performed in the ATR B-11 position over 90 EFPD. To increase the experiment power while utilizing the same position used in earlier moderate power tests the uranium enrichment was increased to $58 \%$ yielding a peak fission density equivalent to more than 100 at $\%$ LEU burnup. The experiment incorporated fuel plates with silicon bearing matrix materials and monolithic fuel plates similar to those irradiated in the RERTR-6 experiment. The monolithic fuel plates were fabricated using the friction stir welding and transient liquid phase bonding processes. Irradiation of the experiment has been completed and post-irradiation examination is scheduled for completion in April 2007.

\subsubsection{The RERTR-7B and -8 Irradiation Test}

The objective of the RERTR-7B test was to evaluate the impact of modified fuel alloys (U-7Mo-1Ti and U-7Mo-2Zr) on the interaction layer growth rate and stability. Dispersion mini-plates were fabricated using 58\% enriched uranium (to reach power targets) and irradiated in the ATR B-12 position for 39 EFPD to a burnup of approximately $30 \% \mathrm{LEU}$ equivalent. The irradiation is complete and PIE is scheduled to be completed in April 2007.

The RERTR-8 experiment will test additional mini-plates in the ATR using the B-11 and B-12 position. It will extend the performance data gathered in the RERTR-7B experiment for the ternary fuel alloys to higher burnup ( $\sim 75 \%$ LEU equivalent). The experiment will also provide the first performance data for monolithic fuel plates fabricated using the hot isostatic pressing technique and will demonstrate the incorporation of burnable poison into a monolithic fuel. Irradiation of the experiment is underway and will be completed in February 2007.

\subsubsection{U-Mo Fuel Failures During U.S. Irradiation Testing}

\subsubsection{Fuel Failures in the U.S. Program}

There have been no fuel performance related failures in the U.S. miniplate irradiation testing program, however one failure occurred due to a fabrication defect. This failure was useful in determining the extent of reaction of the fuel matrix with reactor coolant water.

Plate Q8003I was fabricated at the Idaho National Laboratory (INL) using U-7Mo powder supplied by AECL. The plate occupied position A-8 in the RERTR-5 experiment assembly, in the second row from the top of the experiment, with the fuel plate centerline positioned approximately 10 inches $(25.4 \mathrm{~cm})$ above the core mid-plane. Reactor startup was on August 19, 2001. A slight increase in coolant and stack activity was noted by ATR operations on August 29, 10 days after irradiation start. Activity decreased to normal levels after approximately two weeks. Irradiation of RERTR-4 and RERTR-5 continued for 106 days. Total irradiation time for the RERTR-5 experiment was 116 EFPD.

It appears that the failure of Q8003I was due to a thin area in the cladding that was introduced during fuel plate fabrication. The cladding measured $0.002-0.003$ inches thick in the failure region. Fuel pile-up in this region increased stresses from thermal expansion and fuel meat swelling (due to reaction and fission products) beyond the ultimate strength of the thin area in the cladding. This is exacerbated by the additional local heat loading from the high-density 'dog-bone' region of the fuel plate. A micrograph of the failed fuel plate is shown in Figure 1.6. 
The fuel plate failure was followed by the loss of some of the fuel meat due to water corrosion. An estimate of the total amount of fuel lost by corrosion was made based on metallographic examination, and an upper bound on fuel alloy loss of $0.42 \mathrm{~g}$ (including $0.19 \mathrm{~g}$ of ${ }^{235} \mathrm{U}$ ) was established.

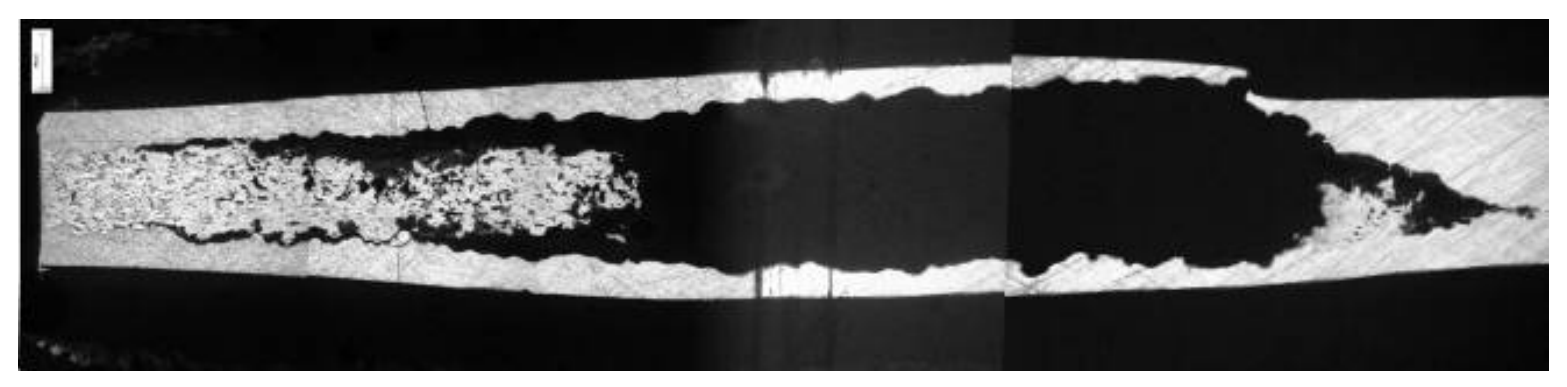

Figure 1.6. RERTR-5 fuel plate Q8003I irradiated for 106 days after cladding failure.

\subsubsection{U-Mo Fuel Irradiation Testing in the Other Countries}

A synopsis of major non-U.S. fuel development activity and fuel failures are summarized below. There were unusual circumstances reported in conjunction with many of these experiments. There have been fuel performance related failures of U-Mo fuel reported in Canada, France, Korea, and Russia. The poor performance of the FUTURE and IRIS-2 experiments in 2002 and 2003, taken together with new insight from the RERTR-4 and RERTR-5 experiments, definitively showed that U-Mo fuel did have serious irradiation performance issues.

\subsubsection{Canadian Program}

AECL irradiated 12 LEU-Mo pin-type mini-elements in the NRU reactor at Chalk River from September to November 2000. The elements were fabricated using U-10Mo fuel powder produced by a proprietary AECL process. Fuel pins were configured as standard MAPLE reactor elements but loaded to $4.5 \mathrm{~g}-$ $\mathrm{U} / \mathrm{cm}^{3}$ and irradiated at a linear power of $165-177 \mathrm{~kW} / \mathrm{m}$. A day after a short duration increase in local power, at a burnup of approximately 22 at.\%, a fuel defect was detected and the experiment was removed from the reactor. Some PIE results that became available in 2002 indicated that two pins had breached, and that the cladding failure appeared to be in a tensile mode. The microstructure of the irradiated fuel was similar to that observed in the UMUS experiment (see section below), and indicated that the failure mode was similar and related to overheating of the cladding.

A subsequent experiment was conducted beginning in May 2003 using identical fuel rods but operating at a much lower peak power of $100 \mathrm{~kW} / \mathrm{m}$. PIE at 20 at.\% burnup reported in $2004\left[{ }^{\mathrm{ix}}\right]$ indicated that the swelling rate of U-Mo fuel was higher than that of $\mathrm{U}_{3} \mathrm{Si}$ fuel, and that the swelling was consistent with that expected due to extensive formation of the $(\mathrm{U}-\mathrm{Mo}) \mathrm{Al}_{\mathrm{x}}$ interaction phase. Porosity that formed was consistent with that observed in out-of-pile thermal testing. Microchemical analysis of the interaction phase was somewhat inconclusive but indicated that the composition was in the range of (U-Mo) $\mathrm{Al}_{3}$ to (U-Mo) $\mathrm{Al}_{4}$ in most regions of the fuel. Some pins continued irradiation under decreasing power conditions to 80 at.\% burnup without failure. Neutron diffraction of specimens irradiated to 60 at.\% burnup indicate the presence of $\mathrm{UAl}_{3}$. 


\subsubsection{French Program}

IRIS-1 - The IRIS-1 test of three Materials Test Reactor (MTR) fuel plates loaded to $\sim 8 \mathrm{~g}-\mathrm{U} / \mathrm{cm}^{3}$ was irradiated in the OSIRIS reactor at CEA-Saclay for 241 EFPD from September 1999 to January 2001. These plates performed well at a peak surface heat flux of $124-145 \mathrm{~W} / \mathrm{cm}^{2}$ to a peak burnup of $67.5 \%$, and a peak cladding temperature of $72^{\circ} \mathrm{C}$. The maximum fuel plate thickness increase was $77 \mu \mathrm{m}$ (out of $1.3 \mathrm{~mm}$ ). These plates were fabricated similarly to the UMUS fuel plates (see below). Commissariat de l'Energie Atomique (CEA) found that the fuel/aluminum reaction layer had a composition in the range of (U-Mo) $\mathrm{Al}_{6}$ to $(\mathrm{U}-\mathrm{Mo}) \mathrm{Al}_{8}$, and that fission products accumulated at the interface between the reaction product and the fuel/aluminum interface. A representative micrograph is shown in Figure 1.7.

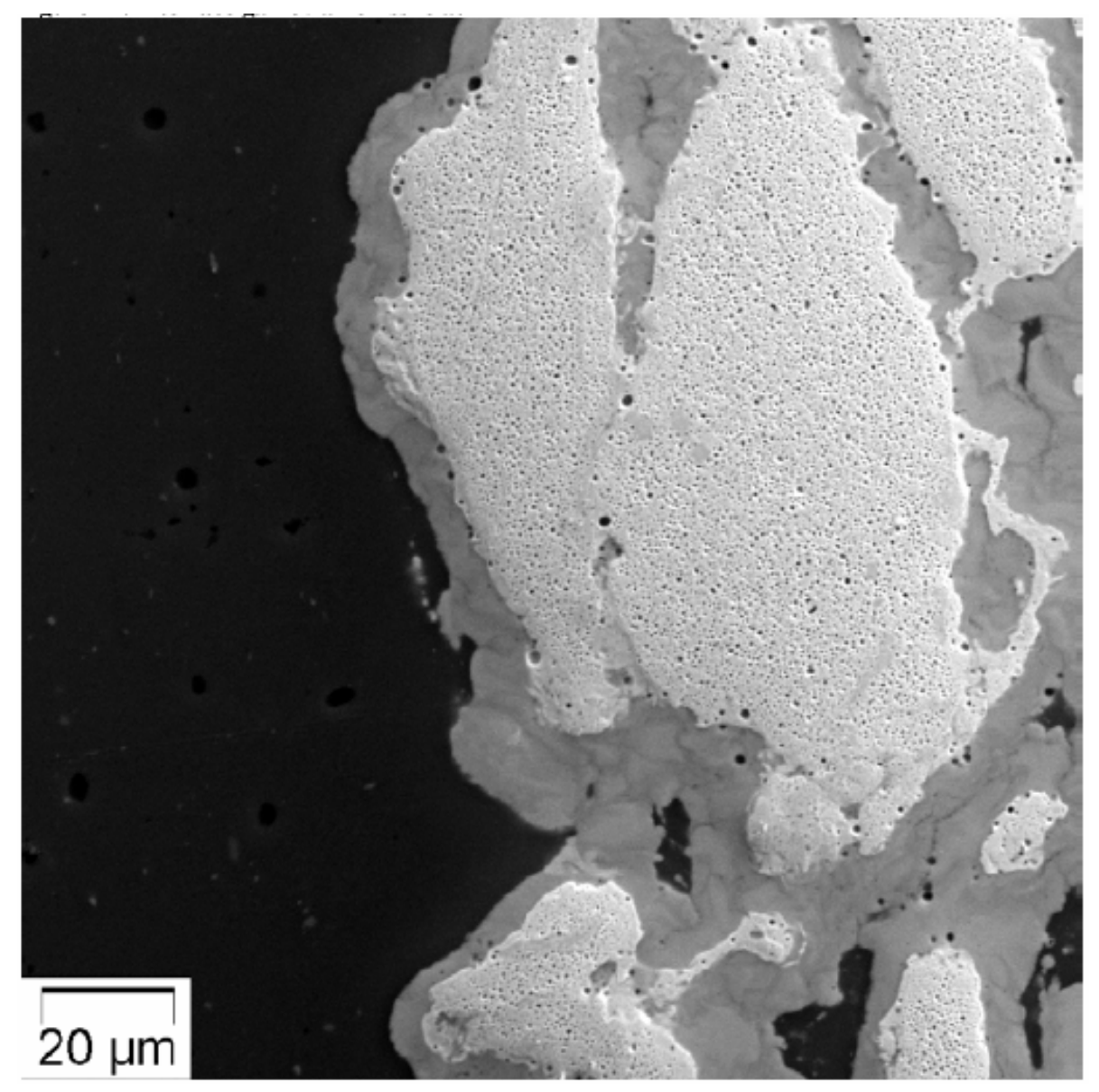

Figure 1.7. Representative micrograph from IRIS-1 fuel plate. 
UMUS - With indications of good fuel performance in the IRIS-1 test, CEA initiated a second test in the High Flux Reactor (HFR) reactor in Petten, The Netherlands. The UMUS experiment tested MTR-size U-Mo fuel plates at $8 \mathrm{~g}-\mathrm{U} / \mathrm{cm}^{3}$ at a higher power density than IRIS-1. A peak experiment surface heat flux of $250 \mathrm{~W} / \mathrm{cm}^{2}$ was achieved, resulting in a beginning of life (BOL) clad surface temperature of $110^{\circ} \mathrm{C}$. The experiment was composed of four fuel plates, two fueled with LEU and two with fuel at $35 \%$ enrichment to increase fuel power density. The plates were made by CERCA with irregularly shaped U-Mo powder with a high content of fines ( -325 mesh). The experiment was inserted into the HFR in Petten, The Netherlands in May of 2000 and irradiated for 48 EFPD over two cycles prior to the detection of a fission product release to the reactor coolant from one of the plates. PIE of a sibling plate beginning in March of 2001 (the failed plate was not examined) showed a low-conductivity surface oxide layer potentially up to $100 \mu \mathrm{m}$ thick due to the high $\mathrm{pH}$ of the HFR coolant water, and high fuel temperature was hypothesized to be the cause of failure; the estimated aluminum cladding temperature was greater than $190^{\circ} \mathrm{C}$. The fuel particles reacted extensively with the matrix aluminum, resulting in almost complete aluminum depletion. PIE micrographs of the sibling fuel plate indicated delamination at the interface between the fuel meat and the cladding. There was no indication of excessive swelling or delamination through the fuel meat. A representative optical micrograph is shown in Figure 1.8.

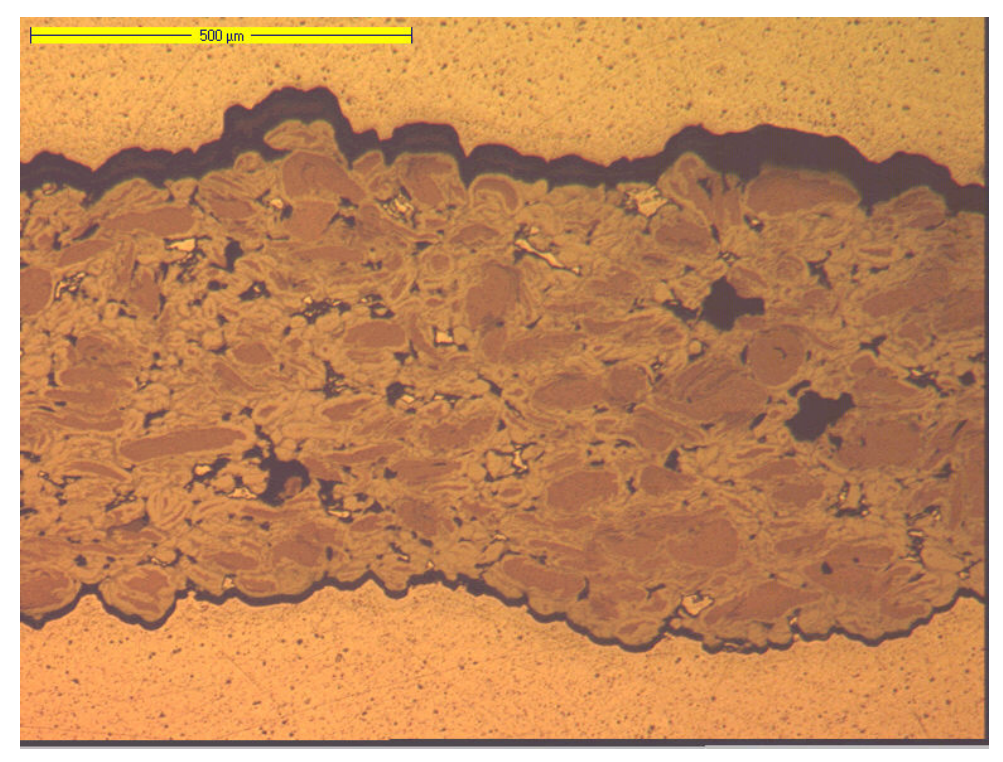

Figure 1.8. Metallographic cross section of sibling to failed plate from the UMUS experiment.

FUTURE - The FUTURE experiment was irradiated by CEA in the Belgian Reactor 2 (BR2) reactor (Mol, Belgium) during the second half of 2002. Two U-7Mo fuel plates containing atomized powder loaded at $8 \mathrm{~g}-\mathrm{U} / \mathrm{cm}^{3}$ were irradiated at high power to determine whether or not the fuel failure in the UMUS experiment was due to plate overheating (due to the formation of a surface oxide layer) or to an intrinsic fuel performance problem with U-Mo fuel. The plates were irradiated at a power that resulted in a surface heat flux of $340 \mathrm{~W} / \mathrm{cm}^{2}$ and a BOL surface temperature of $130^{\circ} \mathrm{C}$. After $40 \mathrm{EFPD}$ and $29 \%$ ${ }^{235} \mathrm{U}$ burnup (fission density $1.25 \times 10^{21} \mathrm{f} / \mathrm{cm}^{3}$ ), a plate thickness increase of $13 \%$ was noted. A specimen from the region of the plate with the highest swelling was examined, and showed a much different evolution of the microstructure during irradiation than revealed by the UMUS fuel plate PIE. In the case of the FUTURE experiment, the fuel plate delaminated through the center of the fuel meat, with ligaments of the $(\mathrm{U}-\mathrm{Mo}) \mathrm{Al}_{\mathrm{x}}$ interaction phase bridging the void, as shown in Figure 1.9. The composition of the 
interaction phase was determined to be in the range of compositions consistent with (U-Mo)Al $\mathrm{Al}_{3}$ or $(\mathrm{U}-$ $\mathrm{Mo}) \mathrm{Al}_{4.4}$. There were also indications of concentration of xenon gas at the boundary between the remaining matrix aluminum and the $(\mathrm{U}-\mathrm{Mo}) \mathrm{Al}_{\mathrm{x}}$ layer.

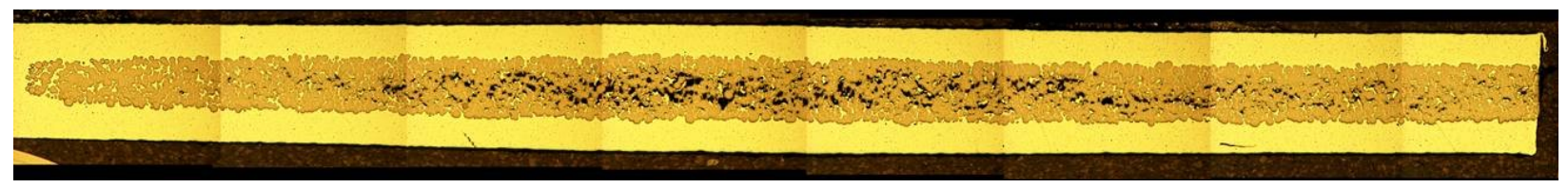

Figure 1.9. Cross section of pillowed fuel plate from the FUTURE experiment.

IRIS-2 - The IRIS-2 test was developed and irradiated by CEA beginning in early 2003 in order to determine whether reasonable limits on operating power could be established that would allow utilization of U-Mo fuel in some reactors. The experiment consisted of four MTR fuel plates fabricated using atomized U-7Mo fuel at $8.3 \mathrm{~g}-\mathrm{U} / \mathrm{cm}^{3}$. The plates operating at a peak surface heat flux of $238 \mathrm{~W} / \mathrm{cm}^{2}$ in the OSIRIS reactor resulted in a peak beginning of life cladding temperature of $93^{\circ} \mathrm{C}$. A plate thickness increase of more than $250 \mu \mathrm{m}$ was observed after 30 EFPD for one plate, which was withdrawn from the experiment. The experiment was terminated after 58 EFPD due to high swelling of the remaining plates. PIE results revealed the same failure mechanism as found in the FUTURE test -delamination of the fuel plate through the meat center. The U-Mo fuel particles behaved well, with no evidence for excessive swelling in this phase. Separation between the reaction layer and the aluminum matrix were noted, as well as what appears to be viscous flow of the interaction layer in the delaminated region. The composition of the interaction layer was found to vary with location in the fuel plate from (U-Mo) $\mathrm{Al}_{6}$ in the unaffected regions of the fuel plate to $(\mathrm{U}-\mathrm{Mo}) \mathrm{Al}_{4.5}$ in the failed region. Micrographs of the failed IRIS-2 plate are shown in Figure 1.10.

IRIS-3 - The IRIS-3 test irradiation $\left[{ }^{\mathrm{x}}\right]$ began in early 2005 in the OSIRIS reactor to test the efficacy of silicon additions to the fuel matrix in stabilizing the fuel/aluminum interaction layer against breakaway swelling. Fuel plates containing $0.3 \mathrm{wt} . \%$ and $2.1 \mathrm{wt} . \%$ silicon are under irradiation in the OSIRIS reactor at a BOL power of $\sim 200 \mathrm{~W} / \mathrm{cm}^{3}$. After four cycles of irradiation, at fission density and power conditions slightly less than those conditions where plates from IRIS-2 had failed (fission density 2.0 $2.6 \times 10^{21} \mathrm{f} / \mathrm{cm}^{3}$ ) both types of plates were exhibiting improved irradiation performance with a maximum thickness increase of 35-40 $\mu \mathrm{m}$ at a peak burnup of 38 at. $\%{ }^{235} \mathrm{U}$. The plates with $0.3 \mathrm{wt} \%$ silicon were reported in December 2005 to have excessive swelling after five irradiation cycles, and were removed from the experiment, while a plate operating at the highest power with a $2.1 \mathrm{wt} \% \%$ matrix silicon content has shown good in-reactor performance and will be irradiated for an additional cycle to a burnup greater than 50 at. $\%{ }^{235} \mathrm{U}$.

IRIS-TUM - The IRIS-TUM irradiation test was a joint experiment conducted by the CEA and Technical University of Munich. The test began in Septermber 2005 in the OSIRIS reactor to evaluate the performance of high loading $(8 \mathrm{~g}-\mathrm{U} / \mathrm{cc}) \mathrm{U}-8 \mathrm{Mo}$ fuel plates with a silicon modified (Al-2.1 Si) matrix. Fuel plates were irradiated at a BOL surface heat flux of $\sim 300 \mathrm{~W} / \mathrm{cm}^{2}$ and to a fission density of $3.1 \times 10^{21}$ $\mathrm{f} / \mathrm{cm}^{3}(\sim 42 \%$ LEU equivalent burnup) in the fuel meat. The silicon bearing fuel plates showed a reduction in fuel plate swelling when compared with the control plates. Complete PIE will be performed in 2007. 

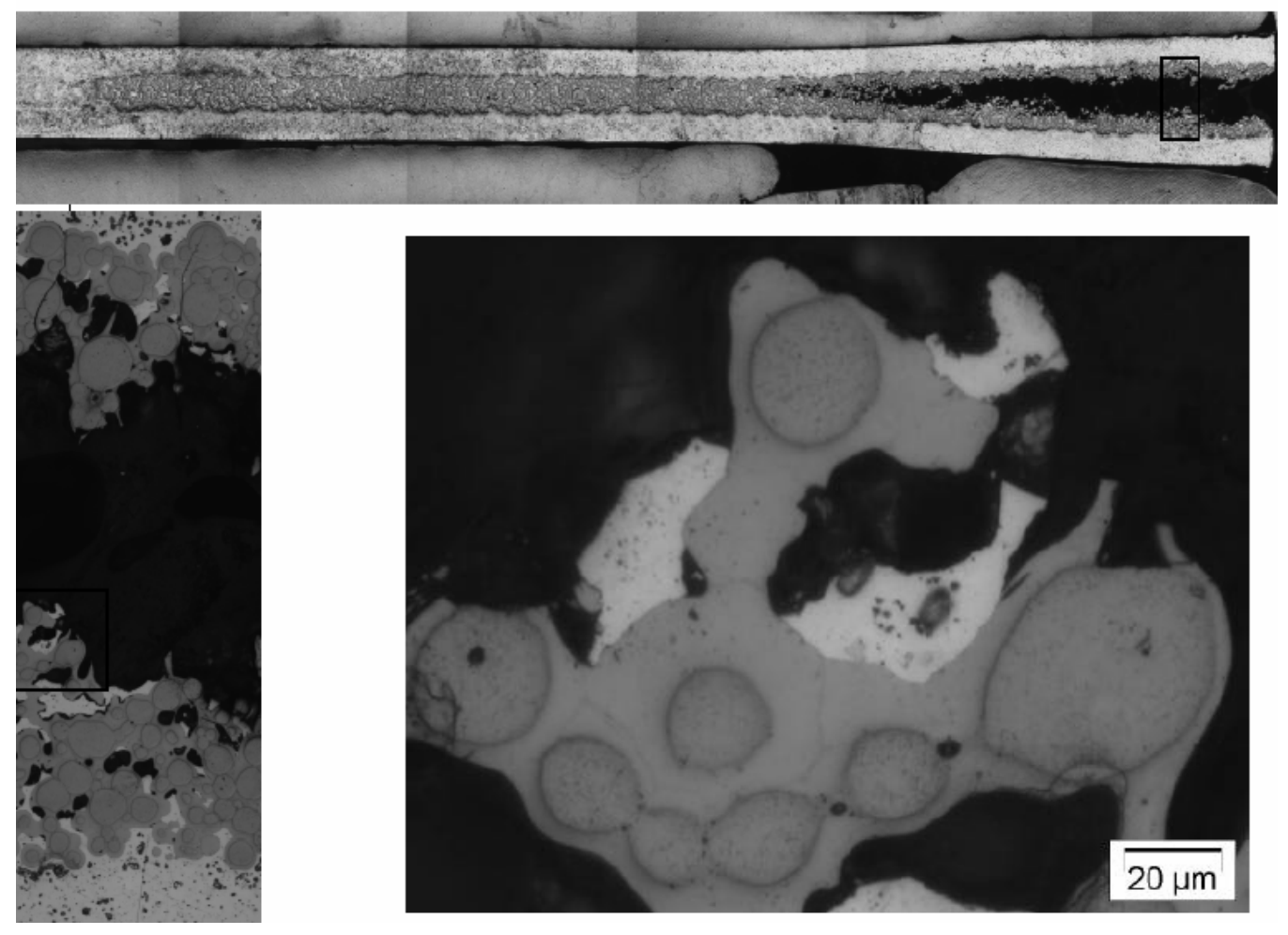

Figure 1.10. Metallographic sections from failed IRIS-2 fuel plate.

\subsubsection{Korean Program}

KOMO-1 - The KOMO-1 irradiation $\left[{ }^{\mathrm{xi}}\right.$ ] included ten U-Mo pin-type fuel specimens (MAPLE-type geometry) of two diameters under aggressive test conditions in the Korean HANARO reactor. Fuel particles with molybdenum contents of 7 and 9 weight percent were tests at fuel loadings of 3.4 and $6.0 \mathrm{~g}$ $\mathrm{U} / \mathrm{cm}^{3}$. The experiment began irradiation in June of 2001 and was discharged due to fission product release to the coolant after 26.6 EFPD (62 days) and $\sim 13$ at. $\%{ }^{235} \mathrm{U}$ burnup. Estimated peak linear power of the failed $6 \mathrm{~g}-\mathrm{U} / \mathrm{cm}^{3}$ fuel pin was $107 \mathrm{~kW} / \mathrm{m}$. PIE indicated a maximum fuel meat volume swelling of $15.9 \%$, extensive reaction of the fuel particles with the matrix aluminum, and formation of a central void. There was no indication of breakaway swelling behavior, and it was hypothesized that the aluminum cladding had ruptured along a fabrication defect (Figure 1.11). Tests of cladding ductility indicated that elongation to failure ranged from 2.5 to $45.8 \%$, and it was concluded that the lower values were caused by cladding defects formed due to inclusions of die lubricant into the cladding during extrusion. The fuel failure was also attributed to this type of cladding defect. It was estimated that high fuel centerline temperatures might also have contributed to fission gas release, however no evidence was presented. 


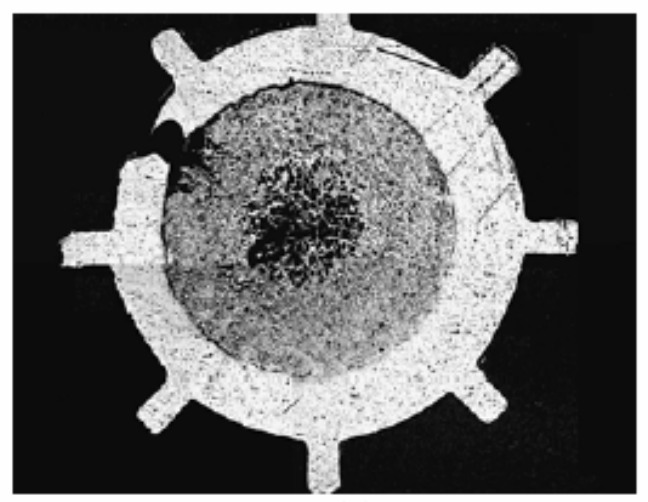

(a)

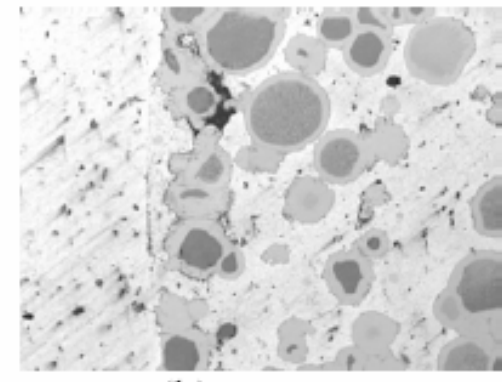

(b)

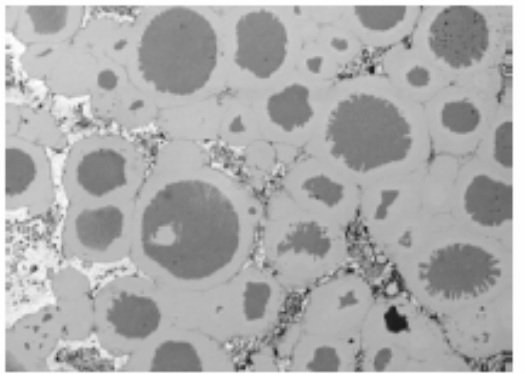

(c)

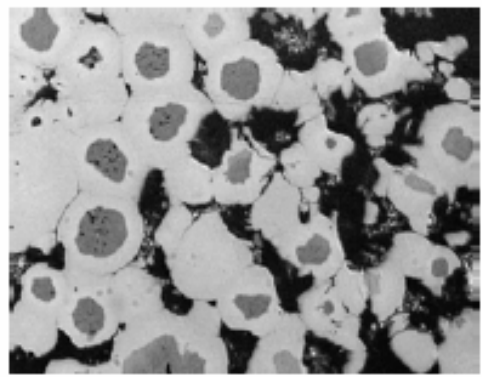

(d)

Figure 1.11. Failed KOMO-1 fuel test pin.

KOMO-2 - Following the failure in the KOMO-1 experiment, the KOMO-2 test $\left[{ }^{\mathrm{xii}}\right]$ irradiated similar pin-type U-Mo dispersions with two diameters at lower fuel loading $\left(4.0-4.5 \mathrm{~g}-\mathrm{U} / \mathrm{cm}^{3}\right)$ in the Korean HANARO reactor. No fuel failures occurred in this test. The experiment was irradiated from January 2003 to January 2004 to a peak burnup of 71 at. $\%{ }^{235} \mathrm{U}$ at a peak linear power of $112 \mathrm{~kW} / \mathrm{m}$. Fuel meat swelling of the large diameter fuel pins in the range of 8.5-15.6\% was observed for burnup in the range of $62-68$ at. $\%{ }^{235} \mathrm{U}$; the upper value being about twice that measured for $\mathrm{U}_{3} \mathrm{Si}$ fuel at $4.0 \mathrm{~g}-\mathrm{U} / \mathrm{cm}^{3}$. Large fuel particles were effective in reducing fuel swelling to the lower end of the observed range.

Microstructural examination indicated that porosity that formed in the center of the fuel meat region is similar to that observed in out-of-pile heat treatment and unlike that found in the IRIS-2 and FUTURE tests.

\subsubsection{Russian Program}

Mini-pins - Two test capsules containing 13 variations of U-Mo fuel were inserted into the Research Reactor (MIR) at the Research Institute of Atomic Reactors (RIAR) in Dimitrovgrad in 2003. Irradiation conditions were moderate with pin surface heat flux of $32-90 \mathrm{~W} / \mathrm{cm}^{2}$ and cladding temperatures of 88 $117^{\circ} \mathrm{C}$. In November of 2004 a fission product release was detected in the capsule containing the highestburnup pins. The average ${ }^{235} \mathrm{U}$ burnup in the mini-pins ranged between $\sim 60$ and $\sim 65 \%$. Subsequent postirradiation inspection determined the cause of the release to be related to an obvious fabrication defect. The irradiation of the second capsule containing mini-pins was resumed and was completed in February 2005 with average fuel burnup of the pins ranging between $\sim 20$ and $\sim 60 \%$. The PIE of the pins 
indicates normal fuel irradiation behavior under the conditions tested, with no indication of breakaway swelling and moderate fuel/matrix interaction.

Full-sized pins - The lifetime test of two full-sized pin-type fuel assemblies are in progress in the VVR$2 \mathrm{M}$ reactor at the Petersburg Nuclear Physics Institute (PNPI) in Gatchina. In February 2005, the average burnup in the fuel assembly containing $\mathrm{UO}_{2}-\mathrm{Al}$ dispersion fuel (being irradiated as a control) was $~ 35 \%$, and that in the fuel assembly containing U-Mo dispersion fuel was $12 \%$. The tests are planned to reach an average burnup of $60 \%$.

IVV-2M tubes - Tubular U-Mo dispersion fuel undergoing irradiation at the IVV-2M reactor at the Institute of Reactor Materials (Zarechny) failed at approximately $60 \%$ burnup. Nominal fuel operating conditions were a surface heat flux of $57-118 \mathrm{~W} / \mathrm{cm}^{2}$ and a cladding temperature of $52-89^{\circ} \mathrm{C}$. The failure mechanism appears to be the same seen in the FUTURE and IRIS-2 tests. Gamma scans of the tubes indicate the presence of a high flux gradient across the failed tubes during the latter part of their irradiation, and it is suspected that movement of the experiment to a location near the beryllium reflector resulted in a local power increase that contributed to the failure. The failure cross section is shown in Figure 1.12. Neutron radiography was performed on samples taken from the fuel elements and did not show the presence of any crystalline $\mathrm{UAl}_{\mathrm{x}}$ phases until the samples were annealed at temperatures greater than $450^{\circ} \mathrm{C}$.

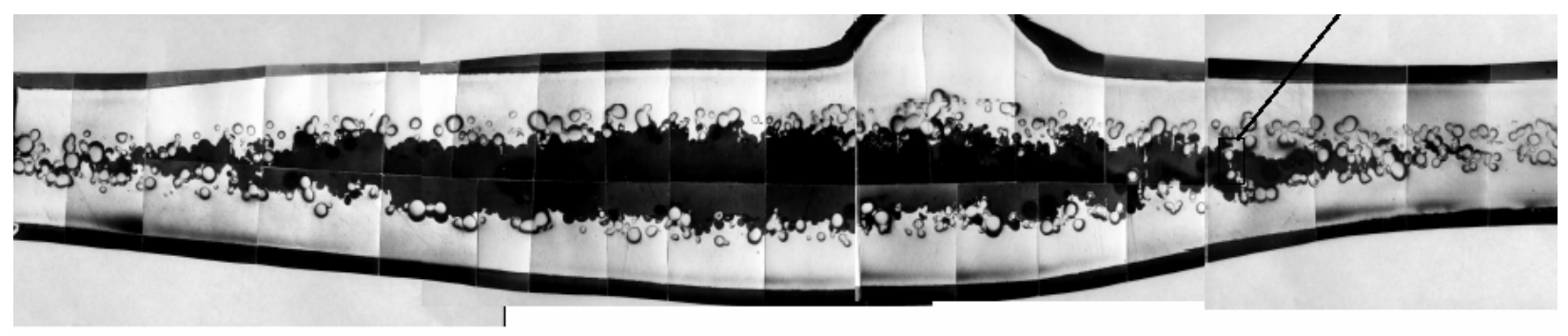

Figure 1.12. Cross section of failed U-Mo fuel tube from testing in the IVV-2M reactor.

\subsubsection{Path forward for very-high-density fuel development}

It became obvious in 2003 that U-Mo/Al dispersion fuels would not perform acceptably under the operating conditions required for high-powered research reactors. It is also clear that the fuel performance limitations are related to the unstable irradiation behavior of the (U-Mo) $\mathrm{Al}_{\mathrm{x}}$ interaction layer that forms during irradiation under certain conditions. In no case is there evidence that the U-Mo fuel particles (or foils) do not behave well under irradiation. Given these observations, there are two primary 'fixes' available that allow for retention of a conventional aluminum clad fuel design. These are:

- Chemical modifications to the aluminum matrix and/or the dispersion fuel particles to stabilize the stoichiometry of the (U-Mo) $\mathrm{Al}_{\mathrm{x}}$ interaction layer that forms. The primary candidate for addition to the matrix is silicon in quantities of less than $5 \mathrm{wt} . \%$. The primary candidates for addition as an alloying element to the U-Mo are titanium and zirconium.

- Elimination of the matrix material, resulting in a 'monolithic' instead of a dispersion fuel. The resulting fuel is a laminate of U-Mo alloy clad in aluminum. This fuel has also shown promising irradiation behavior based on RERTR-4, RERTR-6, and RERTR-7 irradiation test results. 


\subsubsection{Path Forward}

Based on irradiation experiments test results obtained to date, it has become clear that:

- Significant improvements in irradiation behavior occur due to the addition of silicon to the aluminum matrix. Results from RERTR-6 and RERTR-7 show a decreased interaction layer growth rate and stable irradiation behavior of the layer that does form up to very high burnup at high power.

- U-Mo monolithic fuels appear to have acceptable irradiation behavior at moderate burnup. At high burnup, the same unstable irradiation behavior seen in (unmodified) U-Mo/Al dispersions occurs at the fuel/cladding interface. Delamination of some test plates was observed after sectioning on PIE.

Based on these results it is clear that the process for qualification of modified dispersion fuels with density of less than $8.5 \mathrm{~g}-\mathrm{U} / \mathrm{cm}^{3}$ can proceed forward. Full-size dispersion fuel plates will be fabricated for irradiation in the AFIP-1 test and for subsequent element testing. Dispersion fuel research and development $(\mathrm{R} \& \mathrm{D})$ will center on developing methods for fabrication of plates with uranium densities greater than $8 \mathrm{~g} \mathrm{U} / \mathrm{cm}^{3}$.

Monolithic fuels and dispersions with density higher than $8.5 \mathrm{~g}-\mathrm{U} / \mathrm{cm}^{3}$ will require additional research prior to testing of full-size plates and elements. Monolithic fuel research will be focused on correcting the fuel performance problem at the fuel/cladding interface and determining the nature and strength of the fuel to cladding bond.

\subsubsection{Alternative Fuels}

In addition to these more conventional aluminum clad fuels, fuels based on zirconium are considered as an alternative in the case that the fuel performance limitations of the aluminum-based fuels cannot be overcome.

Fuel test plates fabricated by CNEA (Argentina) (with LEU) were irradiated in the RERTR-7 experiment and showed good irradiation behavior at moderate power and burnup. This development path will continue in conjunction with CNEA. It continues to provide a backup for aluminum clad monolithic fuel for those applications that require uranium densities of more than $8 \mathrm{~g}-\mathrm{U} / \mathrm{cm}^{3}$ and may be suitable for use in future high-performance LEU reactors. Most work on fabrication of zircaloy-clad fuel is performed by CNEA, with irradiation testing and PIE performed in the U.S.

\subsubsection{Replacement of the matrix aluminum with magnesium.}

Magnesium does not react with uranium molybdenum alloy during irradiation, as shown by RERTR-3 irradiation test results. Fabrication of aluminum clad magnesium matrix plates presents challenges due to the low melting $\mathrm{Mg} / \mathrm{Al}$ eutectic, which limits the rolling temperature to approximately $400^{\circ} \mathrm{C}$. This low rolling temperature has resulted in inconsistent aluminum-to-aluminum bonding during fabrication by hot rolling. Research was conducted to overcome this issue by using a hybrid process which allows bonding of the assembly prior to rolling. Due to the successful development of aluminum matrix dispersion fuels, further development of magnesium matrix dispersions is considered a low priority. 


\section{Fuel development tasks}

Fuel development and qualification can only proceed through a program focused on irradiation testing and supported by out-of-pile data and fuel performance modeling. The RERTR program is thus focused on:

- Developing fuel concepts that meet reactor operating requirements,

- Developing fabrication processes for these fuels that are amenable to commercial-scale fuel production,

- Proving performance of fuel concepts through irradiation testing of small specimens,

- Supporting irradiation testing data with fuel performance modeling and generation of out-of-pile data,

- Working with commercial fuel vendors to ensure supply of the developed fuels for element testing

- Developing a data set for adequate for NRC approval through large scale demonstration of the performance of successful concepts,

- Working with commercial fuel vendors to ensure supply of the developed fuels reactor conversion,

- Supporting conversions through the provision of fuel performance data and fuel performance models relevant to the reactors being converted, and

- $\quad$ Providing assistance in performing PIE of lead test elements where required.

\subsection{Major milestones}

GTRI program goals announced by Energy Secretary Abraham on May 26, 2004, in Vienna included the conversion of most civilian reactors that use HEU to LEU by 2014. In order to allow time for reactor conversion, fuels suitable for conversion must be developed well in advance of this date. These considerations lead to the target of supplying qualified fuels required for conversion of most listed research reactors to LEU by the end of 2010.

As of January 2007, it appears that dispersion fuels with density of $8.5 \mathrm{~g}-\mathrm{U} / \mathrm{cm}^{3}$ or less will be qualified to convert most of the world's reactors prior to the end of 2010. Pending successful resolution of the issues associated with monolithic fuel, qualification of fuel with density higher than $8.5 \mathrm{~g}-\mathrm{U} / \mathrm{cm}^{3}$ will be delayed by approximately $1-2$ years.

In addition, the fuel development program will support commercialization of qualified fuel technology sufficient to allow the conversion of most listed research reactors by 2014.

Milestones:

- $\quad$ Provide a qualified fuel for conversion of most listed reactors by the end of 2010.

- Work with commercial fuel fabricators to provide high-density fuels to listed reactors by the end of 2014. 


\subsection{Limitations}

Due to the complexities associated with the in-reactor behavior of fuel, novel approaches required for fuel fabrication and the nature of research in general, it is impossible to predict cost and schedule with complete certainty. Proper planning and well-placed expenditures, however, can alleviate some of the risk associated with the RERTR fuel qualification.

Fuel testing cannot be accelerated beyond a certain point due to necessity to maintain prototypic irradiation conditions, the necessity to eliminate excessive fuel failure during testing, and the physical limitations associated with heat transfer from the fuel during testing.

\subsection{Listed reactors}

Research reactors targeted by the RERTR program for which a qualified fuel suitable for conversion to LEU is not available are given in Tables 2.1 and 2.2. These reactors have the potential to consume almost $600 \mathrm{~kg}$ of HEU per year. The reactors in Kazakhstan and Poland will be converted by qualifying oxide and silicide fuels supplied by Russia and western suppliers, respectively.

Recently the French announced that fuel selection for the planned Jules Horowitz Reactor (JHR) will be made at the end of 2007. If LEU-Mo fuels do not show significant promise by this point, it is likely the choice for fuel development will be $>20 \%$ enriched $\mathrm{U}_{3} \mathrm{Si}_{2}$. This decision provides additional motivation to deploy a fuel development program that provides early results.

Table 2.1. Western designed and supplied research reactors that require new very-high-density fuels to convert to LEU and estimated HEU consumption.

\begin{tabular}{|c|l|l|c|c|}
\hline & \multicolumn{1}{|c|}{ Reactor } & \multicolumn{1}{|c|}{ Country } & Power (MW) & HEU (Kg/yr) \\
\hline 1 & BR2 & Belgium & 80 & 29 \\
\hline 2 & RHF & France & 57 & 55 \\
\hline 3 & ORPHEE & France & 14 & 16 \\
\hline & JHR (planned) & France & 100 & - \\
\hline 4 & FRM-II & Germany & 20 & 38 \\
\hline 5 & MITR & USA & 5 & $>5$ \\
\hline 6 & MURR & USA & 10 & 24 \\
\hline 7 & NBSR & USA & 20 & 13 \\
\hline 8 & HIFR & USA & 100 & 80 \\
\hline 9 & ATR & USA & 250 & 120 \\
\hline 10 & ATRC & USA & 0.005 & 0 \\
\hline \multicolumn{2}{|c|}{ Approximate total HEU consumption $(\mathrm{Kg} / \mathrm{yr})$} & $>380$ \\
\hline
\end{tabular}


Table 2.2. Russian designed and supplied research reactors that require new very-high-density fuels to convert to LEU and estimated HEU consumption.

\begin{tabular}{|c|l|l|c|c|}
\hline \multicolumn{1}{|c|}{ Reactor } & \multicolumn{1}{|c|}{ Country } & $\begin{array}{c}\text { Power } \\
\text { (MW) }\end{array}$ & $\begin{array}{c}\text { HEU } \\
\text { (Kg/yr) }\end{array}$ \\
\hline 11 & LWR-15 & Czech R. & 10 & 14 \\
\hline 12 & IRT-MEPI & $\begin{array}{l}\text { Russia } \\
\text { (MEPI, Moscow) }\end{array}$ & 2.5 & 1 \\
\hline 13 & IR-8 & $\begin{array}{l}\text { Russia } \\
\text { (Kurchatov, Moscow) }\end{array}$ & 8 & 2 \\
\hline 14 & IRT-T & $\begin{array}{l}\text { Russia } \\
\text { (NIIYaF, Tomsk) }\end{array}$ & 6 & 6 \\
\hline 15 & VVR-TS & $\begin{array}{l}\text { Russia } \\
\text { (NIFKhI, Obninsk) }\end{array}$ & 15 & 15 \\
\hline 16 & VVR-M & $\begin{array}{l}\text { Russia } \\
\text { (Gatchina) }\end{array}$ & 15 & 9 \\
\hline 17 & IVV-2M & $\begin{array}{l}\text { Russia } \\
\text { (Zarechniy) }\end{array}$ & 100 & 62 \\
\hline 18 & MIR-M1 & $\begin{array}{l}\text { Russia } \\
\text { (RIAR, Dmitrovrad) }\end{array}$ & 0 & 0.0 \\
\hline 19 & CA.MIR-M1 & $\begin{array}{l}\text { Russia } \\
\text { (RIAR, Dmitrovrad) }\end{array}$ & 130 \\
\hline
\end{tabular}

\subsubsection{Reactors that can be converted with very-high-density dispersion fuel}

Table 2.3 lists reactors for which conversion to LEU might be possible using dispersion fuels with a density of $8.5 \mathrm{~g} \mathrm{U} / \mathrm{cm}^{3}$. In the best case scenario, conversion of 17 reactors would eliminate the use of approximately $400 \mathrm{~kg}$ of HEU. It is possible, however, that only 12 reactors could be converted to LEU with this fuel.

Note that several reactors are currently undergoing detailed conversion analysis and may not be convertible with this type of fuel. These reactors could convert to lower enrichment through the use of higher density dispersion fuels, monolithic fuels, or dispersion fuels at $8.5 \mathrm{~g} \mathrm{U} / \mathrm{cm}^{3}$ and higher enrichment. In any case, it is feasible to eliminate all commerce in uranium with enrichments above approximately $50 \%$. 
Table 2.3. Reactors that may be able to convert to LEU with U-Mo dispersion fuel with a density of $8.5 \mathrm{~g}$ $\mathrm{U} / \mathrm{cm}^{3}$.

\begin{tabular}{|c|c|c|c|}
\hline Reactor & Country & Power (MW) & HEU (Kg/yr) \\
\hline BR2 & Belgium & 80 & 29 \\
\hline RHF & France & 57 & 55 \\
\hline ORPHEE & France & 14 & 16 \\
\hline JHR (planned) & France & 100 & \\
\hline NBSR & USA & 20 & 13 \\
\hline HIFR* & USA & 100 & 80 \\
\hline $\mathrm{ATR}^{*}$ & USA & 250 & 120 \\
\hline ATRC* & USA & 0.005 & 0 \\
\hline LWR-15 & Czech R. & 10 & 14 \\
\hline IRT- MEPI & $\begin{array}{l}\text { Russia } \\
\text { (MEPI, Moscow) }\end{array}$ & 2.5 & 1 \\
\hline IR-8 & $\begin{array}{l}\text { Russia } \\
\text { (Kurchatov, Moscow) }\end{array}$ & 8 & 2 \\
\hline IRT-T & $\begin{array}{l}\text { Russia } \\
\text { (NIIYaF, Tomsk) }\end{array}$ & 6 & 6 \\
\hline VVR-TS & $\begin{array}{l}\text { Russia } \\
\text { (NIFKhI, Obninsk) }\end{array}$ & 15 & 21 \\
\hline VVR-M & $\begin{array}{l}\text { Russia } \\
\text { (Gatchina) }\end{array}$ & 18 & 15 \\
\hline IVV-2M & $\begin{array}{l}\text { Russia } \\
\text { (Zarechniy) }\end{array}$ & 15 & 9 \\
\hline MIR-M1* & $\begin{array}{l}\text { Russia } \\
\text { (RIAR, Dmitrovrad) }\end{array}$ & 100 & 62 \\
\hline CA.MIR-M1* & $\begin{array}{l}\text { Russia } \\
\text { (RIAR, Dmitrovrad) }\end{array}$ & 0 & 0.0 \\
\hline \multicolumn{3}{|c|}{ Approximate total HEU consumption $(\mathrm{Kg} / \mathrm{yr})$} & $402 \mathrm{~kg}$ \\
\hline
\end{tabular}

*These reactors represent cases on the margins of conversion feasibility. 


\subsection{Fuel Test Sequence}

The research reactor fuel development testing sequence has typically included initial testing of miniplates, followed by testing of full-size plates, and finally verification of performance and commercial fabrication through the testing of large numbers of plates in prototypic elements. This testing sequence will be maintained in the current fuel qualification effort in order to maintain a balance between programmatic and technical risk.

\subsubsection{Miniplate Testing}

Miniplate tests are designed as scoping tests to provide basic fuel behavior feasibility information on new fuel concepts. The consequences of plate failure to reactor operation are low due to the small amount of fuel and diverse pathways for coolant flow incorporated into the design of fuel test rigs. Key factors for PIE are fuel swelling and characterization of chemical interaction between the fuel particles and the matrix. These tests are often conducted outside of the reactor core to simplify test licensing requirements. Small plate dimensions reduce the cost of testing a large number of variations in fuel design and composition, but do not provide information on the in-pile mechanical performance of fullwidth plates or the effect of flux and temperature gradients in the axial and transverse directions.

\subsubsection{Full-size Plate Testing}

These are typically tests of one to six test plates contained in an MTR subassembly or a special test assembly. Often the plates are demountable; that is they can be removed from the test assembly for inspection in the reactor canal. Test plates are typically visually and dimensionally inspected after each cycle to look for signs of unusual behavior that may be precursors to failure. Plates that show signs of unusual behavior can be pulled from the test assembly. These tests provide assurance of acceptable fuel behavior prior to conducting tests of whole fuel elements, where the consequence of failure of an element is large.

\subsubsection{Fuel Qualification Demonstration}

Full-size fuel elements provide assurance that the fuel performs as designed in all aspects, and that the fuel can consistently be fabricated in a manner that does not lead to fuel performance issues. PIE is nominal, and may consist of dimensional measurement (in-canal and in-cell), visual examination, gamma scanning, and dissection of a plate. Demonstration of acceptable fuel performance in element tests was regarded as the endpoint for fuel qualification for $\mathrm{U}_{3} \mathrm{Si}_{2}$ fuels, and resulted in the issue of NUREG-1313.

NUREG-1313 (Safety Evaluation Report Related to the Evaluation of Low-Enriched Uranium SilicideAluminum Dispersion Fuel for Use in Non-Power Reactors) concluded on the basis of the completed testing of six fuel elements that:

\section{Section 4. CONCLUSIONS}

The tests and examinations summarized in Appendices $A$ and $B$, including the extensive references to $U_{3} S_{2}-A l$ MTR (plate)-type fuel, provide the necessary bases for the staff's evaluations. On the basis of the currently available information, the staff concludes that the described fuel is acceptable for use in licensed nonpower reactors provided that individual safety analyses do not introduce new safety considerations. The staff will review the report on the fullcore irradiation program once it is submitted, and if necessary, a supplement to the report will be 
issued if new safety considerations come to light. This conclusion also is contingent on the use of a uniform set of acceptance specifications consistent with those used for the fabrication of the test specimens.

\section{Other Considerations}

Most MTR-type reactors use a flat fuel plate or a fuel plate with a large radius of curvature. High flux reactors such as High-Flux Isotope Reactor (HFIR), BR2, JHR, and FRM-2 use more complex fuel elements. FRM-2 and HFIR fuel plates use fuel density zoning, burnable poison, and so-called 'involute' curvature. BR2 and JHR use elements composed of rings of three plates bent into a cylinder (each plate comprises a $120^{\circ}$ section of the cylinder). Demonstration of the fuel performance of all of these variants will be necessary for fuel qualification for these reactors. Qualification of fuel elements for BR2 will likely be encompassed by the JHR fuel qualification process if U-Mo fuels are selected for development and qualification by CEA in 2007. If U-Mo fuels are not selected for the JHR startup core, the French will likely make an effort to develop these fuels for implementation in a conversion core.

Demonstrations of the performance of complex fuels will occur through irradiation of prototypic test plates in the AFIP-3 and AFIP-4 experiments in the ATR and MIR reactors. Qualification of complex fuels will consist of fabricating conversion cores, inserting the conversion cores in reactor, and reactor startup and verification of fuel performance using the LEU fuel.

\subsubsection{Russian Fuel Development}

Fuel development in support of the conversion of Russian-designed reactors will proceed by providing consistent technical support and technical exchange with Russian RERTR program counterparts along with adequate and timely financial support through contracts for fuel development.

Fuel development will continue to be funded primarily through the Russian institute VNIINM (Bochvar Institute, Moscow). The U.S. RERTR fuel development program will work with the Russian RERTR program to develop a schedule for qualification of fuel for Russian designed reactors, and fund this work at a level that allows fuel qualification to proceed according to schedule. Support for fuel supply, including fuel specifications and coordination of fuel purchases will be provided according to direction from NA-212.

U.S. contracts will initially focus on the development and demonstration of the feasibility of a universal U-Mo pin-type fuel. This concept, if successful, would provide the base component of fuel that can be configured into element designs suitable for conversion of most Russian designed reactors that use aluminum-based fuel.

It is conceivable that fuel for reactors outside of Russia could be developed, if necessary, by the U.S. RERTR program and that a western supplier could tool up to produce this fuel type and supply it to these reactors. This is not currently under consideration due to the desire to maintain an open and noncompetitive relationship with Russian fuel developers to facilitate technical exchange.

Several issues remain to be addressed to meet GTRI program goals for HEU minimization, principally in relation to ensuring fuel development for four Russian high- temperature reactors (SM-3, PIK, RBT-6, RBT-10/2) and two associated critical facilities that use steel clad fuels with a $\mathrm{Cu}-\mathrm{Be}$ matrix.

Development of LEU fuels for these reactors is not currently funded or addressed by either the U.S. or Russian RERTR programs. 


\subsubsection{International Fuel Development Collaboration}

There are currently seven countries with active U-Mo fuel development programs. These are Argentina, Canada, France, Germany, the Republic of Korea, Russia, and the United States. In addition, Australian Nuclear Science and Technology Organization (ANSTO) has a keen interest in U-Mo fuel development in order to provide a suitable back end solution for the OPAL reactor. Interaction with these countries on fuel development takes place in two ways. First, the RERTR International Fuel Development Working Group includes representatives from these countries and typically meets on a semiannual basis to exchange information. Second the U.S. RERTR program uses bilateral agreements such as memoranda and contracts in order to accomplish work with several fuel development partners.

\subsubsection{Fuel Testing Requirements}

\section{Basic Qualification Criteria}

The most-important criterion for qualification is that the fuel meat and fuel plate, pin, or tube (or hereinafter fuel element) must behave in a predictable and stable manner during normal operation, and during anticipated operational transients up to a U-235 burnup significantly higher than normal discharge burnup. Stable behavior means that:

- The fuel meat and hence, the fuel element, swells in a predictable manner and an acceptably low rate up to the required burnup. Rapidly accelerating or breakaway swelling is unacceptable. Swelling is important because the coolant volume and velocity is reduced when the fuel plate, pin, or tube swells.

- The cladding and meat remain bonded so that the cladding does not blister or "pillow." Therefore, the strength of the cladding/meat bond or the strength of any interaction product formed by interaction of the cladding and the meat must be great enough to resist a rupture during allowed mechanical deformations or during thermal expansion/contraction of the fuel plate. The latter situation must be considered during start-up and shut-down, and especially during scrams.

Predictable behavior means that the fuel behavior can be characterized in terms of the relevant irradiation parameters so that, for example, the amount of swelling can be predicted under all operating conditions.

The second important criterion for qualification is the absence of fission-product leaks during irradiation. The manufacturing process must result in cladding without cracks or pin holes. In addition, blisters or pillows must not form during irradiation because stresses during blistering often result in cracks in the cladding through which the fission product gases that formed the blisters can escape.

Another important criterion for qualification is the requirement for a repeatable and robust fuel fabrication process.

\section{Qualification Testing Requirements for Western-Designed Reactors}

The RERTR program is collecting data on fuel requirements during the course of conversion studies of high-powered reactors. This information will be used to better define fuel testing requirements. As this data is being developed, irradiation test conditions are bracketed by considering the licensed operating envelope for high-powered reactors.

Western-designed reactors that use significant quantities of fuel fall into two broad classes: 1) MTR-type reactors (Japanese Material Test Reactor [JMTR], OPAL) and other reactors (e.g., NBSR) with powers of $50 \mathrm{MW}$ or less and moderate surface heat fluxes, and 2) MTR-type and other reactors with powers greater than $50 \mathrm{MW}$ and/or high surface heat fluxes (e.g., ATR, JHR, BR2, HFIR, HFR-Grenoble, FRM-II). This 
latter class of reactors is the most demanding in terms of fuel operating conditions. In these reactors, high surface heat fluxes result from high volumetric power densities in the fuel meat. Reactors of the second class can have surface heat fluxes (hence, meat volumetric power densities) more than twice that of the first; e.g., BR2 has been licensed to operate with a peak heat flux of $600 \mathrm{~W} / \mathrm{cm}^{2}$. Although HFIR can operate with surface heat fluxes up to $620 \mathrm{~W} / \mathrm{cm}^{2}$, the velocity of the cooling water is greater, resulting in lower fuel-meat temperatures. It appears that BR2 is the limiting case among currently operating reactors.

A heat flux of $600 \mathrm{~W} / \mathrm{cm}^{2}$ in the BR2 reactor results in a temperature rise of $143.4^{\circ} \mathrm{C}$ from the bulk water to the cladding surface. The temperature rise through the cladding is $24.4^{\circ} \mathrm{C}$, so that the temperature at the cladding/meat interface is $206.8^{\circ} \mathrm{C}$. Using a thermal conductivity of fresh U-Mo fuel of $\sim 0.15 \mathrm{~W} / \mathrm{cm}$ $\mathrm{K}$, the temperature rise from the fuel/meat interface to the center plane of the fuel meat is $\sim 24.4^{\circ} \mathrm{C}$.

Therefore, the fuel meat at the central plane will be operating at $232^{\circ} \mathrm{C}$ when the bulk water temperature is $40^{\circ} \mathrm{C}$. The peak heat flux likely will not occur at the top of the channel, but somewhere down the channel where the water has been heated above its inlet temperature. However, the increase in the bulk temperature of the coolant is essentially offset by an increase in the heat transfer coefficient, so that the fuel-meat temperature at the hot spot varies little as the hot spot is moved downward. This simple analysis does not take into account the effect of the surface oxide layer on fuel temperatures.

For purposes of initial design of irradiation tests, the values in the preceding paragraph will be used for the design of irradiation tests that bound fuel operating conditions in all currently operating and planned reactors. As reactor conversion analysis proceeds, a more concrete testing envelope will be developed. 


\section{RERTR Fuel Qualification Plan Summary}

A fuel qualification plan is outlined in this section leading to generic qualification of very high density low-enrichment fuel for conversion of most or all listed reactors prior to the end of 2010. This strategy relies heavily on the ATR to provide scoping data, and the ATR coupled with high-performance foreign reactors (MIR and BR2) to provide the primary qualification data to support fuel approval by the NRC (through the issuance of a Safety Evaluation Report). The strategy for generating fuel qualification data consists of first identifying fuel testing requirements. Irradiation testing of miniplates and then full-size plates follows under the required conditions to obtain data on fuel performance in the required operating envelope. During this process, technologies are down selected as supported by available data. Finally, a large scale demonstration of the adequacy of the fuel is conducted through testing of a series of fuel elements representative of the fuel geometry and operating conditions in the reactors targeted for conversion.

The RERTR irradiation testing plan is based on the ATR reactor operating schedule as of December 2006. This schedule is subject to change, with corresponding changes in testing dates.

\subsection{Fuel Development Strategy}

A series of experiments are described in this section that, if successful, will lead to the qualification of a very high density $(8.5 \mathrm{~g}-\mathrm{U} / \mathrm{cc}) \mathrm{U}-\mathrm{Mo}$ based fuel by the end of 2010 . The experiment plan is extremely aggressive and is based on several important assumptions. It is assumed that the resources (both funding and infrastructure) required to perform the described tests are available in a timely and appropriate manner and that each experiment results in a positive outcome. Unanticipated failures in either regard may significantly impact the schedule and the timing of final qualification. The type and timing of the required experiments are described schematically in Figure 3.1. The experiments can be placed into three basic categories, mini-plate tests, full-size plate tests, and element tests. The arrangement of these experiments shows a logical progression in sophistication and physical scale (from mini-plates to elements) that reflects the maturity of the fuel design and fabrication techniques at the described point in time.

Although qualification of a very high density fuel form $\left(>8.5 \mathrm{~g}-\mathrm{U} / \mathrm{cm}^{3}\right)$ is the primary objective of the RERTR fuel development program, recent advances in dispersion fuel technology (described in the following sections) may also make it possible to qualify a high density $(8-8.5 \mathrm{~g}-\mathrm{U} / \mathrm{cc})$ dispersion fuel as an intermediate step to the process. Recent test results indicate the interaction layer instability observed in early U-Mo tests can be eliminated by modifications to the matrix material and that the primary barrier to very high density dispersion fuel development lies in the fabrication techniques. The test sequence required to perform this qualification activity is embedded in the overall path to qualifying a very high density fuel as is shown in the inset to Figure 3.1. This effort will be the foundation for development and qualification of a very high density fuel form. In addition, interim qualification of a high density U-Mo dispersion fuel will enable conversion of at lease 12 of the 19 reactors currently requiring a new fuel, and might possibly convert 17 of the 19 reactors.

Both monolithic and dispersion fuel forms are still being considered for the very high density ( $>8.5 \mathrm{~g}-$ $\mathrm{U} / \mathrm{cm}^{3}$ ) application. The sequence of experiments designed to address very high density fuel development are shown in the second inset to Figure 3.1. The tests shown in this sequence will address issues specifically related to the remaining high performance reactors requiring a very high density fuel form. These tests will require the development of advanced fabrication techniques for either dispersion or 
monolithic fuels that enable very high loadings, the incorporation of burnable poison, the use of multidimensional graded fuel zones, and/or the fabrication of complex shaped plates.
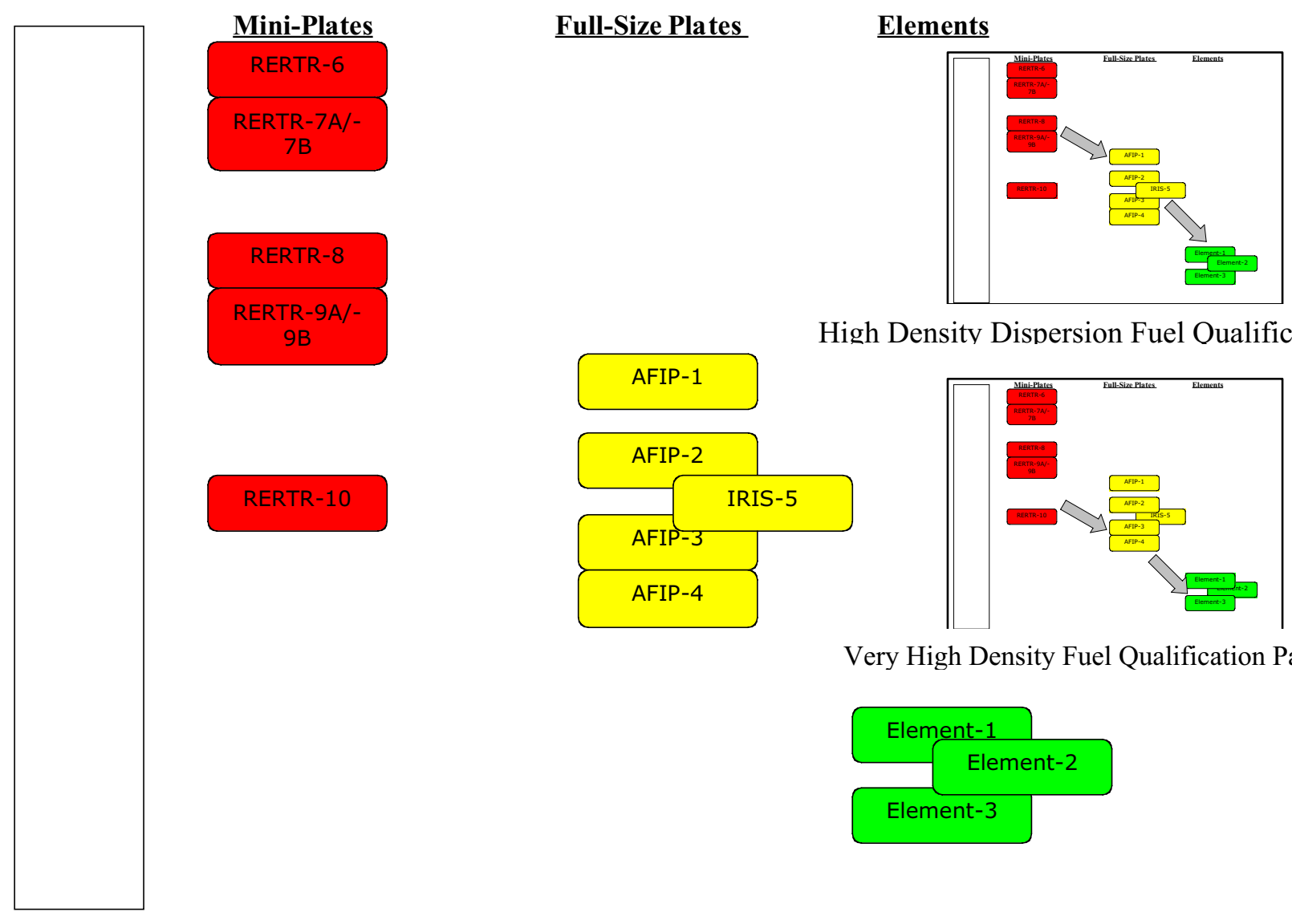

High Density Dispersion Fuel Oualification

AFIP-1

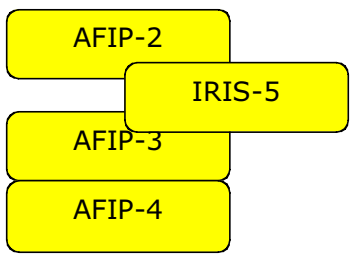

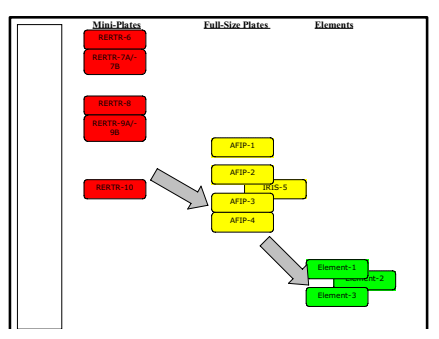

Very High Density Fuel Qualification Path

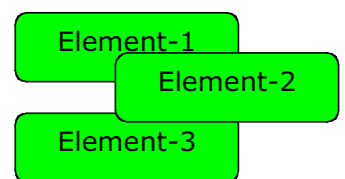

Figure 3.1. Schematic of experiment test sequence leading up to fuel qualification. The path to an intermediately qualified high density dispersion fuel is shown in the upper inset and the complex fuel specific experiments are shown in the lower inset. 


\subsection{RERTR Fuel Testing Plan}

The scope and schedule of the program for developmental fuel irradiation testing is described in this section. Eight developmental irradiation tests are planned, beginning with scoping miniplate tests and continuing with full-size plate irradiations in preparation for fuel element testing.

The developmental fuel testing phase of the program began with the RERTR-1 test in 1997 and will end with PIE of the AFIP-4 full-size plate test in 2009. A schedule for developmental fuel testing in ATR is provided in Table 3.1 .

Table 3.1. ATR RERTR experiment irradiation schedule

\begin{tabular}{|c|c|c|c|c|c|c|c|c|c|c|c|c|c|c|c|}
\hline \multicolumn{16}{|c|}{ ATR cycle } \\
\hline & $134 \mathrm{AB}$ & $\begin{array}{l}\text { 135A } \\
\text { PALM }\end{array}$ & $135 \mathrm{~B}$ & $135 \mathrm{C}$ & $136 \mathrm{~A}$ & 136B & $137 \mathrm{~A}$ & $\begin{array}{l}\text { 137B } \\
\text { PALM }\end{array}$ & $\begin{array}{c}\text { 138A } \\
\text { OUTAGE }\end{array}$ & $138 \mathrm{~B}$ & $139 \mathrm{~A}$ & 139B & $140 \mathrm{~A}$ & 140B & $141 \mathrm{~A}$ \\
\hline Month/Year* & $4 / 05$ & & $7 / 05$ & $9 / 05$ & $11 / 05$ & $1 / 06$ & $3 / 06$ & 6/06 & $10 / 06$ & $12 / 06$ & 2/07 & 6/07 & $8 / 07$ & $9 / 07$ & $12 / 07$ \\
\hline \multicolumn{16}{|c|}{ Tests completed as of December 2006} \\
\hline $\begin{array}{l}\text { RERTR-6 } \\
\text { B-12 }\end{array}$ & $\mathbf{X}$ & & $\mathbf{X}$ & $\mathbf{X}$ & & & & & & & & & & & \\
\hline $\begin{array}{l}\text { RERTR-7A } \\
\text { B-11 }\end{array}$ & & & & & $\mathbf{X}$ & $\mathbf{X}$ & & & & & & & & & \\
\hline $\begin{array}{l}\text { RERTR-7B } \\
\text { B-12 }\end{array}$ & & & & & & $\mathbf{X}$ & & & & & & & & & \\
\hline \multicolumn{16}{|c|}{ Tests planned or in progress as of December 2006} \\
\hline & $138 \mathrm{~A}$ & $138 \mathrm{~B}$ & $139 \mathrm{~A}$ & 139B & $140 \mathrm{~A}$ & 140B & $141 \mathrm{~A}$ & $141 \mathrm{~B}$ & $142 \mathrm{~A}$ & $142 B$ & $143 \mathrm{~A}$ & $143 B$ & $144 \mathrm{~A}$ & 144B & $145 \mathrm{~A}$ \\
\hline Month/Year* & $10 / 06$ & $12 / 06$ & $2 / 07$ & $6 / 07$ & $8 / 07$ & $10 / 07$ & $12 / 07$ & $2 / 08$ & $4 / 08$ & $6 / 08$ & 9/08 & $11 / 08$ & $1 / 09$ & $3 / 09$ & $5 / 09$ \\
\hline $\begin{array}{c}\text { RERTR-8 } \\
\text { B-12 }\end{array}$ & $\mathbf{X}$ & $\mathbf{X}$ & & & & & & & & & & & & & \\
\hline $\begin{array}{l}\text { RERTR-9A } \\
\text { B-12 }\end{array}$ & & & $\mathbf{X}$ & $\mathbf{X}$ & & & & & & & & & & & \\
\hline RERTR-9B & & & & $\mathbf{X}$ & $\mathbf{X}$ & $\mathrm{T}$ & $\mathrm{T}$ & $\mathrm{T}$ & $\mathrm{T}$ & \multicolumn{6}{|c|}{ Potential long duration LEU test } \\
\hline $\begin{array}{l}\text { RERTR-10 } \\
\text { B-12 }\end{array}$ & & & & & & & & $\mathbf{T}$ & $\mathbf{T}$ & $\mathbf{T}$ & & & & & \\
\hline $\begin{array}{c}\text { AFIP-1 } \\
\text { Center Flux Trap }\end{array}$ & & & $\mathrm{C}$ & $\mathbf{X}$ & $\mathbf{X}$ & & & & & & & & & & \\
\hline $\begin{array}{c}\text { AFIP-2 } \\
\text { Center Flux Trap }\end{array}$ & & & & & & $\mathbf{T}$ & $\mathbf{X}$ & $\mathbf{X}$ & & & & & & & \\
\hline $\begin{array}{c}\text { AFIP-3 } \\
\text { Center Flux Trap }\end{array}$ & & & & & & & & & $\mathbf{T}$ & $\mathbf{X}$ & $\mathbf{X}$ & & & & \\
\hline $\begin{array}{c}\text { AFIP-4 } \\
\text { Center Flux Trap }\end{array}$ & & & & & & & & & & & $\mathbf{T}$ & $\mathbf{X}$ & $\mathbf{X}$ & & \\
\hline
\end{tabular}

*Reactor operating schedule as of $11 / 2006, \mathrm{~T}$-tentative. ${ }^{\mathrm{C}}$ Insertion into ATR-C critical facility. 
Additional irradiation testing of MTR plates will be conducted in the IRIS-5 test in the French OSIRIS reactor beginning in the FY08.

Larger scale testing, including testing of fuel elements in MIR and ATR, is discussed in section 3.3. The overall schedule leading to fuel qualification is shown in Figure 3.2. Major decision points and milestones associated with this schedule are:

1) Preliminary downselection of primary technology(s) - December 2006

2) Technology downselection for element testing - June 2007

3) JHR fuel downselection (external) - December 2007

4) Preliminary reactor specific fuel qualification plans for high power reactors - September 2008

5) Final reactor specific fuel qualification plans - April 2010

6) Decision to begin fabrication elements for Phase II qualification - May 2010 


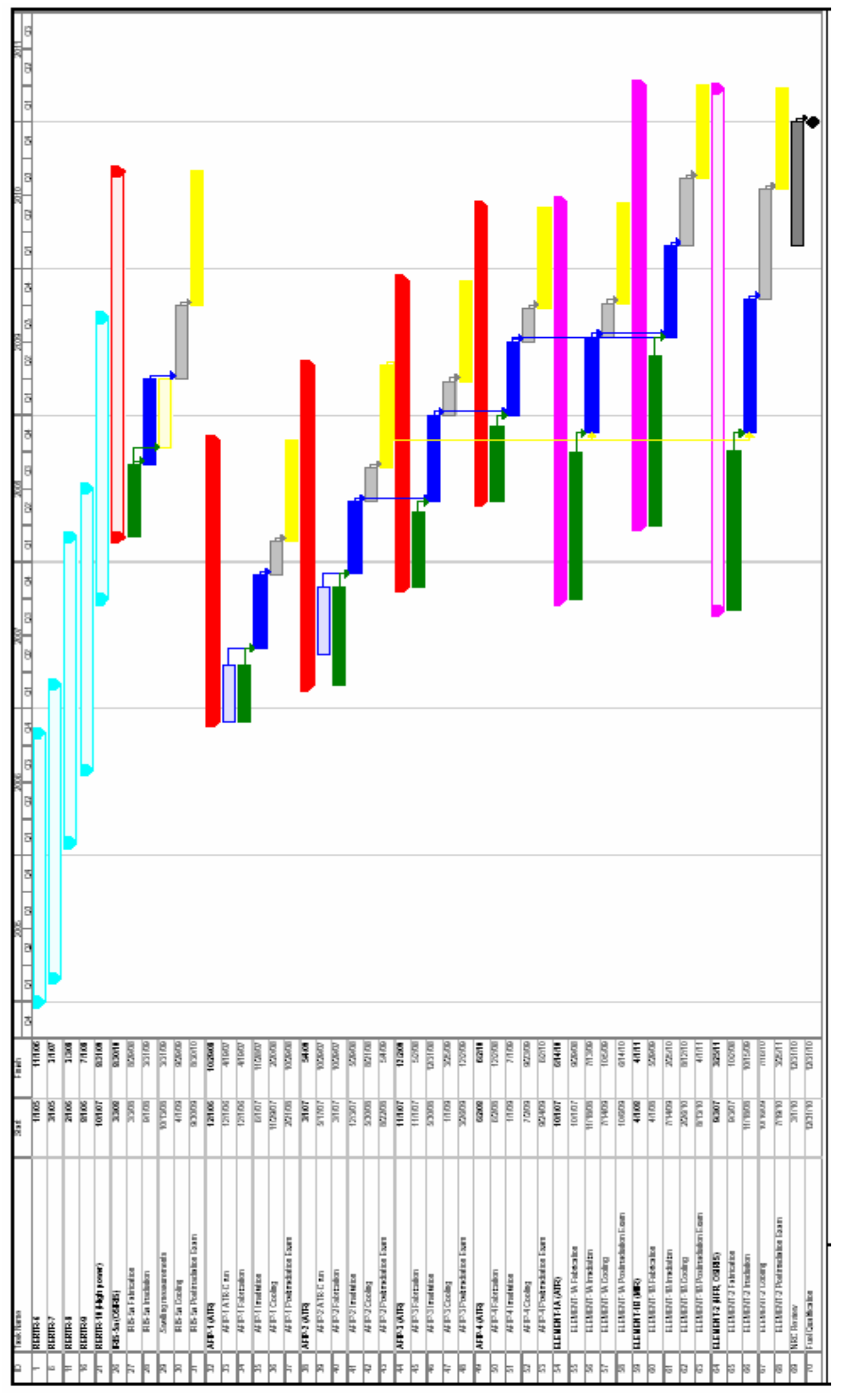

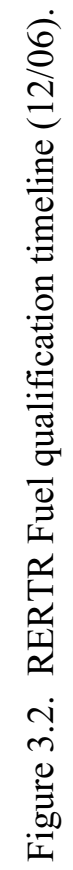




\section{Miniplate Testing}

Four additional miniplate irradiation testing campaigns (RERTR-6 through RERTR-10) are planned as scoping studies to determine the feasibility of new fuel technologies under consideration. These tests continue to build on the database for U-Mo fuel performance established with the RERTR-1 through RERTR-5 experiments and ends with completion of RERTR-10 in 2009.

These tests utilize up to 32 small plates per experiment to test a wide range of parameters at relatively low cost. The test specimens are easily fabricated, transported, and examined.

A sketch of a generic miniplate to be used in all tests is shown in Figure 3.3.

The scope and schedule for the planned miniplate tests are given below.

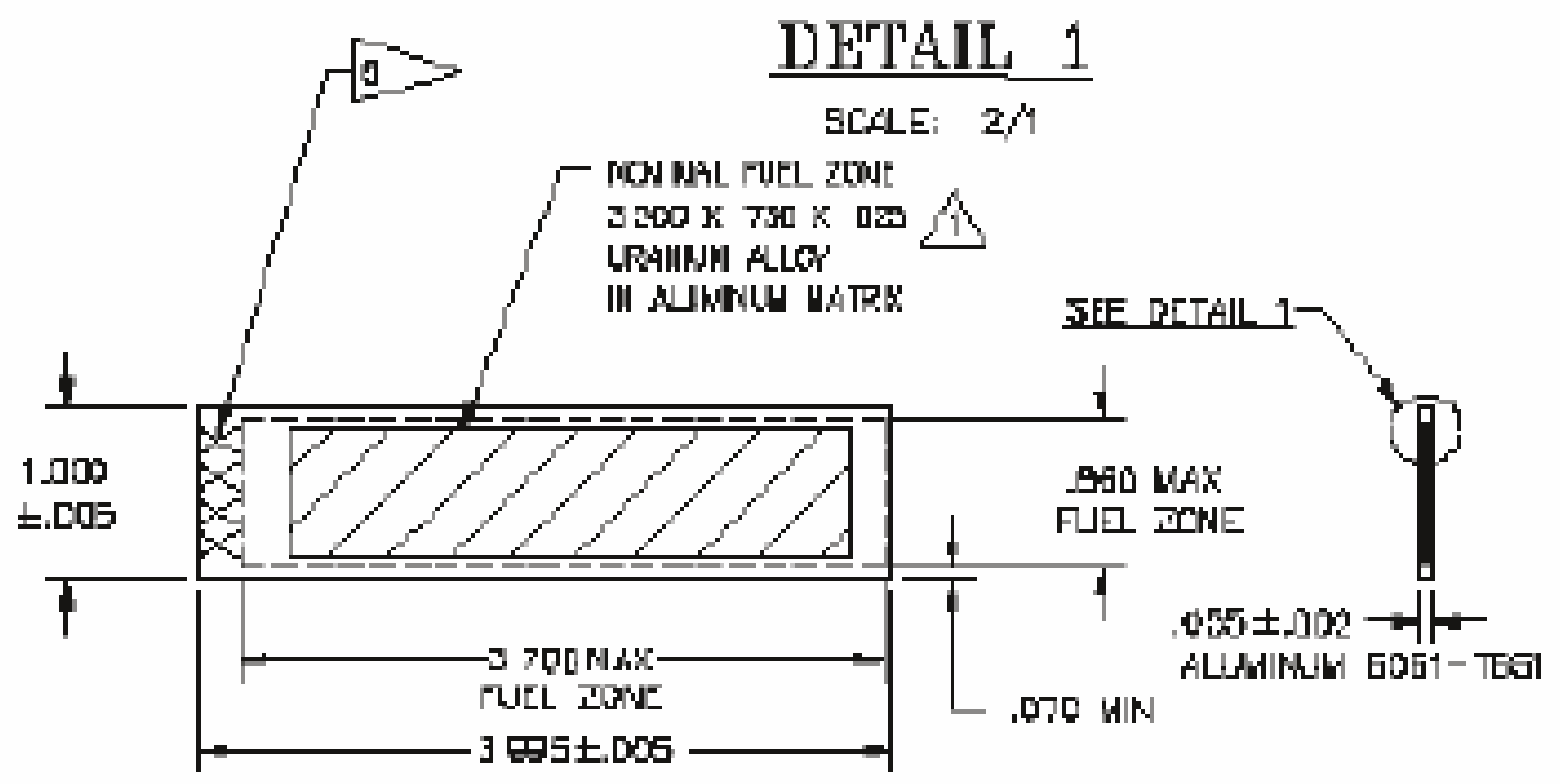

Figure 3.3. Sketch of generic miniplate to be used in the RERTR-6, $-7,-8$, and -9 experiments.

\subsubsection{The RERTR-6 and RERTR-7 Experiments}

Irradiation of the RERTR-6 and RERTR-7 miniplate irradiation tests in the ATR have been completed. Irradiation test conditions are summarized here.

\section{RERTR-6 Experiment}

The RERTR-6 experiment was the first test of 'second generation' U-Mo fuels designed to overcome the fuel performance problems encountered in U-Mo/Al dispersions. Irradiation of the RERTR-6 experiment in the ATR began in cycle 134AB on April 14, 2005. The experiment remained in core through cycles $134 \mathrm{AB}, 135 \mathrm{~B}$, and $135 \mathrm{C}$. The experiment was removed from the reactor during short duration PALM cycle 135A. The experiment was discharged from the ATR at the end of cycle $135 \mathrm{C}$ in November of 2005 after a total irradiation time of 135.1 EFPD and a calculated peak U-235 burnup of $50.4 \%$. Peak surface heat flux was $170 \mathrm{~W} / \mathrm{cm}^{2}$. The experiment was shipped in the GE-100 cask to the Hot Fuel Examination Facility (HFEF) hot cell in January of 2006. The RERTR-6 experiment includes both 
monolithic and dispersion fuel types. The monolithic fuels include foil thicknesses of 0.01 and 0.02 -in. The dispersion fuel plates included in the experiment also leverage previous experience. In an effort to reduce the extent of fuel/matrix interactions observed in previous fuel studies an aluminum alloy (either $6061,4043, \mathrm{Al}-2 \mathrm{Si}$, or Al-0.5Si) matrix replaced the pure aluminum alloy matrix used in earlier experiments. U-10Mo dispersion fuel plates using an unalloyed aluminum matrix were included as a benchmark fuel form. The RERTR-6 experiment matrix is shown in Table 3.2.

Table 3.2. RERTR-6 experiment matrix.

\begin{tabular}{|c|c|c|c|c|}
\hline \multicolumn{5}{|c|}{ RERTR-6 Experiment Matrix } \\
\hline Capsule & Column 1 & Column 2 & Column 3 & Column 4 \\
\hline \multirow[b]{2}{*}{ A-Top } & $\mathrm{A} 1$ & A2 & A3 & A4 \\
\hline & Blank1 & $\begin{array}{c}\text { R1R010 } \\
\text { U-7Mo Roll } \\
\text { Al-6061 }\end{array}$ & Blank3 & $\begin{array}{c}\text { L2F020 } \\
\text { U-10Mo FSW } \\
0.020 \text { Ó Fól }\end{array}$ \\
\hline \multirow[b]{2}{*}{ A-Bottom } & A5 & A6 & A7 & A8 \\
\hline & $\begin{array}{l}\text { R5R010 } \\
\text { U-7Mo Roll } \\
\text { Al-0.2 Si }\end{array}$ & $\begin{array}{c}\text { L1F090 } \\
\text { U-10 Mo FSW } \\
\text { 0.010Ó Fäl }\end{array}$ & Blank4 & $\begin{array}{l}\text { N1F090 } \\
\text { U-7Mo FSW } \\
\text { 0.010Ó Fol }\end{array}$ \\
\hline \multirow[b]{2}{*}{ B-Top } & $\mathrm{B} 1$ & B2 & B3 & B4 \\
\hline & $\begin{array}{l}\text { R1R020 } \\
\text { U-7Mo Roll } \\
\text { Al-6061 }\end{array}$ & $\begin{array}{c}\text { R2R020 } \\
\text { U-7Mo Roll } \\
\text { Al-2.0Si }\end{array}$ & $\begin{array}{c}\text { V0R020 } \\
\text { U-10Mo Roll } \\
\text { Al }\end{array}$ & $\begin{array}{l}\text { N1F010 } \\
\text { U-7Mo FSW } \\
\text { 0.010Ó Fìl }\end{array}$ \\
\hline \multirow[b]{2}{*}{ B-Bottom } & B5 & B6 & B7 & B8 \\
\hline & $\begin{array}{c}\text { R3R030 } \\
\text { U-7Mo Roll } \\
\text { Al-4043 }\end{array}$ & $\begin{array}{l}\text { N1F040 } \\
\text { U-7Mo FSW } \\
0.010 \text { Ó Fól }\end{array}$ & $\begin{array}{l}\text { L1F040 } \\
\text { U-10Mo FSW } \\
0.010 \text { Ó Fíl }\end{array}$ & $\begin{array}{c}\text { V1R020 } \\
\text { U-10Mo Roll } \\
\text { Al-6061 }\end{array}$ \\
\hline \multirow[b]{2}{*}{ C-Top } & $\mathrm{C} 1$ & $\mathrm{C} 2$ & $\mathrm{C} 3$ & $\mathrm{C} 4$ \\
\hline & $\begin{array}{c}\text { V0R010 } \\
\text { U-10Mo Roll } \\
\text { Al } \\
\end{array}$ & $\begin{array}{c}\text { R3R010 } \\
\text { U-7Mo Roll } \\
\text { Al-4043 } \\
\end{array}$ & $\begin{array}{c}\text { R2R010 } \\
\text { U-7Mo Roll } \\
\text { Al-2.0Si } \\
\end{array}$ & $\begin{array}{l}\text { N1F030 } \\
\text { U-7Mo FSW } \\
\text { 0.010Ó Fodl }\end{array}$ \\
\hline \multirow[b]{2}{*}{ C-Bottom } & $\mathrm{C} 5$ & C6 & $\mathrm{C} 7$ & $\mathrm{C} 8$ \\
\hline & $\begin{array}{l}\text { R5R020 } \\
\text { U-7Mo Roll } \\
\text { Al-0.2 Si }\end{array}$ & $\begin{array}{l}\text { N1F060 } \\
\text { U-7Mo FSW } \\
0.010 O \text { Fól }\end{array}$ & $\begin{array}{l}\text { V5R030 } \\
\text { U-10Mo Roll } \\
\text { Al- } 0.2 \mathrm{Si}\end{array}$ & Blank5 \\
\hline \multirow[b]{2}{*}{ D-Top } & D1 & D2 & D3 & $\mathrm{D} 4$ \\
\hline & $\begin{array}{l}\text { L1F100 } \\
\text { U-10Mo FSW } \\
\text { 0.010Ó Fdil }\end{array}$ & $\begin{array}{l}\text { R2R030 } \\
\text { U-7Mo Roll } \\
\text { Al-2.0Si }\end{array}$ & $\begin{array}{l}\text { V1R010 } \\
\text { U-10Mo Roll } \\
\text { Al-6061 }\end{array}$ & Blank6 \\
\hline \multirow[b]{2}{*}{ D-Bottom } & $\overline{\mathrm{D} 5}$ & $\overline{\mathrm{D} 6}$ & D7 & $\overline{\mathrm{D} 8}$ \\
\hline & $\begin{array}{c}\text { R1R030 } \\
\text { U-7Mo Roll } \\
\text { Al-6061 }\end{array}$ & Blank9 & $\begin{array}{c}\text { L2F030 } \\
\text { U-10Mo FSW } \\
0.020 \text { Ó Fdil } \\
\end{array}$ & $\begin{array}{c}\text { V5R020 } \\
\text { U-10Mo Roll } \\
\text { Al-0.2Si } \\
\end{array}$ \\
\hline
\end{tabular}

\section{The RERTR-7 Experiments}

The RERTR-7 experiment was composed of two test baskets irradiated in two separate ATR B-positions.

RERTR-7A - The RERTR-7A miniplate irradiation test, relative to RERTR-6, was a higher power, higher burnup test designed to target fission density representative of a peak LEU burnup in excess of $90 \%$ U235 at peak experiment power sufficient to generate a peak surface heat flux on the order of 300 $\mathrm{W} / \mathrm{cm}^{2}$. The test used the same hardware geometry as was used in the RERTR $-4,-5$, and -6 experiments. Uranium enriched to $58 \%$ U-235 was used to meet the test requirement for higher power density. The RERTR-7A test was inserted into ATR cycle 136A in November of 2005 and remained in reactor through cycle 136B for a total irradiation time of 91 EFPD. A fission product release from the experiment 
was observed after 73 EFPD. The test train contained monolithic and modified matrix dispersion fuels. The fuel plates are similar to those irradiated in the RERTR-6 experiment, but irradiated at higher power and to higher burnup.

The monolithic fuel plates were fabricated by transient phase liquid bonding and friction stir welding using both U-10Mo and U-12Mo alloys. Foils fabricated with thicknesses of 0.010 " and 0.020 " were included. Dispersion fuel plates include levels of silicon in the matrix that vary from 0 to $5 \mathrm{wt} . \%$. Two zirconium clad LEU-10Mo monolithic fuel plates from CNEA (Argentina) are also included in the RERTR-7A test. These latter plates are fueled with low-enrichment uranium, and operate at lower power than the remainder of the experiments.

U-10Mo dispersion fuel plates using an unalloyed aluminum matrix were included as a benchmark fuel in the RERTR-7A test vehicle.

Table 3.3. RERTR-7A experiment matrix.

\begin{tabular}{|c|c|c|c|c|}
\hline \multicolumn{5}{|c|}{ RERTR-7A Experiment Matrix } \\
\hline Capsule & Column 1 & Column 2 & Column 3 & Column 4 \\
\hline \multirow{3}{*}{ A-Top } & $\mathrm{A} 1$ & $\mathrm{~A} 2$ & $\mathrm{~A} 3$ & A4 \\
\hline & DUM11 & DUM14 & DUM12 & DUM8 \\
\hline & BLANK & BLANK & BLANK & BLANK \\
\hline \multirow{4}{*}{ A-Bottom } & A5 & A6 & A7 & A8 \\
\hline & R3R040 & V5R040 & R5R030 & H1F020 \\
\hline & U-7Mo Roll & U-7Mo Roll & U-10Mo Roll & U-12Mo FSW \\
\hline & Al 4043 Matrix & Al-0.5Si Matrix & Al-0.5 Si Matrix & $0.010^{\prime \prime}$ Foil \\
\hline \multirow{4}{*}{ B-Top } & $\mathrm{B} 1$ & $\mathrm{~B} 2$ & B3 & B4 \\
\hline & R1R040 & $\mathrm{R} 2 \mathrm{R} 040$ & R0R010 & H1Т010 \\
\hline & U-7Mo Roll & U-7Mo Roll & U-7Mo Roll & U-12Mo TLPB \\
\hline & Al 6061 Matrix & Al-2Si Matrix & Pure Al Matrix & $0.010^{\prime \prime}$ Foil \\
\hline \multirow{4}{*}{ B-Bottom } & B5 & B6 & B7 & B8 \\
\hline & L1F01L & V5R050 & L1F140 & MZ25 \\
\hline & U-10Mo FSW & U-7Mo Roll & U-10Mo FSW & U-7Mo Roll \\
\hline & Holed Foil & Al-0.5Si Matrix & $0.010^{\prime \prime}$ Foil & Zr Clad CNEA \\
\hline \multirow{4}{*}{ C-Top } & $\mathrm{Cl}$ & $\mathrm{C} 2$ & $\mathrm{C} 3$ & $\mathrm{C} 4$ \\
\hline & H1F030 & L1T020 & L1F110 & MZ50 \\
\hline & U-12Mo FSW & U-10Mo TLPB & U-10Mo FSW & U-7Mo Roll \\
\hline & $0.010^{\prime \prime}$ Foil & $0.010^{\prime \prime}$ Foil & $0.010 "$ Foil & Zr Clad CNEA \\
\hline \multirow{4}{*}{ C-Bottom } & $\mathrm{C} 5$ & C6 & $\mathrm{C7}$ & $\mathrm{C} 8$ \\
\hline & $\mathrm{L} 1 \mathrm{~F} 120$ & Н1Т020 & $\mathrm{R} 3 \mathrm{R} 050$ & R5R040 \\
\hline & U-10Mo FSW & U-12Mo TLPB & U-7Mo Roll & U-10Mo Roll \\
\hline & $0.010^{\prime \prime}$ Foil & $0.010^{\prime \prime}$ Foil & Al 4043 Matrix & Al-0.5 Si Matrix \\
\hline \multirow{4}{*}{ D-Top } & D1 & D2 & D3 & D4 \\
\hline & R1R050 & DUM13 & R0R020 & DUM19 \\
\hline & U-7Mo Roll & BLANK & U-7Mo Roll & BLANK \\
\hline & Al 6061 Matrix & & Pure Al Matrix & \\
\hline \multirow{4}{*}{ D-Bottom } & D5 & D6 & D7 & D8 \\
\hline & DUM05 & L1F160 & L2F040 & R2R050 \\
\hline & BLANK & U-10Mo FSW & U-10Mo TLPB & U-7Mo Roll \\
\hline & & $0.010^{\prime \prime}$ Foil & $0.020 "$ Foil & Al-2Si Matrix \\
\hline
\end{tabular}

\section{Error!}

$\boldsymbol{R E R T R}$-7B - The RERTR-7B miniplate irradiation test was designed as a high power test of 'second generation' dispersion fuels at peak experiment power sufficient to generate a peak surface heat flux on the order of $230 \mathrm{~W} / \mathrm{cm}^{2}$. The test matrix was targeted toward dispersion fuels with ternary element additions to the fuel particles and silicon additions to the matrix. Uranium enriched to $58 \% \mathrm{U}-235$ was 
used to meet the test requirement for plate operating power. The RERTR-7B matrix is shown in Table 3.4 .

The RERTR-7B test was inserted into the ATR for cycle 136B in January of 2006 and was irradiated for one cycle (39 EFPD) to a fission density equivalent to a peak LEU burnup of $30 \%$. The test was withdrawn following the fission product release observed in the RERTR-7A experiment in March of 2006.

Table 3.4. RERTR-7B experiment matrix.

\begin{tabular}{|c|c|c|c|c|}
\hline \multicolumn{5}{|c|}{ RERTR-7B Experiment Matrix } \\
\hline Capsule & Column 1 & Column 2 & Column 3 & Column 4 \\
\hline \multirow{3}{*}{ A-Top } & A1 & A2 & A3 & A4 \\
\hline & DUM11 & DUM14 & DUM12 & DUM8 \\
\hline & BLANK & BLANK & BLANK & BLANK \\
\hline \multirow{3}{*}{ A-Bottom } & A5 & A6 & A7 & A8 \\
\hline & DUM & DUM & DUM & DUM \\
\hline & BLANK & BLANK & BLANK & BLANK \\
\hline \multirow{3}{*}{ B-Top } & B1 & B2 & B3 & B4 \\
\hline & DUM & DUM & DUM & DUM \\
\hline & BLANK & BLANK & BLANK & BLANK \\
\hline \multirow{4}{*}{ B-Bottom } & B5 & B6 & B7 & B8 \\
\hline & F3R040 & D3R030 & L1F200 & D3R040 \\
\hline & U-7Mo-2Zr Roll & U-7Mo-1Ti Roll & U-10Mo FSW & U-7Mo-1Ti Roll \\
\hline & Al-4043 Matrix & Al-4043 Matrix & $0.010 "$ Foil & Al-4043 Matrix \\
\hline \multirow{3}{*}{ C-Top } & $\mathrm{C} 1$ & $\mathrm{C} 2$ & $\mathrm{C} 3$ & $\mathrm{C} 4$ \\
\hline & DUM & DUM & DUM & DUM \\
\hline & BLANK & BLANK & BLANK & BLANK \\
\hline \multirow{3}{*}{ C-Bottom } & $\mathrm{C} 5$ & $\mathrm{C} 6$ & $\mathrm{C} 7$ & $\mathrm{C} 8$ \\
\hline & DUM & DUM & DUM & DUM \\
\hline & BLANK & BLANK & BLANK & BLANK \\
\hline \multirow{3}{*}{ D-Top } & D1 & D2 & D3 & D4 \\
\hline & DUM & DUM & DUM & DUM \\
\hline & BLANK & BLANK & BLANK & BLANK \\
\hline \multirow{3}{*}{ D-Bottom } & D5 & D6 & D7 & D8 \\
\hline & DUM & DUM & DUM & DUM \\
\hline & BLANK & BLANK & BLANK & BLANK \\
\hline
\end{tabular}

\subsubsection{RERTR-8 Experiment}

The RERTR-8 experiment was inserted into the ATR in October 2006 and will remain in reactor through January 2007. This experiment will deliver performance data for ternary fuel alloys (U-7Mo-1Ti and U7Mo-2Zr) similar to those tested in the RERTR-7B experiment under high power and higher burnup ( $\sim 75 \%$ LEU equivalent) conditions. The experiment will also provide the first performance data for monolithic fuel plates fabricated using the hot isostatic pressing technique and will demonstrate the incorporation of burnable poison into a monolithic fuel. A dispersion fuel plate with a magnesium matrix will be irradiated for a single cycle (56 EFPD) to approximately 44\% LEU equivalent burnup after which it will be removed from the experiment and stored until completion of irradiation of the other capsules. Uranium silicide based fuel meats with well known performance parameters will be used for control plates. Irradiation of the experiment will be completed in February 2007. 
Table 3.5. RERTR-8 experiment matrix.

\begin{tabular}{|c|c|c|c|c|}
\hline \multicolumn{5}{|c|}{ RERTR-8 Experiment Matrix } \\
\hline Capsule & Column 1 & Column 2 & Column 3 & Column 4 \\
\hline \multirow{4}{*}{ A-Top } & $\mathrm{A} 1$ & $\mathrm{~A} 2$ & $\mathrm{~A} 3$ & A4 \\
\hline & U0R60 & LIF200 & D3R040 & F3R030 \\
\hline & $\mathrm{U}_{3} \mathrm{Si}_{2}$ & U-10Mo FSW & U-7Mo-1Ti & $\mathrm{U}-7 \mathrm{Mo}-2 \mathrm{Zr}$ \\
\hline & $\mathrm{Al}$ & $0.01 O$ fál & $\mathrm{Al}-4043$ & $\mathrm{Al}-4043$ \\
\hline \multirow[b]{2}{*}{ A-Bottom } & A5 & A6 & A7 & A8 \\
\hline & Blank & Blank & Blank & Blank \\
\hline \multirow[b]{2}{*}{ B-Top } & B1 & B2 & B3 & B4 \\
\hline & Blank & Blank & Blank & Blank \\
\hline \multirow[b]{2}{*}{ B-Bottom } & B5 & B6 & B7 & B8 \\
\hline & $\begin{array}{c}\text { H1P02B } \\
\text { U-12Mo HIP } \\
0.01 \text { Ó fäl/BorAl }\end{array}$ & Blank & Blank & Blank \\
\hline \multirow{4}{*}{ C-Top } & $\mathrm{C} 1$ & $\mathrm{C} 2$ & $\mathrm{C} 3$ & $\mathrm{C} 4$ \\
\hline & L1P020 & J1F020 & LIF190 & H1P010 \\
\hline & U-10Mo HIP & U-8Mo FSW & U-10Mo FSW & U-12Mo HIP \\
\hline & 0.010 fól & 0.01 Ó fál & 0.01 Ó fäl & $0.01 O$ fàl \\
\hline \multirow{4}{*}{ C-Bottom } & $\mathrm{C} 5$ & C6 & C7 & $\mathrm{C} 8$ \\
\hline & D3R030 & U0R040 & R3R060 & F3R040 \\
\hline & U-7Mo-1Ti & $\mathrm{U}_{3} \mathrm{Si}_{2}$ & U-7Mo & U-7Mo-2Zr \\
\hline & $\mathrm{Al}-4043$ & $\mathrm{Al}$ & Al-4043 & $\mathrm{Al}-4043$ \\
\hline \multirow{3}{*}{ D-Top } & D1 & D2 & D3 & D4 \\
\hline & Blank & R9R010 & Blank & Blank \\
\hline & & $\begin{array}{c}\text { U-7Mo } \\
\text { Mg Matrix }\end{array}$ & & \\
\hline \multirow{3}{*}{ D-Bottom } & D5 & D6 & D7 & D8 \\
\hline & Blank & Blank & Blank & Blank \\
\hline & & & & \\
\hline
\end{tabular}

\subsubsection{RERTR-9 Experiment}

The RERTR-9 experiment will be a two part experiment consisting of -9A and -9B components. The RERTR-9A experiment is scheduled for insertion in the ATR cycle 139A in February 2007 and will utilize the $-\mathrm{A}$ and $-\mathrm{C}$ capsules of the miniplate test rig. The RERTR-9B experiment will be inserted in ATR cycle 139B in June 2007 and will utilize the -B and -D capsules. The experiment will use the same basic hardware configuration as used in the RERTR-4 through RERTR-8 experiments. This experiment will provide design input data for planned full size plate and element dispersion fuel qualification tests and to examine ways to improve the fuel/clad bond integrity of monolithic fuels at the end of irradiation. The experiment will also be used to further evaluate zircalloy clad monolithic fuel plates at high power through an ongoing collaboration with the CNEA (Argentina).

The dispersion fuels will be fabricated at a nominal uranium density of $8 \mathrm{~g}-\mathrm{U} / \mathrm{cc}$ (rather than the $6 \mathrm{~g}-\mathrm{U} / \mathrm{cc}$ in RERTR-6, -7, and -8) and will include several levels of silicon addition to select the optimal level for qualification tests. Plates will be fabricated with matrix materials consisting of Al-2.0 Si binary alloy, Al$4043(\sim 5 \% \mathrm{Si})$, and an unalloyed Al-2.0 Si mixture. These dispersion plates will be the focus of the RERTR-9A experiment. 
Concepts to improve the fuel/clad bond in monolithic fuels at the end of irradiation have been proposed and will be evaluated in this test. Proposals include the control of interaction layer growth using additional silicon at the fuel clad interface, insertion of a zirconium diffusion barrier, improved beginning of life bonding due to enhanced fabrication techniques, carburization of the fuel surface prior to bonding, and use of a ternary fuel alloy in the foil. Inclusion of any of these concepts in either the RERTR-9A or 9B tests are dependent on results from fabrication development and characterization studies currently underway.

CNEA supplied zircalloy clad monolithic fuel plates will be included in the RERTR-9B experiment. In order to gauge the performance of U-Mo fuels at long times and lower powers, plates at enrichment in the range of 30\% may be irradiated for 5-6 reactor cycles to achieve high burnup.

\subsubsection{RERTR-10 Experiment}

The RERTR-10 experiment will use the standard mini-plate hardware to subject fuel plates to very aggressive conditions (surface heat flux on the order of $550 \mathrm{~W} / \mathrm{cm}^{2}$ ) for one reactor cycle. Insertion of this test is tentatively planned for cycle 141B in February of 2008.

\subsubsection{Full-size Plate Testing}

Full-size plate tests typically consist of two to six test plates contained in a special test fixture. Often the plates are demountable; that is they can be removed from the test assembly for inspection in the reactor canal. Test plates are typically visually and dimensionally inspected after each cycle for signs of unusual behavior that may be precursors to failure. Plates that show signs of unusual or unacceptable behavior can be pulled from the test assembly and replaced with additional plates. These tests provide assurance of acceptable fuel behavior under the mechanical conditions prior to conducting tests of whole fuel elements, where the consequence of failure of an element is large.

\subsubsection{IRIS-5 Experiment in OSIRIS}

The IRIS-5 test in the OSIRIS reactor is a joint test with the CEA that will generate the first fuel performance data on full-size monolithic fuel plates.

\section{IRIS-5 Test Description}

A drawing of the IRIS test fuel plate is shown in Figure 3.6. The RERTR program will provide two LEU test plates for irradiation, to be complemented by two plates fabricated by CERCA (France). If plates cannot be fabricated by CERCA, the U.S. RERTR program may provide four test plates. Plate thickness profiles will be monitored after each irradiation cycle for excessive swelling. A full PIE will be conducted at the CEA Cadarache site.

\section{IRIS-5 Objectives}

The objectives of the IRIS-5 test are to:

1) Generate the first irradiation performance data for full-size MTR U-Mo monolithic fuel plates through the use of in-canal plate thickness measurements and subsequent PIE.

2) Provide a comparison of the performance of monolithic fuel plates fabricated in France and the U.S. using different processes.

3) Provide diversity in fuel testing with irradiation conditions that differ from those in the ATR and to establish the framework for continued joint U.S./French testing in OSIRIS and other reactors. 


\section{IRIS-5 Schedule}

The IRIS-5 test is scheduled for delivery to CEA-Saclay in August of 2008, pending successful resolution of U-Mo monolithic fuel performance issues. Irradiation will begin in OSIRIS later in 2008. This will require shipping of the plates to CEA in June of 2008. Irradiation will require nine months, and be completed in February/March of 2009, followed by cooling prior to shipment to CEA Cadarache for PIE in December of 2009. It is anticipated that irradiated fuel will be returned to the U.S. for disposal prior to 2011.

Preliminary agreement with CEA has been made regarding experiment schedule and cost sharing. The CEA will fund irradiation in OSIRIS and one-half of PIE and disposal costs. The U.S. RERTR program will supply two (or four) monolithic plates for testing and pay one-half of the PIE costs.

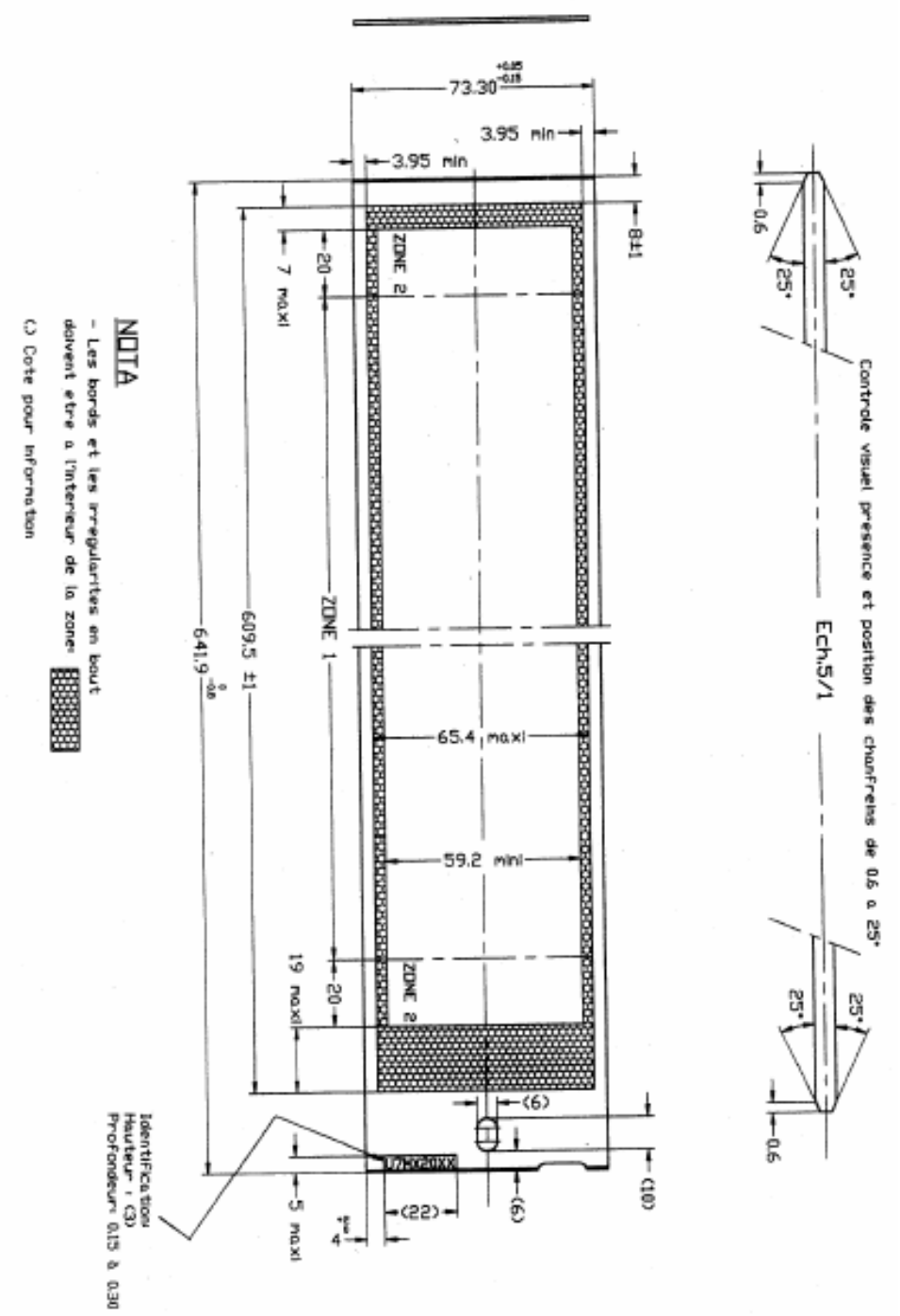

Figure 3.3. IRIS-5 test plate geometry. 


\subsubsection{Full-size Plate Testing in ATR}

Four tests of full-size fuel plates are proposed for ATR. Labeled the AFIP (ATR Full-size-plate In center flux trap Position) experiments, these tests will be conducted in the ATR center flux trap. Surface heat flux in excess of $350 \mathrm{~W} / \mathrm{cm}^{2}$ can be achieved using this arrangement. The first two AFIP tests (AFIP-1 and -2) will focus on demonstrating the performance of standard geometry (i.e. flat) fuel plates in preparation for element level testing. The first test (AFIP-1) will focus on the scale up from mini-plates to a prototypic size plate. The fuel plates will utilize U-7Mo with a modified matrix material (one each with Al-4043 and Al-2.0 Si) and will have a nominal loading of $8 \mathrm{~g}-\mathrm{U} / \mathrm{cc}$. This test will provide input data to form the design basis for element testing. The AFIP-2 test will include two monolithic fuel plates and an option for an additional two dispersion or zircalloy clad fuel plates. The second two AFIP tests (AFIP3 and -4) will be designed to evaluate the 'complex' fuels required for some unique reactors (i.e. HFIR and ATR) including plates with burnable poison, density zoning, and involute geometry. The geometry of the AFIP-1 and -2 test hardware is shown in Figure 3.4. AFIP test geometry will be modified as necessary for the AFIP-3 and -4 tests of density zoned and curved plates.

Testing of full-size plates in ATR will benefit from the development of the capability for following plate swelling and fuel/clad bond integrity as a function of burnup through the measurement of plate thickness and ultrasonic scanning between cycles. A demountable plate irradiation facility coupled with a thickness measurement system will be used for in-canal measurement of plate swelling for the AFIP series experiments.

Full-size plate testing in the ATR will begin with the insertion of the AFIP-1 test in ATR cycle 139B in June 2007.

\subsubsection{AFIP-1 Experiment in the ATR}

\section{AFIP-1 Test Description}

The AFIP-1 test will irradiate two modified matrix dispersion fuel plates to high burnup (60-80\% LEU equivalent burnup) at high power (surface heat flux $\sim 300 \mathrm{~W} / \mathrm{cm}^{2}$ ). The test will require critical tests in the ATR-C facility and the AFIP-C hardware and fuel will be delivered to ATR-C in Early 2006 for this purpose. Insertion of AFIP-1 into ATR cycle 139B is scheduled for June 2007. AFIP-1 experiment insertion is supported by RERTR-6 and -7 PIE data, preliminary RERTR-8 visual examination data, and fabrication development and characterization performed for RERTR-9. The AFIP test is configured so that plates may be removed and replaced with additional plates pending confirmation of adequate experiment safety performance. AFIP-1 test plates will be subjected to in-canal visual examination, dimensional (thickness), and fuel/clad bond integrity measurement between ATR cycles. The experiment will be removed from the reactor for cooling in October 2007. After cooling, the experiment will be shipped in the GE-2000 cask to the HFEF at INL for a two phases PIE process. Phase I will be completed in December 2007 to provide input for the element test down selection. Completion of phase II of the PIE is scheduled for February 2008.

\section{AFIP-1 Objectives}

The objectives of the AFIP-1 test are to:

1) Produce data to inform the down-selection of dispersion fuel technologies for the element testing based on the performance of full-size fuel plates at surface heat flux higher than attainable in the IRIS-5 experiment.

2) To provide diversity in test conditions and testing reactors relative to the IRIS-5 test. 
3) To provide early data on fuel swelling of advanced very-high-density fuels through the use of an incanal thickness measurement device.
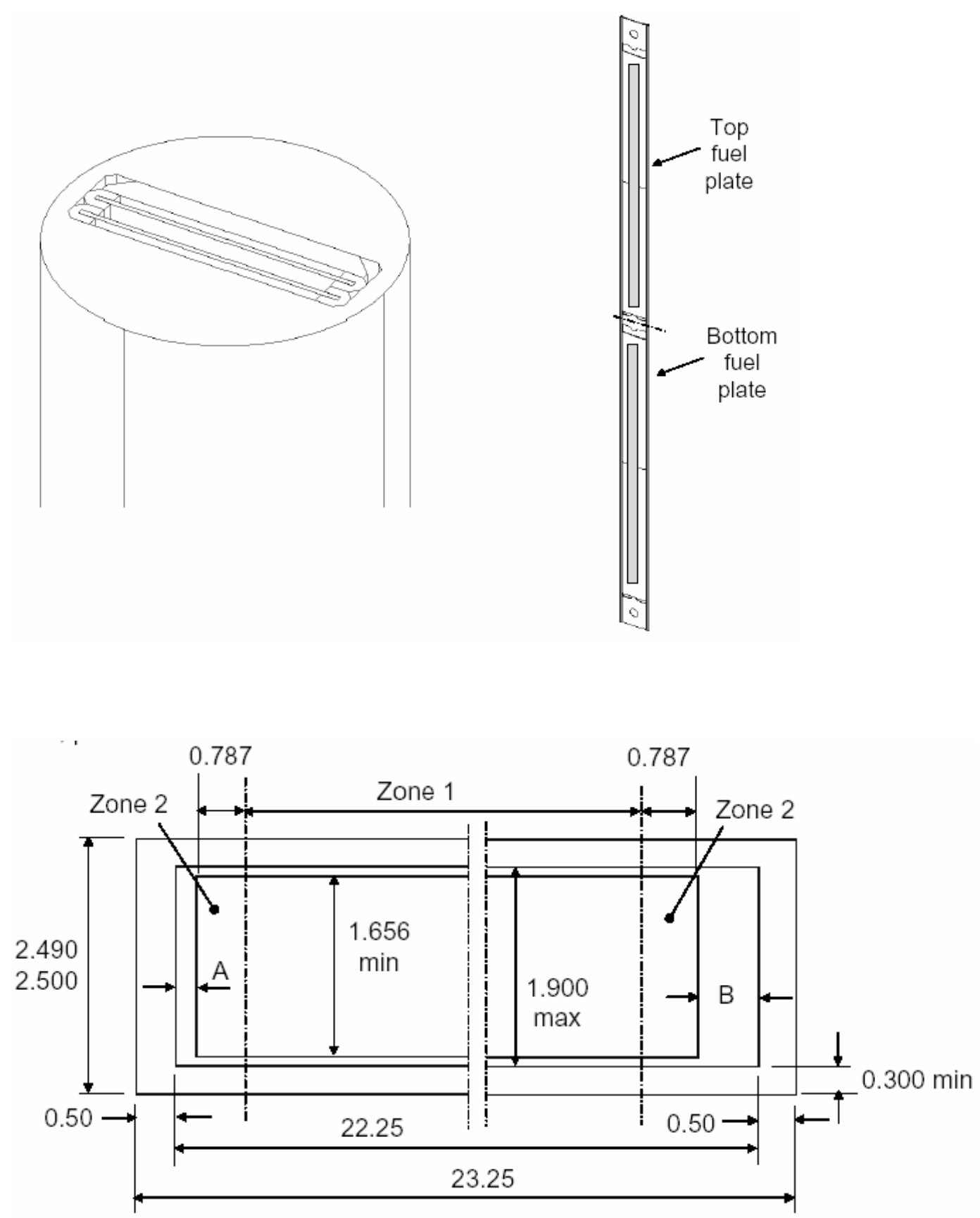

Figure 3.4. Top - AFIP center flux trap position concept. Bottom - Approximate AFIP plate dimensions. 


\subsubsection{AFIP-2 Experiment in the ATR}

\section{AFIP-2 Test Description}

The AFIP-2 test will provide irradiation of monolithic fuel technologies to high burnup (6-800\% LEU equivalent burnup) at high power (surface heat flux $\sim 350 \mathrm{~W} / \mathrm{cm}^{2}$ ). Insertion of AFIP-2 is tentatively scheduled for ATR cycle 140B, currently planned for September 2007. AFIP-2 will be irradiated for two cycles, through cycle 141A. Design input data for the AFIP-2 experiment will be supplied by data collected from RERTR-6, -7, -8, and -9A PIE data. The AFIP-2 test will also provide and opportunity for follow up tests on dispersion fuel plates or testing of full size zircalloy clad monolithic plates. Incanal visual examination, dimensional (thickness), and fuel/clad bond integrity measurement will be available between ATR cycles (at $\sim 15-20 \%$ burnup) in November 2007 . The experiment will be removed from the reactor for cooling in January 2008. After cooling, the experiment will be shipped in the GE2000 cask to the HFEF at INL for PIE. Completion of AFIP-2 PIE is scheduled for May 2008 and will provide design input to the second element test.

\section{AFIP-2 Objectives}

The objectives of the AFIP-2 irradiation test are:

1) To irradiate prototypic scale monolithic MTR-type fuels to high burnup at high power density in preparation for element tests.

2) To provide additional irradiation data on advanced dispersion fuels or zircalloy clad (through collaboration with CNEA) to higher burnup at higher power density than achieved in the AFIP-1 test.

\subsubsection{AFIP-3 and AFIP-4 Experiments in the ATR}

\section{AFIP-3 and AFIP-4 Test Description}

The AFIP-3 test is targeted at generating fuel performance data for plates with density zoning, involute shape, and burnable poisons. Qualification of this fuel follows the qualification of more standard MTR-type plates. AFIP test hardware will be reconfigured as necessary to support irradiation of these fuel plates. Experiment insertion is supported by irradiation data from the RERTR-6, -7, -8, and -9 mini-plate tests as well as the AFIP-1 and AFIP-2 irradiation tests of full size plates. The AFIP-3 test may also allow the opportunity to bolster test data or repeat plate tests conducted in the AFIP-1 and AFIP-2 experiments. Plates tested in the AFIP-3 experiment will be subjected to in-canal dimensional measurement and visual examination between ATR cycles. The test will be configured to allow for continuation of testing as needed to support development of complex fuels. The AFIP-4 test allows for follow-on irradiations in support of complex fuel testing.

The AFIP-3 test is tentatively scheduled for insertion into ATR during cycle 142A beginning in April 2008. The AFIP-3 test will be irradiated for two long ATR cycles to a peak fission density equivalent to $60-80 \%$ U-235 LEU burnup at high power density (sufficient to produce a surface heat flux $>350$

$\mathrm{W} / \mathrm{cm}^{2}$ ). The AFIP-3 experiment will be removed from the reactor for cooling in September 2008. The AFIP-4 experiment will be inserted in the ATR after removal of AFIP-3, during the last quarter of 2008. AFIP-4 will irradiate until early 2009. After cooling, the experiments will be shipped in the GE-2000 cask to the HFEF at INL for PIE. 


\section{AFIP-3 and AFIP-4 Objectives}

The objectives of the AFIP-3 and AFIP-4 irradiation tests are:

1) To provide the first fuel performance data for density-zoned involute plates containing burnable poisons.

2) To continue to test complex fuels as required to demonstrate that very-high-density fuel performance is adequate for high-power reactors that require complex fuels.

3) To provide the opportunity for follow up irradiation testing of other fuel concepts as required by the program.

\subsection{Qualification Demonstration}

The last phases of fuel qualification entail proof-of-performance demonstrations that the developed fuel behaves adequately during all reactor normal (and potentially some off-normal) operating conditions and that it can be fabricated in a manner that guarantees stable fuel performance. This demonstration is normally made by irradiating several fuel elements. The elements can be manufactured by different fabricators using slightly different processes and materials.

In December 2006, after irradiation testing and partial PIE of the RERTR-7A experiment, a preliminary down selection of preferred fuel technology(s) was made. Very-high-density modified matrix dispersion fuels, those with a density of $8.5 \mathrm{~g}-\mathrm{U} / \mathrm{cm}^{3}$ or less, were selected for initial qualification. Preliminary conversion studies specific to the requirements of each reactor will be completed in September of 2008. Final versions of the conversion strategy for each reactor should be completed by April of 2010 .

Fuel qualification will thus be completed in two phases. Phase I of the qualification will focus on testing MTR-type very-high-density $\left(8.5 \mathrm{~g}-\mathrm{U} / \mathrm{cm}^{3}\right)$ dispersion fuel elements (density up to $8.5 \mathrm{~g}-\mathrm{U} / \mathrm{cm}^{3}$ ) in test reactor(s). Three options are under consideration; testing in the ATR Northeast flux trap, testing in BR2 in Mol, Belgium, or testing in loop positions in the MIR reactor in Dimitrovgrad, Russia. All three alternatives will be developed in parallel, and all testing options may be used to ensure adequate test space, diversity in test conditions, and diversity in test facilities. At the end of Phase I of the qualification process, very-high-density dispersion fuels will have been tested under a range of conditions sufficient to demonstrate that fuel performance and fuel manufacturing technology is adequate to support safe operation of reactors to be converted. It is anticipated that generic approval for use of the developed high density dispersion fuels will be granted by the NRC through the issuance of a Safety Evaluation Report.

Phase II of the qualification process will involve irradiation testing of ultra-high density test fuels with uranium loadings in excess of $8.5 \mathrm{~g}-\mathrm{U} / \mathrm{cm}^{3}$. Detailed plans, for this testing is pending the outcome of developmental irradiation tests through RERTR-9B.

Additional irradiation of lead test elements will be required in many reactors. This is especially true of reactors that utilize more complex annular fuel elements for which performance of an entire fuel element cannot be demonstrated in a test reactor due to space limitations. These reactors include HFIR, RHF, and FRM-II. A recent example of this type of qualification was that of the FRM-II core. The FRM-II fuel element is an annular design composed of plates that feature involute curvature and density zoning. No testing of the full element was conducted prior to installation into FRM-II. Instead, irradiation of test plates was completed in test reactors to demonstrate fuel performance, and the actual 'qualification' of the elements occurred by bootstrapping the reactor to power using the new element design. Use of LTAs will be guided by the each reactor's detailed conversion plan. 
Data from the U.S. fuel development program will be supplemented by data from foreign fuel development programs. In particular data from the Jules Horowitz reactor fuel qualification effort (JHR test elements will be irradiated in the BR2 reactor in Belgium), will support qualification of fuels for JHR. Qualification of JHR elements, by CEA will also likely envelope fuels required for conversion of BR2.

The last RERTR fuel qualification demonstration began in the early 1980's with fabrication of ORR nineteen plate fuel assemblies by three vendors; CEA, NUKEM (now defunct), and Babcock \& Wilcox (now BWXT). One element from each vendor was irradiated nominally to approximately $50 \%$ average burnup, the other to more than $75 \%$ burnup. Surface heat flux was $94-140 \mathrm{~W} / \mathrm{cm}^{2}$, much less than the requirements for very high density fuel (peak $>300 \mathrm{~W} / \mathrm{cm}^{2}$ ).

\subsubsection{Phase I Fuel Qualification}

The reference Phase I U.S. qualification demonstration calls for irradiation of four very-high density dispersion fuel $\left(8.5 \mathrm{~g}-\mathrm{U} / \mathrm{cm}^{3}\right)$ test elements in loop or open irradiation testing positions and irradiation of two test elements in an MTR-type reactor. Between irradiation cycles, channel gap thickness will be measured to indicate swelling or excessive oxide layer growth. Destructive and non-destructive PIE will be conducted after element irradiation.

Due to the successful demonstration of the in-reactor performance of the plates with silicon in the matrix fabricated in the RERTR-6 and RERTR-7 tests, dispersion fuels will be the target of the initial qualification demonstration. These fuels, containing LEU and loaded to approximately $8.5 \mathrm{~g}-\mathrm{U} / \mathrm{cm}^{3}$ are suitable for conversion of 12-17 reactors listed in Table 2.3. At higher enrichments these fuels would be suitable for conversion of additional reactors from HEU to some intermediate enrichment level.

It is also likely to be feasible to fabricate fuel at densities of $10 \mathrm{~g} \mathrm{U} / \mathrm{cm}^{3}$ using novel fabrication methods. Development of these higher density fuels will be undertaken as part of the fabrication development effort. If these higher density fuels exhibit good irradiation performance, qualification will be undertaken as an extension of the current program.

Several reactors may not be able to convert to LEU dispersion fuels without significant penalties in reactor performance. These reactors can likely be converted using monolithic fuels. Initial irradiation test results have indicated that there are issues associated with the in reactor performance of monolithic fuels related to delamination of the fuel and cladding. As a result, additional research and development is required for this fuel type, and the fuel will not be qualified prior to the end of 2010. An additional element test sequence (Phase II) has been reserved for testing of ultra-high density dispersion fuels and monolithic fuels.

Two tests are included in the Phase I qualification process. After successful completion of the ELEMENT-1 and ELEMENT-2 tests a fuel qualification data package will be submitted to NRC for review. Issuance of a NUREG fuel safety evaluation report by the NRC is anticipated in September 2010.

\subsubsection{ELEMENT-1 Fuel Qualification Test}

The reference strategy for obtaining primary fuel qualification data in support of licensing will be to generate data by irradiating test elements in ATR flux trap positions and MIR test loops under conditions enveloping reactors for which the fuel is targeted. Two elements will be tested in the ATR and two in MIR. 


\section{ELEMENT-1 Test Objective}

The objective of the ELEMENT-1 irradiation is to demonstrate robust and reliable fuel performance for selected very-high-density fuel types required for conversion of Phase I targeted reactors. This testing will provide data supporting a fuel qualification report to the NRC, after which issuance of a Safety Evaluation Report concerning the suitability for use in reactor conversions is anticipated. This Safety Evaluation Report would serve to 'qualify' very-high density fuels for use as LEU replacement fuel suitable for conversion of all reactors listed in Table 3.1. The ELEMENT tests will utilize in-canal channel gap width measurements between irradiation cycles as a monitor of fuel swelling. The ELMENT-1A test will be conducted in the ATR, while the ELEMENT-1B test will be conducted in MIR. BR2 will serve as a backup capability for these reactors.

\section{ELEMENT-1 Schedule}

ELEMENT-1 dispersion fuel fabrication will begin in September 2007. Planned insertion of the ELEMENT-1 test is in September of 2008. At the time of insertion, PIE data will be available from RERTR-6, RERTR-7, RERTR-8 and the AFIP-1 and AFIP-2 tests. If possible, test elements will be fabricated by commercial vendors (foreign and domestic), or at minimum, using a prototypic fuel fabrication line at a DOE laboratory. The four test elements will reside in in-core for 3-5 irradiation cycles under irradiation test conditions that envelope those in reactors targeted for conversion. The first elements will be withdrawn from the reactor for cooling in approximately May of 2009, and shipped to the appropriate hot cells for PIE.

PIE of the intact element will consist of visual examination, dimensional inspection (twist, bow, and element dimensions), and gamma scanning. The elements will then be disassembled and all individual fuel plates subjected to visual inspection. Approximately five plates from each element will be selected for thickness measurement and individual plate gamma scanning, and one plate will be selected for destructive metallographic analysis and sampling for burnup measurement. The majority of PIE will be completed in December 2009 and will provide input to the fuel qualification data package submitted to NRC in February 2010.

\subsubsection{ELEMENT-2 Test}

Fuel element testing in either the French OSIRIS or the HFR in Petten, The Netherlands, will add to the quantity and diversity of fuel qualification data generated by the ELEMENT irradiation test. Two U.S. fabricated fuel elements may be supplemented by elements fabricated in France in an irradiation test conducted by replacing standard MTR driver core elements by U-Mo very-high density test elements. Testing will be conducted at a lower surface heat flux imposed by the nature of the pool-type MTR reactors under coolant chemistry conditions that differ from that in the ATR. The differing coolant chemistry lead to a potentially thicker surface oxide layer and a different ratio of fission rate to fuel temperature than in ATR testing.

\section{ELEMENT-2 Test Objectives}

The objectives of the ELEMENT-2 test are to:

1) Provide supplemental information in addition to the fuel qualification data generated in the ELEMENT-1 test.

2) Provide fuel performance data for fuels fabricated by non- U.S. vendors

3) Provide for diversity in irradiation suppliers and irradiation test conditions. 


\section{ELEMENT-2 Test Schedule}

ELEMENT-2 test fabrication will begin in September 2007 for a planned insertion in October 2008, lagging slightly the insertion of the ELEMENT-1 test in ATR. At the time of insertion, PIE data will be available from the RERTR- $6,-7$, and -8 miniplate tests and from the AFIP-1 and AFIP-2 tests. The two test elements will reside in core for approximately one year, and be subject to in-canal visual and channel gap width examinations between irradiation cycles. Elements will be withdrawn from the reactor and subject to a final examination in canal in October 2009. The elements will be shipped to hot cells either at CEA Cadarache or Petten for PIE beginning in April 2010. The in-canal examinations will provide support for the phase I fuel qualification package.

PIE will consist of element visual examination, dimensional inspection, and gamma scanning. The elements will then be disassembled and all individual fuel plates subjected to visual inspection.

Approximately five plates from each element will be selected for thickness measurement and individual plate gamma scanning, and one plate will be selected for destructive metallographic analysis and sampling for burnup measurement. PIE will be completed in 2010, and will be available to provide supplemental input into the phase I fuel qualification data package submitted to NRC.

\subsubsection{Phase II Fuel Qualification}

Phase II qualification will be targeted at developing ultra-high density fuels for reactors that require uranium densities in excess of $8.5 \mathrm{~g}-\mathrm{U} / \mathrm{cm}^{3}$. Candidate fuels are highly loaded dispersions and monolithic fuels. Two to six reactors may require these fuel types. All included, these candidate reactors consume almost half of the estimated LEU required for listed reactors.

\subsubsection{ELEMENT-3 Test}

\section{Element-3 Test Objective}

The objective of the ELEMENT-3 irradiation test is to demonstrate robust and reliable fuel performance for ultra-high-density fuel types required for conversion of those reactors which require fuels with a density in excess of $8.5 \mathrm{gU} / \mathrm{cm}^{3}$. Fuel types considered are dispersions with loading greater than 8.5 $\mathrm{gU} / \mathrm{cm}^{3}$ and monolithic fuel. This testing will provide data supporting a fuel qualification report to the NRC, after which issuance of a Safety Evaluation Report concerning the suitability for use in reactor conversions is anticipated. The Element tests will utilize in-canal channel gap width measurements between irradiation cycles as a monitor of fuel swelling. The ELMENT-3 test will be conducted in the ATR. The MIR reactor will serve as a backup capability for ATR.

\section{Element-3 Schedule}

For the purpose of establishing a planning basis, it is assumed that fuel performance issues associated with monolithic fuel and fabrication issues associated with high density dispersion fuels will be resolved by the end of 2009. ELEMENT-3 fuel fabrication will begin in January 2010. Planned insertion of the ELEMENT-1 test is in July of 2010. At the time of insertion, PIE data will be available from RERTR-6, RERTR-7, RERTR-8 and the AFIP-1, AFIP-2, AFIP-3, and AFIP-4 tests. If possible, test elements will be fabricated by commercial vendors (foreign and domestic), or at minimum, using a prototypic fuel fabrication line at a DOE laboratory. The four test elements will reside in in-core for three to five irradiation cycles under irradiation test conditions that envelope those in reactors targeted for conversion. The elements will be withdrawn from the reactor for cooling in approximately January of 2011, and shipped to the appropriate hot cells for PIE.

PIE of the intact element will consist of visual examination, dimensional inspection (twist, bow, and element dimensions), and gamma scanning. The elements will then be disassembled and all individual 
fuel plates subjected to visual inspection. Approximately five plates from each element will be selected for thickness measurement and individual plate gamma scanning, and one plate will be selected for destructive metallographic analysis and sampling for burnup measurement. The majority of PIE will be completed in December 2009 and will provide input to the fuel qualification data package submitted to NRC in February 2010.

\subsubsection{IAEA U-Mo Element Irradiation}

An early element test has been proposed by the IAEA to demonstrate the performance of moderate loading (6-7 g-U/cc) U-Mo dispersions fuels with a modified matrix in under standard MTR conditions. The test design would be based on data collected in the RERTR- $6,-7,-8$, and possible -9 mini-plate experiments. As many as six elements will be fabricated by various international vendors (CERCA, BWXT, and/or CNEA) and irradiated in an MTR (most likely the HFR Petten reactor). The test elements will reside in core for approximately one year, and be subject to in-canal visual and channel gap width examinations between irradiation cycles. Elements will be withdrawn from the reactor and subject to a final channel gap examination prior to shipment to hot cells either at CEA Cadarache, Petten, or INL for PIE. The in-canal examinations will provide support for the phase I fuel qualification package.

PIE will consist of element visual examination, dimensional inspection, and gamma scanning. The elements will then be disassembled and all individual fuel plates subjected to visual inspection. Approximately five plates from each element will be selected for thickness measurement and individual plate gamma scanning, and one plate will be selected for destructive metallographic analysis and sampling for burnup measurement. The irradiation is expected to begin no earlier than late 2008 and PIE to be completed in 2010. Data from this irradiation test will be provided as supplemental input into the phase I fuel qualification data package submitted to NRC.

\subsubsection{Lead Test Elements}

Following issuance of a Safety Evaluation Report by the NRC, lead test elements will be inserted into some or all of the converting reactors to further demonstrate safe fuel operation. Reactors to be converted fall into two categories. Those reactors that use multiple fuel elements can presumably be converted gradually. Lead test elements can be inserted in the reactor core, followed by gradual change out to LEU as the HEU elements are burned.

The HFIR, RHF, and FRM-II reactors utilize more complex annular fuel elements. Final qualification and conversion of these reactors will likely be a one-step process requiring insertion of an entire LEU core (a possible exception is HFIR, which uses a two-piece element). A recent example of this type of fuel qualification was that of the FRM-II core. The FRM-II fuel element is an annular design composed of plates that feature involute curvature and density zoning. No testing of the full element was conducted prior to installation into FRM-II. Instead, irradiation of test plates was completed in test reactors to demonstrate fuel performance, and the actual 'qualification' of the elements occurred by bootstrapping the reactor to power using the new element design. In some cases, it may be possible to test individual LEU plates assembled into a standard HEU core first, or to design a transition core that allows for removal and inspection of fuel plates during startup testing.

In both cases, fuel elements will be fabricated that are representative of production fuel that is to be used in the targeted reactor. The issuance of the NRC Safety Evaluation Report in late 2010 concerning generic acceptance of new fuels as demonstrated by miniplate, full-sized plate, and element testing will 
serve as the basis document for supporting the licensing changes required for inserting lead test elements into the converting reactors.

Since each of these reactors has unique licensing requirements, a detailed startup and test plan will be required for each reactor. These specific plans must be generated by the converting facility in conjunction with the RERTR program. Planning for the fuel loading required for the conversion process can begin in 2007 in conjunction with conversion studies that will be carried out for each reactor. Draft plans, including facility specific requirements for fuel element testing should be completed in September 2008. Final plans for the fuel loading required for the physical conversion process should be completed by April 2010.

Fabrication of LEU lead test elements will begin in 2010 and will be completed by 2012. Startup testing requirements will be individually determined by each reactor, including verification of fuel performance, and will be determined prior to delivery of cores. Requirements for PIE will also vary, and may range from in-canal visual and dimensional examination to destructive examination of removable plates in a core, to destructive examination of an entire core to gain access to individual plates.

\subsubsection{Fuel Qualification Reports}

Three reports are planned for transmittal or submission to NRC for phase I fuel qualification; two preliminary reports on U-Mo irradiation behavior for informational purposes and a final fuel qualification report submitted for NRC review as input to the anticipated Safety Evaluation Report for very-high density fuels.

A preliminary report on U-Mo fuel behavior will be transmitted for information to the NRC in July of 2007, following completion of RERTR-7 PIE. A second report will be transmitted to NRC for information following completion of the RERTR-8, IRIS-5, and AFIP-1 PIE in July 2008.

The final fuel qualification report will be officially transmitted to NRC as data supporting the issuance of an NRC Safety Evaluation Report for very-high density fuel. Transmittal in February 2010 will follow completion of the majority of PIE on the ELEMENT-1 test in ATR and in-canal examination of the ELEMENT-2 test. It is anticipated that NRC review will require nine months, during which time RERTR staff will be available to support requests for additional information. This schedule will result in issue of a Safety Evaluation Report in September 2010. 


\section{Fuel Fabrication Development}

Fuel development hinges on the ability to fabricate representative fuel specimens for testing. Fuel fabrication methods and the details of particular processes can impact fuel performance. It is important to realize that the RERTR fuel development task be front loaded in this area to allow for the development of fabrication processes and the production of specimens for testing. Technologies to be developed are discussed in the following sections.

\subsection{Monolithic Fuel}

Monolithic fuel features the highest possible uranium density, thus allowing the most flexibility in reactor conversions. Monolithic fuel is based on elimination of matrix aluminum and replacement with a solid U-Mo alloy foil. This concept eliminates the fuel performance problems related to reaction of fuel and aluminum during irradiation. Principal obstacles to development of this fuel include unknown irradiation behavior of full-size plates and fabrication scale up.

\subsubsection{Monolithic Fuel Fabrication Development}

Fabrication requires a significant departure from the conventional dispersion fuel fabrication process. Two methods are currently under consideration; these are friction stir welding and Hot Isostatic Pressing. All of these processes require demonstration of fuel performance through irradiation testing.

\subsubsection{Uranium Alloy Foil Fabrication}

Integral to the deployment of monolithic fuels is the development of a simple and economic process for foil production. Three lines of $R \& D$ are being followed. These are cold rolling and continuous casting. The continuous casting process is being developed using custom designed process equipment. The cold rolling process will require the acquisition of a small rolling mill. This equipment will also be used to finish foils made by continuous casting to final thickness. DOE's Y-12 complex is also developing methods for commercial-scale foil fabrication beginning in FY06.

\subsection{Modified matrix fuels}

Irradiation test results from RERTR-6 and RERTR-7 indicate that the performance of dispersion fuels with silicon additions to the matrix with these fuels will be adequate for use in reactors operating at high power.

\subsubsection{Modified matrix dispersion fuel with density $<8.5 \mathrm{gU} / \mathrm{cm}^{3}$}

Indications from fabrication of $\mathrm{Al} / \mathrm{Si}$ matrix miniplates are that some process development work will be required to develop methods suitable for commercial production.

Process development will be conducted on both the miniplate and full-size plate scale. Modified matrix miniplates loaded to approximately $8 \mathrm{gU} / \mathrm{cm}^{3}$ will be fabricated for the RERTR-9A experiment to extend 
the irradiation performance database to this loading. Full-size plates at $8 \mathrm{gU} / \mathrm{cm} 3$ will be fabricated for insertion into the AFIP-1 experiment in ATR.

Process knowledge will be available to the public through published reports, papers, and conference proceedings.

\subsubsection{Modified matrix dispersion fuel with density $>8.5 \mathrm{gU} / \mathrm{cm}^{3}$}

Development of novel techniques for fabrication of ultra-high density fuels will likely be required. These techniques may include hybrid processing, where bonding is obtained by friction stir welding or hot isostatic pressing, followed by minimal rolling reduction to obtain the proper plate dimensions.

Process development will be conducted on both the miniplate and full-size plate scale. Modified matrix miniplates loaded to at least $10 \mathrm{gU} / \mathrm{cm}^{3}$ will be fabricated for the RERTR-9B experiment to extend the irradiation performance database to this loading.

Process knowledge will be available to the public through published reports, papers, and conference proceedings.

\subsection{Mg-matrix Fuels}

The success of modified matrix dispersion fuels alleviates the need to further develop magnesium matrix dispersions as an alternative fuel type. A magnesium matrix fuel specimen was irradiated in the RERTR3 experiment with good results, and the test was repeated on the miniplate scale in the RERTR- 8 experiment.

\subsection{Other Fuel Types}

If during further irradiation testing, the performance of aluminum clad monolithic and ultra-high-density modified matrix fuels should prove to be inadequate, other possibilities can be explored, although it will not be possible to meet the FY10 milestone for fuel qualification using these fuels. Some alternate possibilities are listed here.

\section{Zr-matrix Dispersion Fuels}

If the potential for the reaction of magnesium with reactor coolant during operation or canal water during long-term storage becomes an issue, the potential for use of a zirconium matrix exists.

\section{Zr Clad Monolithic Fuels}

If reaction of U-Mo with aluminum remains an issue with monolithic fuels, it may be possible to substitute zirconium cladding. The Argentine fuel development program has conducted some preliminary experiments in rolling Zr-clad monolithic fuel plates. Two zirconium clad U-Mo monolithic miniplates are currently under irradiation in the RERTR-7A experiment. U-Nb-Zr monolithic fuels may also be pursued as an alternative to U-Mo monolithic fuels. 


\section{Out-of-Pile Testing \& Analysis}

Out-of-pile analysis activities are conducted in support of the core irradiation testing. This effort falls into three areas: (1) fuel performance code development, (2) fuel/matrix interaction, and (3) ion beam irradiation.

\subsection{Fuel Performance Codes}

Two fuel performance codes are currently developed and used by the RERTR program. These codes are the DART code and the PLATE code. The PLATE code is based on a thermohydraulic backbone and is used to analyze fuel performance through the understanding of fuel operating conditions. DART is a more complex code that attempts to use mechanistic models to predict fuel behavior on a more fundamental level. Although both codes are useful to some degree, development of a single code provides for the best use of program resources. The PLATE code will be validated against fuel performance data from U.S. and foreign experiments and benchmarked against foreign fuel performance codes. The code will eventually support reactor conversion through analysis of fuel operating conditions in targeted reactors. It is not anticipated that the code will support NRC licensing of developed fuels.

\subsection{Fuel Matrix Interaction}

Studies of fuel matrix interaction support the understanding of in-reactor fuel behavior through the identification and analysis of reaction products that may potentially form in reactor. Measurement of UMo reaction enthalpy is also important in order to understand fuel behavior during off-normal conditions.

\subsection{Ion Irradiation}

Ion irradiation allows out-of-pile observation of the effects of irradiation damage and the combined processes of fuel/aluminum reaction and irradiation. This task will continue through FY08. 


\section{Capability and Infrastructure}

Development of infrastructure to support RERTR fuel development is required in four areas. These are (1) fuel fabrication, (2) minor upgrades to HFEF equipment to allow for measurements on flat plates, (3) the qualification of additional casks for irradiated fuel transport, and (4) design and installation of ATR in-canal fuel examination facilities for plates and elements.

\subsection{PIE Capability}

The U.S. infrastructure for PIE is adequate for basic miniplate examinations, although some minor upgrades are required for full-size plate and fuel element examinations. However, the U.S. lacks the a modern shielded microprobe to provide the data necessary for understanding the complex compositional changes occurring during irradiation of U-Mo alloys in the presence of aluminum.

\subsubsection{Hot Cell Engineering}

Hot cell upgrades are conducted in three phases as needed to support handling and examination of fuel specimens. Phase I designs and implements necessary handling fixtures in HFEF, and includes modifications to the gamma scanner to allow for miniplate scanning, provisions for measuring fuel thickness and density, and postirradiation blister testing. Phase II makes similar modifications for fullsize plates. Phase III allows for the handling and examination of fuel elements.

\subsection{In-canal Examination}

Facilities for in-canal measurement of the thickness changes in fuel due to irradiation do not exist in the U.S. Such a facility will need to be developed to support U.S. very-high density fuel qualification. This capability allows monitoring of fuel swelling between irradiation cycles, which gives early indications of fuel performance problems.

\subsection{Transportation of Irradiated Fuel}

Transport of irradiated fuels from reactor to hot cell may be a significant issue due to the projected retirement of the GE- 100 and T-2 casks in 2008. Retirement of theses casks affects not only the ability to ship RERTR fuels using the GE- 100 and T-2, but also impacts the availability of other casks in service that must make up for shipments that would have been made using the GE-100. This situation can cause long delays in shipment of fuel due to cask unavailability.

The GE-100 cask will be used for miniplate transport through October 2008, with the more expensive GE-2000 as a backup option. As the GE-100 is retired from service and the emphasis of the program shifts to larger plates, another cask will be qualified for transport of fuel specimens between ATR and HFEF. 


\subsection{Fuel Fabrication Facilities}

RERTR fuel fabrication laboratories at ANL and INL will be upgraded as required including equipment for friction stir welding, fuel plate cleaning, and a clean test assembly and inspection area. 


\section{Summary}

In late 2003 it became evident that U-Mo aluminum fuels exhibited significant fuel performance problems under the irradiation conditions required for conversion of most high-powered research reactors. Solutions to the fuel performance issue have been proposed and show promise in early testing. Based on these results, a RERTR program strategy has been mapped that will allow generic fuel qualification to occur prior to the end of FY10 and reactor conversion to occur prior to the end of FY14. This strategy utilizes a diversity of technologies, test conditions, and test types.

Scoping studies using miniature fuel plates will be completed in the time frame of 2006-2008. Irradiation of larger specimens will occur in the Advanced Test Reactor (ATR) in the United States and in the OSIRIS reactor in France in 2006-2009. These scoping irradiation tests provide a large amount of data on the performance of advanced fuel types under irradiation and allow the down selection of technology for larger scale testing during the final stages of fuel qualification.

Final qualification of fuels will occur in two phases. Phase I will obtain generic approval for use of veryhigh-density $\left(8.5 \mathrm{~g}-\mathrm{U} / \mathrm{cm}^{3}\right) \mathrm{U}-$ Mo dispersion fuels. In order to obtain this approval, a larger scale demonstration of fuel performance and fabrication technology will be necessary. Several MTR plate-type fuel assemblies will be irradiated in both the OSIRIS reactor and the ATR (or MIR reactor) in 2008-2009. Following PIE, a report detailing very-high density fuel behavior will be submitted to the NRC. This 'qualification report' will cover all very-high density fuel variants, including those that require burnable poisons and density zoning. Assuming acceptable fuel behavior, it is anticipated that NRC will issue a Safety Evaluation Report granting generic approval of the fuels based on this report. It is anticipated that Phase I of fuel qualification will be completed prior to the end of FY10.

Phase II of the qualification process will develop the ultra-high-density fuels necessary for conversion of the two to seven reactors that may not be able to convert with very-high-density dispersion fuels. These fuels will not be ready for commercial deployment by the end of 2010 .

In conjunction with irradiation testing, fabrication processes must be developed and made available to commercial fabricators. The commercial fabrication infrastructure must also be upgraded to ensure a reliable LEU fuel supply in 2010 to 2011.

Lead Test Assemblies will be required for some or all converting reactors. Each reactor that plans to convert using the developed high-density fuels will develop a reactor specific conversion plan based upon the reactor safety basis and operating requirements. For some reactors (FRM-II, HFIR, and RHF) conversion will be a one-step process.

In addition to the U.S. fuel development effort, a Russian fuel development strategy has been developed, and contracts with Russian Federation institutes in support of fuel development for Russian are in place.

The overall RERTR fuel development program thus currently results in qualification of fuels suitable for conversion of 19 targeted research reactors that consume almost $600 \mathrm{~kg}$ of HEU per year. 


\section{References}

$\left[{ }^{i}\right]$ This section is a condensed version of a narrative written by Argonne National Laboratory describing the history of the RERTR program.

[ii] G.L. Hofman, R.F. Domagala, G.L. Copeland, "Irradiation Behavior of Low-Enriched U ${ }_{6} \mathrm{Fe}-\mathrm{Al}$ Dispersion Fuel Elements,"'J. Nuc. Mat., 238-43 complete (1987)

[iii] M. K. Meyer, T. C. Wiencek, S. L. Hayes, G. L. Hofman, "Irradiation Behavior of U 6 Mn-Al Dispersion Fuel Elements,” J. Nucl. Mat. 278 (2000) 358-363.

[iv $]$ M. K. Meyer, C. L. Trybus, G. L. Hofman, S. M. Frank, T. C. Wiencek, "Selection and Microstructures of High Density Uranium Alloys," Proceedings of the 1997 International Meeting on Reduced Enrichment for Research and Test Reactors, Jackson Hole, WY, October 5-10, 1997, ANL/TD/TM99-06 (1999).

['] S. L. Hayes, C. L. Trybus, M. K. Meyer, "Irradiation Testing of High-Density Uranium Alloy Dispersion Fuels," Proceedings of the 1997 International Meeting on Reduced Enrichment for Research and Test Reactors, Jackson Hole, WY, October 5-10, 1997, ANL/TD/TM99-06 (1999).

${ }^{\mathrm{vi}}{ }^{\mathrm{i}}$ M.K. Meyer, G.L. Hofman, S.L. Hayes, C.R. Clark, T.C. Wiencek, J.L. Snelgrove, R.V. Strain, and K.-H. Kim, "Low-temperature Irradiation Behavior of Uranium-Molybdenum Alloy Dispersion Fuel," J. Nucl. Mat. 304 (2002) 221-236.

[iii] W. Dienst, S. Nazare, F. Thummler, "Irradiation behavior of UAlx Dispersion Fuels for Thermal High Flux Reactors" J. Nuc. Mat. 64 (1-13) (1977).

[iiii] J. Gómez, R. Morando, E.E. Pérez, D.R. Giorsetri, G.L. Copeland, G.L. Hofman, J.L. Snelgrove, "Postirradiation Examination of High-U-Loaded, Low-Enriched $\mathrm{U}_{3} \mathrm{O}_{8}, \mathrm{UAl}_{2}$, and $\mathrm{U}_{3} \mathrm{Si}$ Test Fuel Plates," Proc. of the 1984 International Meeting on Reduced Enrichment for Research and Test Reactors, Argonne, IL, Oct 15-18 (1984).

$\left[{ }^{\mathrm{ix}}\right]$ D. Sears, A. Davidson, J. Mason, C. Buchanan, P. Ryan, "Development, Irradiation Testing, and PIE of UMo Fuel at AECL," Proc. Of the 2004 International Meeting on Reduced Enrichment for Research and Test Reactors, Vienna, Austria, Nov. 7-12 (2004).

$\left[{ }^{\mathrm{x}}\right]$ LeMoine RERTR2005 IRIS-3 paper

${ }^{[\mathrm{xi}}$ C.K. Kim, K.H. Kim, J.M. Park, D.B. Lee, S.J. Oh, K.H. Lee, H.T. Chae, and D.S. Sohn, "Progress of U-Mo Dispersion Rod Fuel Qualification Program in Korea," Proc. Of the 2004 International Meeting on Reduced Enrichment for Research and Test Reactors, San Carlso de Bariloche, Argentina Nov. 3-8 (2002), ANL/TD/TM03-04 (2003).

$\left.{ }^{\mathrm{xii}}\right]$ J.M. Park, H.J. Ryu, Y.S. Lee, D.B. Lee, S.J. Oh, B.O. Ryu, Y.H. Jung, D.S. Sohn, C.K. Kim, “An investigation of the Irradiation Behavior of Atomized U-Mo/Al Dispersion Rod Fuels," Proc. Of the 2004 International Meeting on Reduced Enrichment for Research and Test Reactors, Vienna, Austria, Nov. 7-12 (2004). 